\title{
Safety Evaluation of the Single-Shell Tanks Modified Sluicing Waste Retrieval System
}

\author{
R.D. Smith \\ CH2M HILL Hanford Group, Inc. \\ Richland, WA 99352 \\ U.S. Department of Energy Contract DE-AC27-99RL14047
EDT/ECN: 723847-RO UC: N/A
Cost Center: $7 \mathrm{~B} 300 \quad$ Charge Code: 502644
B\&R Code: N/A Total Pages: 140

Key Words: Single-shell tank, SST, modified sluicing system, double-shell tank, DST, chemical additions, sodium hydroxide, mixing of incompatible materials

Abstract: The purpose of this safety evaluation is to evaluate chemical additions of sodium hydroxide to 100-series SSTs to support waste retrieval.

TRADEMARK DISCLAIMER. Reference herein to any specific commercial product, process, or service by trade name, trademark, manufacturer, or otherwise, does not necessarily constitute or imply its endorsement, recommendation, or favoring by the United States Government or any agency thereof or its contractors or subcontractors.

Printed in the United States of America. To obtain copies of this document, contact: Document Control Services, P.O. Box 950, Mailstop H6-08, Richland WA 99352, Phone (509) 372-2420; Fax (509) 376-4989.

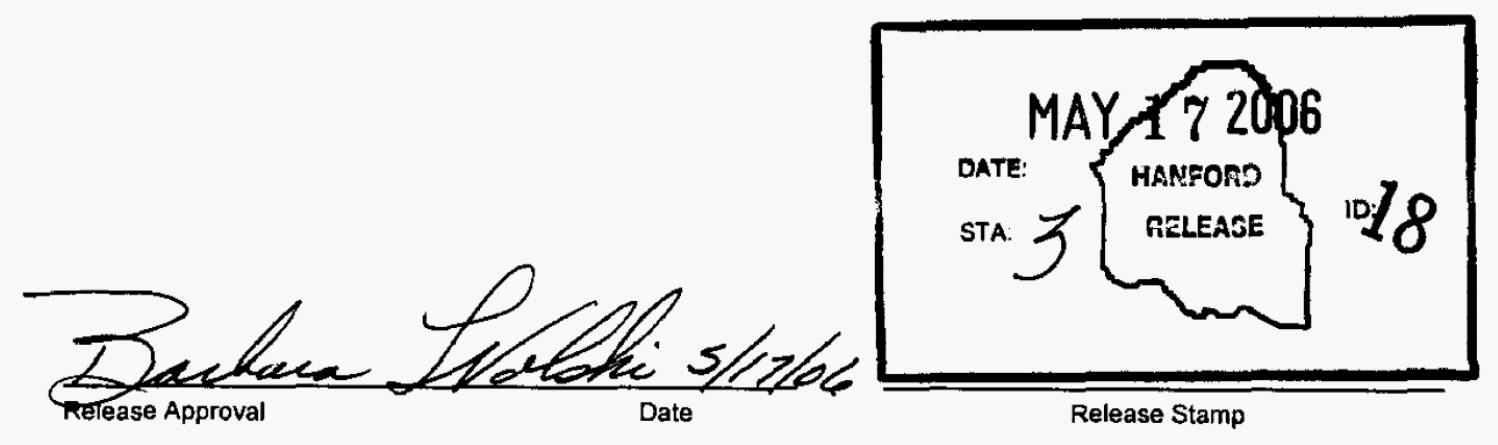

\section{Approved For Public Release}


RPP-17965 REV 5

\section{CONTENTS}

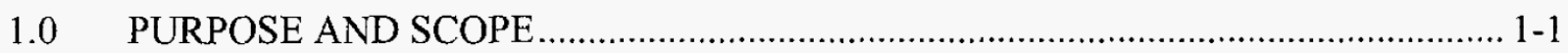

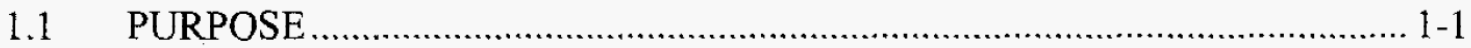

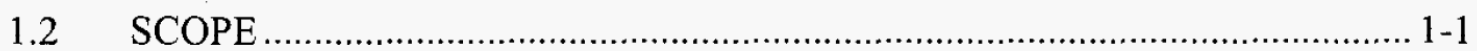

2.0 DESCRIPTION OF THE SINGLE-SHELL TANK MODIFIED SLUICING WASTE RETRIEVAL SYSTEM DESIGN AND PROCESS ……….......................... 2-1

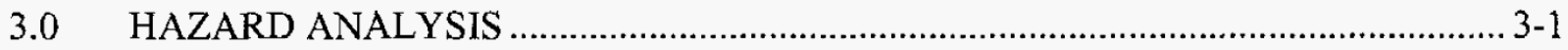

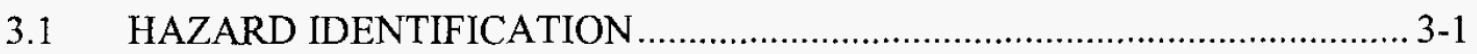

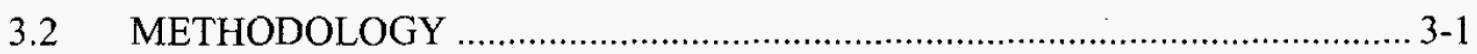

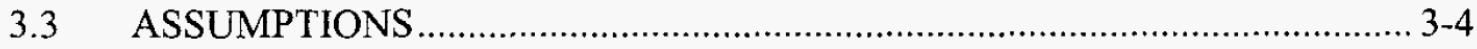

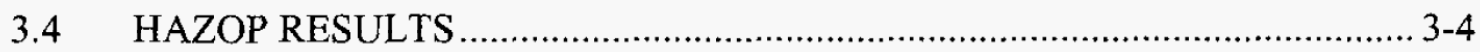

3.5 HAZARDOUS CONDITION SCREENING ……....................................... 3-4

3.6 DETAILED DISCUSSION …………………........................................ 3-5

4.0 ACCIDENT ANALYSIS..........................................................................................

4.1 EVALUATION OF RISK FROM MODIFIED SLUICING OF WASTE FOR DSA REPRESENTATIVE ACCIDENTS ............................................... 4-1

4.1.1 Flammable Gas Accidents ................................................................. 4-1

4.1.2 Criticality ……......................................................................... 4-

4.1.3 Release from Contaminated Facility .................................................. 4-8

4.1.4 Waste Transfer Leaks ..................................................................... 4-11

4.2 EVALUATION OF RISK FROM MODFIED SLUICING OF WASTE FOR DSA CANDIDATE ACCIDENTS NOT SELECTED AS REPRESENTATIVE ACCIDENTS............................................................ 4-18

4.2.1 Filtration Failures Leading to Unfiltered Releases ................................ 4-18

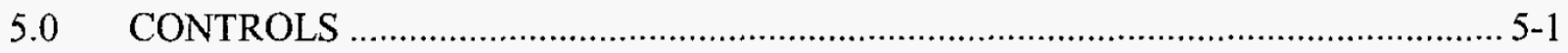

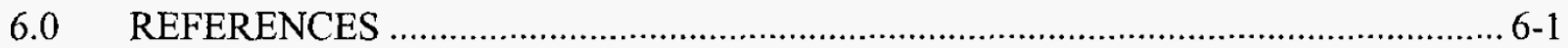

\section{APPENDICES}

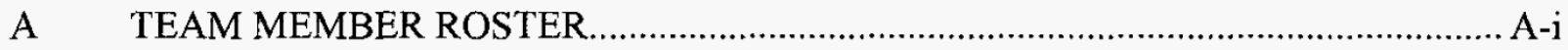

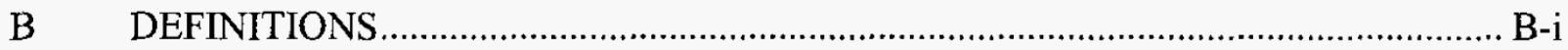

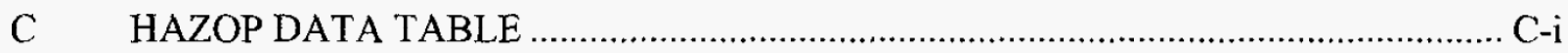

D SAFETY EVALUATION FOR SLUICING IN SINGLE-SHELL TANK 241-S-102 WITH DOUBLE-SHELL TANK 241-SY-102 SUPERNATANT ……….... D-i 


\section{RPP-17965 REV 5}

E SAFETY EVALUATION FOR SLUICING IN SINGLE-SHELL TANK 241-C-103 WITH DOUBLE-SHELL TANK 241-AN-106 SUPERNATANT E-i

F SAFETY EVALUATION FOR SODIUM HYDROXIDE ADDITION TO

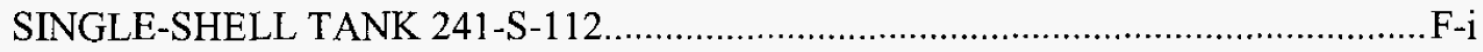

G PEER REVIEW CHECKLISTS G-i

\section{LIST OF TABLES}

Table 3-1. Deviation Guide For Process Variables. 3-2

Table 4-1. Properties Associated with the Waste 4-12

Table 4-2. Properties Associated with the Transfer Pumps. 4-15

Table 4-3. Seepex Pump Maximum Pressure Exposure Comparison. 4-16 


\section{RPP-17965 REV 5}

\section{LIST OF TERMS}

AC

AIChE

ARF

CAM

DCRT

DSA

DST

FHA

GRE

HAZOP

HEPA

HIHTL

LCO

LFL

LPF

MAR

NFPA

ORP

RF

SER

SSC

SST

TSR

ULD administrative control

American Institute of Chemical Engineers

airborne release fraction

continuous air monitor

double-contained receiver tank

documented safety analysis

double-shell tank

fire hazards analysis

gas release event

Hazards and Operability Study

high-efficiency particulate air (filter)

hose-in-hose transfer line

limiting condition for operation

lower flammability limit

leak path factor

material at risk

National Fire Protection Association

Office of River Protection

respirable fraction

Safety Evaluation Report

structures, systems, and components

single-shell tank

technical safety requirements

unit-liter dose 
RPP-17965 REV 5

\section{This page intentionally left blank.}


RPP-17965 REV 5

\subsection{PURPOSE AND SCOPE}

\subsection{PURPOSE}

The purpose of this safety evaluation is to determine if the potential risk associated with using the single-shell tank (SST) modified sluicing system for retrieval of the 100-series SSTs in the tank farms is adequately addressed and bounded by the current tank farms safety basis (documented safety analysis [DSA]) and to determine if additional controls may be required. This safety evaluation also supports the requirement to perform a generic safety basis amendment for the retrieval of any additional SSTs (other than 241-S-112, and 241-U-107) by modified sluicing from the U.S. Department of Energy, Office of River Protection (ORP) Safety Evaluation Report (SER) 03-TED-066, Safety Evaluation Report (SER) for Approval of Justification for Continued Operation (JCO) for Tank Farms Single-Shell Tank (SST) Retrieval/Closure Modified Sluicing.

\subsection{SCOPE}

The scope of this safety evaluation is SST modified sluicing waste retrieval system operations that are planned for conduct in 100-series SSTs. Waste from the 100-series tanks is planned to be transferred to double-shell tank (DST) storage. Initially modified sluicing campaigns are planned for the 241-S, 241-C, and 241-U tank farms. This safety evaluation is based on two separate designs originally prepared for SSTs 241-C-106 and 241-S-112; however, the design for these two tanks is expected to be bounding for future tanks to be modified sluiced. When the system designs and processes for the retrieval of these subsequent tank farms' 100-series tanks are established, the analysis of this safety evaluation will be reviewed via the Unreviewed Safety Question process to determine whether this analysis satisfactorily bounds the retrievals from these subsequent tank farms.

Revision 2 of this document adds Appendix D, which is a safety evaluation for modified sluicing with DST supernatant in SST 241-S-102.

Revision 3 of this document adds Appendix E, which is a safety evaluation for modified sluicing with DST supernatant in SST 241-C-103.

Revision 4 of this document evaluates the potential for higher than expected ventilation flow rates for the high-efficiency particulate air (HEPA) filter filtration failures leading to unfiltered releases accident. The higher than expected ventilation flow rates were due to the re-evaluation of the variable frequency drives of the ventilation system.

Revision 5 of this document adds Appendix F, which is a safety evaluation for the addition of sodium hydroxide to a 100-series SST in support of modified sluicing waste retrieval. 
RPP-17965 REV 5

This page intentionally left blank. 


\subsection{DESCRIPTION OF THE SINGLE-SHELL TANK MODIFIED SLUICING WASTE RETRIEVAL SYSTEM DESIGN AND PROCESS}

SST modified sluicing waste retrieval systems will retrieve waste from designated tanks to the extent needed for tank closure and transfer the retrieved waste to the DST system. The SST modified sluicing waste retrieval system is designed to dissolve SST crystallized salt and to mobilize sludge through the application of high pressure water or supernatant spray to break down the waste salt, sludge, and solids and to direct the waste to the intake of a slurry transfer pump for transfer into the DST system. Various SST waste retrieval system sluicing designs may be used. Each system uses sluicing nozzles, waste transfer pump(s), monitoring and control systems, portable exhauster ventilation, and new and existing waste transfer systems. Support systems necessary for the sluicing design include raw water and electrical supply.

The SST waste retrieval system sluicing designs employ remote controlled or automatic sluicing nozzles that are strategically placed and installed in the tank headspace via SST risers. The number of sluicing nozzles can vary depending on the amount and location of solidified waste within the SST. Current sluicing designs rely upon one to six sluicing nozzles. The nozzle system is designed to aim pressurized fluid (raw water or SST supernatant) that will break up, mobilize, and move the sludge, dissolved saltcake, and compacted solids slurry to a location where they are picked up by a slurry transfer pump. The design flow rate of the remote operated sluicing nozzles is variable up to approximately $100 \mathrm{gal} / \mathrm{min}$ with normal operating pressures up to approximately $100 \mathrm{lb} / \mathrm{in}^{2}$. The automatic self-indexing sluicers operate at a flow rate of approximately $20 \mathrm{gal} / \mathrm{min}$. The nozzle spray range will cover a minimum range of $30 \mathrm{ft}$ up to a maximum range of approximately $75 \mathrm{ft}$. The sluicers are capable of 360 degree rotation in the horizontal, and vertical pan and tilt from 0 degrees to 90 degrees.

The nozzles are remotely directed from a control trailer by use of hydraulic or electric controls. Automatic self-indexing sluicing nozzles may also be used that do not require operator action.

SST waste retrieval system sluicing designs use different pump configurations that could include one or two pumps in series for waste retrieval, with the possibility of the addition of a separate supernatant recirculation pump. The primary waste retrieval pump(s) are typically located near the center of the SST. The pump(s) are physically located within the SST or external to the tank in an enclosed structure, with the pump suction draw located near the tank bottom. Pump designs include centrifugal pumps and progressive cavity positive displacement pumps. Except for positive displacement pumps where higher pressures are possible, the slurry transfer pumps operate at flow rates and pressures bounded by existing waste transfer pumps (see Section 2.4.2.3 of RPP-13033). An SST supernatant recirculation pump may be used during the sluicing operation to provide recirculation capability to the sluicing system. The supernatant recirculation pump operates at a nominal $100 \mathrm{gal} / \mathrm{min}$ at $100 \mathrm{lb} / \mathrm{in}^{2}$.

Dilution water may be used to aid in the retrieval process by diluting the slurry to the appropriate specific gravity conducive to waste transfer. Dilution water can also be supplied to flush the slurry transfer pump and/or the waste transfer line. Dilution water can be added at up to approximately $100 \mathrm{gal} / \mathrm{min}$, with a nominal flow rate of $50 \mathrm{gal} / \mathrm{min}$. 


\section{RPP-17965 REV 5}

Sodium hydroxide may also be used to help retrieve the water-insoluble solids by dissolving aluminum oxide compounds and suspending solids in the waste of the 100-series SSTs. Sodium hydroxide is delivered in vendor-owned tanker trucks and added directly to the SST. The sodium hydroxide is typically introduced into the SST using a pressurized tanker truck via the dilution drop leg on the transfer pump or into the supernatant recirculation drop leg. Sodium hydroxide may also be introduced via the sluice nozzles using the pressurized tanker truck in conjunction with a skid-mounted pump. The maximum addition rate of sodium hydroxide is $175 \mathrm{gal} / \mathrm{min}$. A flexible hose system delivers the sodium hydroxide to the SST using a flow metering device to measure the amount of chemical added to the SST. See Appendix F for a complete safety evaluation for the addition of sodium hydroxide to a 100-series SST.

Operators located within a control trailer direct the monitoring and control system. The control trailer could be located within the tank farm or nearby outside the fenced boundary. The control trailer contains sluicing operation controls and closed-circuit television monitors and controls. The sluice nozzles are remotely operated using joysticks and observed via the television monitors displaying the view from cameras located within the source SST. In-tank lighting is used to enhance in-tank camera viewing. During retrieval operations, the video cameras provide visual feedback on the waste mobilization process; assisting operations in the control of water or supernatant spray application and moving slurry to the transfer pump suction.

Process parameters that are monitored during the sluicing process include system temperatures, pressures, waste temperature and density, flow rates of the system, and raw water flow and waste transfer volume. Liquid depth in the SST pool is also monitored.

Active ventilation is connected to the SST to aid the sluicing operations by removing aerosols and/or fog generated during sluicing to enable better visual monitoring capability. The tank ventilation system is comprised of an inlet HEPA filter, a portable exhauster, and a demister. The portable exhauster contains a heater, pre-filter, two stages of HEPA filters, a fan, an exhaust stack, an effluent monitoring system, and ventilation stack continuous air monitor interlock system. The portable exhausters use variable speed blowers that normally operate at between $100 \mathrm{ft}^{3} / \mathrm{min}$ and $1,000 \mathrm{ft}^{3} / \mathrm{min}$ but have been analyzed up to $5,600 \mathrm{ft}^{3} / \mathrm{min}$.

The slurry transfer pumping system is connected to either an existing underground waste transfer system or to a hose-in-hose transfer line (HIHTL) that is used to transfer the retrieved waste to the DST system. The HIHTL is heat traced and insulated. The waste transfer system includes required leak detection and alarm capabilities.

The SST waste retrieval system sluicing designs use raw water and electric power. Raw water is provided to the sluicing nozzles and auxiliary equipment. Backflow preventers or service water pressure detection systems are used to assure that no contamination of the raw water supply can occur. Raw water supply may be heat traced and insulated as necessary. Heated water may also be provided.

Electric power is used to power the operation control trailers, the portable exhausters, electric pump motors, raw water and waste transfer line heat tracing, and the process monitoring and control systems, including leak detection and alarms. Electric power is provided via connection to the Hanford Site power distribution system or via portable power generators. 


\section{RPP-17965 REV 5}

\subsection{HAZARD ANALYSIS}

\subsection{HAZARD IDENTIFICATION}

SST modified sluicing waste retrieval system operations are proposed activities that have not been approved under the DSA; however, approval of modified sluicing waste retrieval system operations is approved under the final safety analysis report for SSTs 241-S-112 and 241-U-107 via ORP SER 03-TED-066 and SST 241-C-106 via a negative Unreviewed Safety Question and ORP SER 03-TED-029, "Approval of Interim Authorization Using Alternate Controls Related to the Operation of Active Ventilation on Single-Shell Tank (SST) 241-C-106 During Accelerated Waste Retrieval," which allowed for the passive breather filter to be closed during active ventilation.

A Hazards and Operability Study (HAZOP) was performed to identify and evaluate potential hazards associated with the SST modified sluicing waste retrieval system for 100 -series SSTs retrieval. In addition, HAZOPs performed on SSTs 241-S-112 (RPP-9014, Process Hazards Analysis for the S-112 Saltcake Waste Retrieval Technology Demonstration Project Preconceptual Design), 241-U-107 (RPP-7689, Hazard Evaluation for Single-Shell Retrieval Via Salt Cake Dissolution Proof of Concept in Tank 241-U-107), and 241-C-106 (RPP-13557, Safety Evaluation of the Phase I Retrieval of Liquid Waste from Single-Shell Tank 241-C-106) were reformatted to conform with the DSA and were added to the modified sluicing HAZOP.

The results of the combined HAZOPs were reviewed to identify potential hazardous conditions associated with the modified sluicing waste retrieval system that may not be adequately bounded or represented by the DSA analyzed representative accidents.

\subsection{METHODOLOGY}

The hazards identification and evaluation of modified sluicing waste retrieval system operations used the HAZOP method. A HAZOP is a systematic process for identifying potential causes and consequences of off-normal conditions in a system or process. The HAZOP uses a team leader to guide an interdisciplinary team of subject matter experts (Appendix A) in evaluating a system or process. The HAZOP process is based on "brainstorming" and uses a standardized set of process parameters (e.g., temperature, pressure, flow) and guide words (e.g., high, low, part of, reverse) to facilitate the "brainstorming." Table 3-1 presents a list of process parameters and guide words. The HAZOP team also established consequence and frequency estimates for radiological and toxicological effects to three receptor categories. These are offsite individual, onsite worker, and facility worker. Each hazardous condition was evaluated using a qualitative estimation process, without consideration of the application of any controls. The definitions/criteria for the information developed during the HAZOP process are found in Appendix B. 


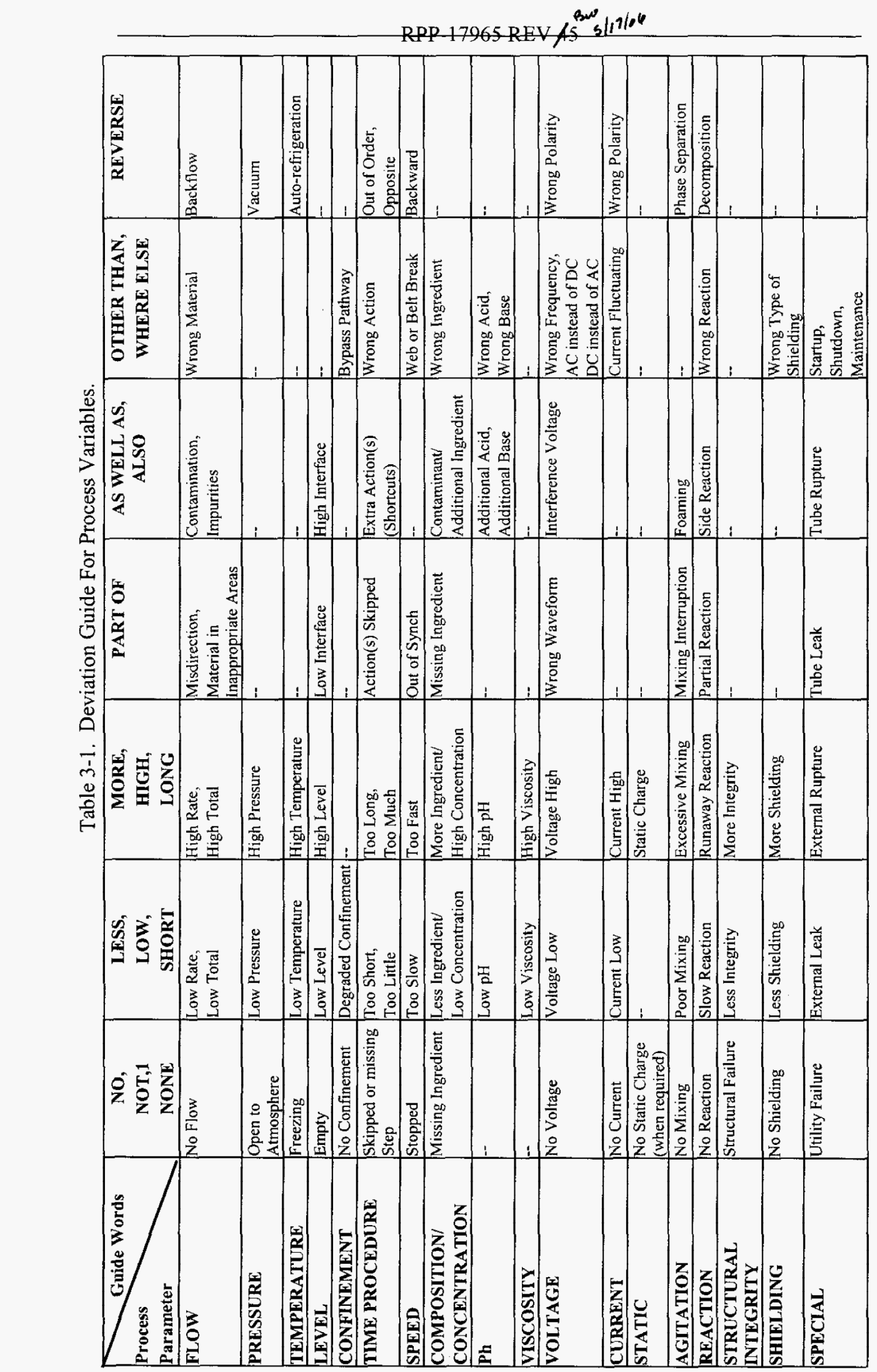

蛋

䙓 홍

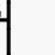




\section{RPP-17965 REV 5}

The expertise and experience of the HAZOP team is of primary importance in establishing the credibility of the analysis because of the largely qualitative nature of the HAZOP process. The attendance roster is included in Appendix A to document the presence of each team member. The HAZOP process is recognized by the American Institute of Chemical Engineers (AIChE) and is described in Guidelines for Hazard Evaluation Procedures (AIChE 1992).

One of the important features of a HAZOP is the division of a process or activity into discrete segments called nodes. Node selection is designed to facilitate the hazard identification process by focusing the attention of the team on specific process sections or operating steps. The team applies the HAZOP process to each node in a stepwise fashion. The waste retrieval system HAZOP for the modified sluicing system was based on the following nodes to capture points in the process where deviations could result in significant consequences:

- Node A: Equipment installation and decommissioning

- Node B: Water supply system, including flush systems for transfer lines

- Node C: Sluicing system

- Node D: Transfer pump

- Node E: Transfer lines, SST to DST and SST recirculation

- Node F: $\quad$ SST ventilation system

- Node G: DST receiver tank ventilation system

- Node H: $\quad$ SST being retrieved

- Node I: $\quad$ DST receiver tank

- Node J: Instrumentation and camera system

- Node K: Criticality Concerns (what if?).

The hazardous conditions presented under Node $\mathrm{K}$ are intended to indicate that the hazard evaluation team performed a broad brush "what if" evaluation to ensure that criticality concerns are appropriately addressed.

The HAZOP resuits were used as input for this safety evaluation to identify and evaluate hazardous conditions that may not be adequately addressed by the tank farms safety basis.

The HAZOP data was used in this safety evaluation to compare the identified hazardous conditions to the DSA representative and/or candidate accidents. The safety evaluation includes consideration of the safety basis controls (i.e., safety SSCs and technical safety requirements [TSR]), which the HAZOP did not consider. Any HAZOP identified hazardous conditions that were estimated not to be adequately addressed by the DSA accident analysis and controls are discussed in this safety evaluation. 


\section{RPP-17965 REV 5}

\subsection{ASSUMPTIONS}

No key assumptions were identified for this safety evaluation.

\subsection{HAZOP RESULTS}

The HAZOP team identified 111 hazardous conditions associated with operation of the SST waste retrieval modified sluicing system. The team used the consolidated hazardous conditions from the HAZOPs for SSTs 241-S-112 (RPP-9014), 241-U-107 (RPP-7689), and 241-C-106 (RPP-13557) and the Justification for Continued Operation for modified sluicing in SSTs 241-S-112 and 241-U-107 as a starting point, identifying new hazardous conditions as necessary.

\subsection{HAZARDOUS CONDITION SCREENING}

Hazardous conditions were screened to determine if they 1) are not represented by a DSA representative accident, 2) are similar to, but not bounded by a DSA representative accident, 3) are similar to and bounded by a DSA representative accident but are unique in regard to process or control applicability, or 4) are not appropriately represented by a candidate accident. Hazardous conditions meeting one or more of these criteria require further evaluation. Chapters 4.0 and 5.0 of this safety evaluation document the evaluation of these hazardous conditions. Hazardous conditions not meeting the screening criteria were not further evaluated and will not be incorporated into the DSA hazard evaluation database.

Hazardous conditions involving exposure to radioactive and other hazardous materials were assigned a representative accident and/or a candidate accident designator as appropriate. The representative accident designator allows cross reference to the appropriate analysis in the DSA. Candidate accident designators allow hazardous conditions to be compared with the hazardous conditions contained in the DSA hazard evaluation database. Thirty-one hazardous conditions were identified as meeting the screening criteria and are presented in Appendix $\mathrm{C}$. The information in Appendix $\mathrm{C}$ reflects the final results of this safety evaluation.

The break down of these hazardous conditions is as follows:

10 Representative Accident 1, Flammable Gas Accidents (Candidate Accidents 04/05)

6 Representative Accident 2, Nuclear Criticality (Candidate Accident 01)

3 Representative Accident 4, Release from Contaminated Facility (Candidate Accident 07)

3 Representative Accident 13, Waste Transfer Leak (Candidate Accident 33)

8 Identifiable to a Candidate Accident but DSA Hazardous Conditions Determined to be Risk Bin III or IV (i.e., no Representative Accident identified), Filtration Failures Leading to Unfiltered Releases (Candidate Accidents 06/18B)

1 Identifiable to a Candidate Accident but DSA Hazardous Conditions Determined to be Risk Bin III or IV (i.e., no Representative Accident identified), Tank Bump (Candidate Accident 18A) 


\subsection{DETAILED DISCUSSION}

The following text provides a brief discussion of the specific reasons that hazardous conditions were identified for further evaluation:

Ten hazardous conditions involving flammable gas accidents (Representative Accident 1, Candidate Accident 05, deflagrations in other than DSTs) were identified as having the characteristics sufficiently different from the hazardous conditions in the DSA hazard evaluation database to warrant further evaluation. The specific concern involves deflagrations resulting from induced gas release events (GRE). The process of retrieving waste by sluicing from an SST has the potential for creating induced releases of flammable gas that were not evaluated in the DSA.

Hazardous conditions involving nuclear criticality (Representative Accident 2, Candidate Accident 01 ) were identified that are very similar to the hazardous conditions in the DSA hazard evaluation database. They are included with the hazardous conditions requiring further evaluation to ensure that criticality concerns are verified as adequately addressed.

Three hazardous conditions involving release from contaminated facility (Representative Accident 4, Candidate Accident 07) were identified as having characteristics sufficiently different from the hazardous conditions in the DSA hazard evaluation database to warrant further evaluation. The concern is associated with the possible use of a hydraulic motor driven positive displacement transfer pump, hydraulically powered nozzle indexer (rotation), and hydraulically powered articulation actuator (radial position). Use of hydraulic power creates the potential for combustible fluid to be released and ignited in a contaminated area pit which is not addressed in the current DSA.

Three hazardous conditions involving waste leaks (Representative Accident 13, Candidate Accidents $33 \mathrm{~A}, 33 \mathrm{C}$, and $33 \mathrm{E}$ ) were identified as having characteristics sufficiently different from the hazardous conditions in the DSA hazard evaluation database to warrant further evaluation. The specific concerns involve the potential for transfer system pressures higher than what was evaluated in the current DSA analysis. This is due to the use of a progressive cavity positive displacement pump to transfer mobilized waste from an SST. Positive displacement pumps have the potential for producing very high pressures under the off-normal conditions.

Eight hazardous conditions associated with filtration failures leading to unfiltered releases (Candidate Accidents 06 and 18B) were identified as having higher consequences than reported in the DSA. The specific concern involves the potential for the release source term to be greater than what was used in the current DSA analysis.

One hazardous condition associated with tank bump (Candidate Accident 18A) was identified as having characteristics sufficiently different from the hazardous conditions in the DSA hazard evaluation database to warrant further evaluation. The specific concern involves water infiltration and subsequent steam evolution behind the steel SST liner. Such an event has happened in the tank farms in the past. The current DSA control suit does not address this accident. However, based on the following qualitative argument, no discussion is necessary in Chapters 4.0 or 5.0 of this safety evaluation. 
Tank bump resulting from water intrusion behind an SST liner is judged to have a frequency "beyond extremely unlikely. Hazardous conditions with a frequency of "beyond extremely unlikely" require no further evaluation. The frequency estimate is based on the fact that a heat load of $>11.3 \mathrm{~kW}$ is required to result in waste temperatures that exceed the saturation temperature of water (RPP-6213). Only four SSTs (241-A-104, 241-AX-104, 241-C-103, and 241-C-107) have heat loads in excess of $11.3 \mathrm{~kW}$ (RPP-5926, Steady-State Flammable Gas Release Rate and Lower Flammability Level Evaluation for Hanford Tank Waste). Current waste temperature data shows that these tanks are well below the saturation temperature of water. The highest temperature found in these four tanks is $76{ }^{\circ} \mathrm{C}\left(168.8^{\circ} \mathrm{F}\right)$ (SST $\left.241-\mathrm{A}-104\right)$. These tanks have been under passive cooling conditions for many years and show no trend of increasing temperature. Since the temperature is substantially below the saturation of water there is no possibility of steam bubble formation behind the tank liner no matter what quantity of water is involved. 
RPP-17965 REV 5

\subsection{ACCIDENT ANALYSIS}

\subsection{EVALUATION OF RISK FROM MODIFIED SLUICING OF WASTE FOR DSA REPRESENTATIVE ACCIDENTS}

\subsubsection{Flammable Gas Accidents}

\subsubsection{DSA Representative Accident}

The DSA related representative accident is (Candidate Accident 04/05), Flammable Gas Accidents and is addressed in DSA Section 3.3.2.4.1, "Flammable Gas Accidents," addresses this hazardous condition. The DSA evaluates flammable gas hazards in all tank farm facilities where waste is present, including DSTs, SSTs, double-contained receiver tanks (DCRT), active catch tanks, inactive tanks, waste transfer-associated structures, waste transfer systems, and waste-intruding equipment. There are two mechanisms by which waste-generated flammable gases can reach high concentrations in tank farm facilities. First, flammable gases generated by the waste are continuously released into vapor spaces. In the absence of adequate ventilation, the steady-state concentration of these gases can potentially exceed the lower flammability limit (LFL). Second, a fraction of the gas generated by the waste can be retained within the waste. This retained gas can be released in a spontaneous or induced GRE thereby increasing the flammable gas concentration in a tank headspace to above the LFL.

The representative accident for DSTs (Candidate Accident 04) is a headspace deflagration due to a steady-state accumulation of flammable gas or a spontaneous GRE. Without controls, the DSA qualitatively determined the frequency of a headspace deflagration in a DST due to a steady-state accumulation of flammable gases or a spontaneous GRE to be "unlikely." The deflagration in the headspace of a DST is qualitatively determined to result in "low" onsite radiological consequences, "low" offsite toxicological consequences, and "moderate" onsite toxicological consequences. Safety-significant structures, systems, and components (SSC) and/or TSRs are required based on the Risk Bin II result associated with the onsite toxicological consequences.

Other hazardous conditions associated with the DST flammable gas representative accident address various DST deflagration scenarios (e.g., different flammable gas sources, different ignition sources). The other accident scenarios identified in the DSA as requiring safety-significant SSCs and/or TSRs based on either their risk binning results or their potential for significant facility worker consequences are DST Headspace Deflagration Due to an Induced GRE, Deflagration in a DST Annulus, Deflagration in DST Waste-Intruding Equipment, Deflagration in a Waste Transfer Line, and DST Gasoline Deflagration. The DST accident scenarios relevant to modified sluicing operations are summarized below:

- DST Headspace Deflagration Due to an Induced GRE. This hazardous condition is identical to the representative accident except that the flammable gas concentration in the headspace reaches the LFL due to an induced GRE. As documented in PNNL-13781, Effects of Globally Waste-Disturbing Activities on Gas Generation, Retention, and Release in Hanford Waste Tanks, activities with the potential to induce a significant GRE 
in DSTs are waste transfers, mixer pump operation, air lift circulator operation, and large water or chemical additions. Because these are current or planned activities, the frequency without controls was qualitatively determined to be "anticipated." Safety-significant SSCs and/or TSRs are required based on the Risk Bin I result associated with the onsite toxicological consequences.

- Deflagration in DST Waste-Intruding Equipment. Waste-intruding equipment is equipment that is inserted below the waste surface and is open ended, breached, or uses a mechanical seal as a barrier to electrical components and creates an unvented vapor space where flammable gases generated or retained in the waste may accumulate (e.g., core sample drill pipes, pump suction legs, weight factor dip tubes). Incidents have occurred where the concentration of flammable gas in waste-intruding equipment has exceeded the LFL. These incidents were attributed to the equipment encountering gas pockets in the waste. Flammable gas concentrations exceeding the LFL in waste-intruding equipment have also resulted from steady-state generation and accumulation. Given this operational history, the frequency of a deflagration in waste-intruding equipment without controls was qualitatively determined to be "anticipated." The consequences were qualitatively determined to be "low" for the onsite and offsite receptors due to the localized nature of the deflagration and the smaller material at risk (MAR) relative to the representative accident. This frequency/consequence combination yields a Risk Bin III result for the onsite and offsite receptors. It was, however, qualitatively determined that a deflagration in waste-intruding equipment could result in significant facility worker consequences (i.e., a prompt fatality or serious injuries or significant radiological or chemical exposures). Accordingly, safety-significant SSCs and/or TSRs are required. This evaluation is also applicable to waste-intruding equipment in SSTs.

- Deflagration in a Waste Transfer Line. There is limited potential for flammable gas accumulation and ignition in either the primary or encasement piping of a waste transfer line. The frequency of a deflagration without controls was qualitatively determined to be "unlikely." The consequences were qualitatively determined to be "low" for the onsite and offsite receptors due to the limited volume of hydrogen and the smaller MAR relative to the representative accident. This frequency/consequence combination yields a Risk $\mathrm{Bin}$ III result for the onsite and offsite receptors. It was, however, qualitatively determined that a deflagration in a waste transfer line could result in significant facility worker consequences (i.e., a prompt fatality or serious injuries or significant radiological or chemical exposures). Accordingly, safety-significant SSCs and/or TSRs are required.

The representative accident for SSTs (Candidate Accident 05) is a headspace deflagration due to a steady-state accumulation of flammable gas. Without controls, the DSA qualitatively determined the frequency of a headspace deflagration in an SST due to a steady-state accumulation of flammable gas to be "unlikely." The deflagration in the headspace of an SST is qualitatively determined to result in "moderate" onsite radiological consequences, "low" offsite toxicological consequences, and "moderate" onsite toxicological consequences. Safetysignificant SSCs and/or TSRs are required based on the Risk Bin II result associated with the onsite radiological and toxicological consequences. 


\section{RPP-17965 REV 5}

Other hazardous conditions associated with the SST flammable gas representative accident address various SST deflagration scenarios (e.g., different flammable gas sources, different ignition sources). The other accident scenarios identified in the DSA as requiring safety-significant SSCs and/or TSRs based on either their risk binning results or their potential for significant facility worker consequences are SST Headspace Deflagration Due to an Induced GRE, Deflagration in SST Waste-Intruding Equipment, SST Gasoline Deflagration, Deflagration in a Double-Contained Receiver Tank, Deflagration in an Active Catch Tank, Deflagration in a Waste Transfer-Associated Structure, Deflagration in a Waste Transport Cask, and Deflagration in Inactive Tanks. The accident scenarios relevant to modified sluicing operations are summarized below:

- SST Headspace Deflagration Due to an Induced GRE. This hazardous condition is identical to the representative accident except that the flammable gas concentration in the headspace reaches the LFL due to an induced GRE. As documented in PNNL-13781, activities with the potential to induce a significant GRE in SSTs are saltwell pumping and water additions/saltcake dissolution. Because these are planned activities, the frequency without controls was qualitatively determined to be "anticipated." Safety-significant SSCs and/or TSRs are required based on the Risk Bin I result associated with the onsite radiological and toxicological consequences.

- Deflagration in SST Waste-Intruding Equipment. Refer to the DST summary above.

- Deflagration in a Waste Transfer-Associated Structure. There are two means by which flammable gas can be present in a waste transfer-associated structure. First, flammable gases can enter a structure if it is connected via open piping, drain lines, or risers to an SST, DST, or other waste storage facility. Second, flammable gases would be produced if waste were present in a structure due to a waste transfer misroute or transfer line failure. In the absence of controls, the flammable gas concentration could exceed the LFL via either means.

The frequency and consequences of flammable gas deflagrations in typical waste transfer-associated structures (e.g., pump pits, valve pits) are qualitatively addressed in DSA Section 3.3.2.4.4. The frequency of a postulated flammable gas deflagration in a waste transfer-associated structure without controls depends on the source of the flammable gas hazard (e.g., flammable gases entering from a connected tank, flammable gases generated by waste from a new or past leak) with the highest frequency being "anticipated." The radiological consequences to the onsite worker and toxicological consequences to the offsite public are qualitatively determined to be "low," and the toxicological consequences to the onsite worker are qualitatively determined to be "moderate." Safety-significant SSCs and/or TSRs are required based on the Risk Bin II result associated with the onsite toxicological consequences.

\subsubsection{Modified Sluicing Operations Hazardous Conditions}

The HAZOP for modified sluicing systems and operations described in Chapter 3.0 identified potential hazardous conditions that could result in a flammable gas deflagration. However, the only hazardous conditions identified that require additional safety evaluation are associated with 
the induced release of flammable gases caused by modified sluicing operations in SSTs. The other identified flammable gas hazardous conditions are addressed by the existing DSA hazard and accident analyses and derived controls (i.e., safety SSCs and/or TSRs), and no further evaluation is required. This section, therefore, only evaluates induced GRE flammable gas hazardous conditions in SSTs caused by modified sluicing operations.

During modified sluicing operations in SSTs flammable gases retained in the waste will be released. Trapped gases exist as small bubbles in the interstices of the solid waste matrix, separated from other bubbles and the headspace by interstitial liquid. During modified sluicing operations, drainage of the interstitial liquid from the undisturbed solid waste matrix, dissolution of the saltcake matrix, and mechanical break-up of the solid waste matrix will release trapped gases. Draining reduces the tank interstitial liquid level, releasing any entrained gas bubbles. Waste dissolution involves liquid addition causing saltcake to dissolve, thus releasing any trapped gas. Mechanical disturbance of the waste such as by sluicing, vortex action, or pump suction and return, causes shear forces on the solid waste matrix releasing entrained gas bubbles. All three of these gas release mechanisms (draining, dissolution, and mechanical disturbance) individually and collectively contribute to the flammable gas concentration within the SST headspace during modified sluicing operations.

PNNL-14271, Flammable Gas Release Estimates for Modified Sluicing Retrieval of Waste from Selected Hanford Single-Shell Tanks, evaluates the potential for induced GRE flammable gas hazards in SSTs during modified sluicing operations. Models developed to estimate retained gas releases, conservative retained gas inventory estimates, tank data, and anticipated waste retrieval rates were used to evaluate the dissolution and erosion of saltcake by water jets impinging on the waste surface, and the drainage of interstitial liquids from saltcake and the dissolution of saltcake by unsaturated liquids during a shutdown of modified sluicing operations.

The results of the evaluation in PNNL-14271 show that under conservative assumptions the flammable gas concentration in the SST headspace can rapidly approach $25 \%$ of the LFL when the tank is passively ventilated (e.g., for SST $241-\mathrm{S}-112,25 \%$ of the LFL is reached in just over $8 \mathrm{hr}$ ). Use of a portable exhauster within the assumed operating range of 270 to $475 \mathrm{ft}^{3} / \mathrm{min}$ prevents the SST headspace from reaching $25 \%$ of the LFL. Conservative estimates of gas release volumes after modified sluicing shutdown show that SST headspace flammable gas concentrations could exceed $100 \%$ of the LFL assuming no ventilation, complete interstitial drainage, and release of all retained gas from the region above the final interstitial liquid level. The free liquid inventories in an SST (i.e., maximum allowable tank inventory of process water and minimum level of liquid in the central pool) that would prevent exceeding $100 \%$ of the LFL in the SST headspace after modified sluicing shutdown are calculated.

\subsubsection{Accident Consequence Comparison}

The consequences of a flammable gas deflagration caused by an induced GRE during modified sluicing operations are bounded by the DSA analysis of SST deflagrations (i.e., "moderate" onsite radiological consequences, "low" offsite toxicological consequences, and "moderate" onsite toxicological consequences). That is, material source terms, release fractions, and airborne respirable fractions are bounded by the DSA analysis for deflagration in an SST. 


\section{RPP-17965 REV 5}

\subsubsection{Accident Frequency Comparison}

Flammable gas deflagrations due to induced GRE flammable gas hazardous conditions caused by modified sluicing operation in SSTs was qualitatively determined to be "anticipated" which is the same as the frequency of the induced GRE accident scenario in the DSA.

\subsubsection{Accident Risk Bin Results Without Controls}

Based on the risk binning methodology presented in the DSA, an induced GRE flammable gas deflagration accident caused by modified sluicing operations in an SST with an "anticipated" frequency results in a Risk Bin I for onsite radiological and toxicological (moderate consequence) and Risk Bin III for offsite toxicological (low consequence).

\subsubsection{Safety-Significant SSCs and TSR Controls}

Based on the hazard evaluation of postulated induced GRE flammable gas hazards in SSTs caused by modified sluicing operations, safety-significant SSCs and/or TSRs are required to protect the onsite (and facility) worker. For induced GRE flammable gas hazards in the DSA, there are no identified safety-significant SSCs, but the following TSR is established to prevent induced GRE flammable gas hazards.

A flammable gas concentration control point of $\leq 25 \%$ of the LFL shall be implemented for all tank farm facilities during activities that can induce a gas release that can achieve $100 \%$ of the LFL without the use of flammable gas concentration controls (e.g., active or manually configured passive ventilation, process controls, flammable gas concentration monitoring and proceduralized actions). Any combination of flammable gas concentration controls may be used to maintain the flammable gas concentration $\leq 25 \%$ of the LFL. Flammable gas concentration controls shall be monitored on a sufficient frequency to ensure that appropriate actions are taken for conditions $>25 \%$ of the LFL.

Flammable gas concentration controls shall be documented in a process control plan such that the flammable gas concentration is maintained $\leq 25 \%$ of the LFL. A process control plan will not be required for saltwell pumping.

If the concentration of flammable gas is $>25 \%$ of the LFL:

1. Immediately stop all activities in and directly above the affected tank, except for the following:

a. Flammable gas sampling/monitoring.

b. Deenergizing, removing, or stopping the use of equipment that does not meet ignition controls.

c. Actions to reduce the flammable gas concentration. 


\section{RPP-17965 REV 5}

2. Prior to the concentration of flammable gas exceeding $60 \%$ of the LFL:

a. Stop all activities in enclosed spaces connected to the affected tank headspace, except for flammable gas sampling/monitoring and actions to reduce the flammable gas concentration.

b. Deenergize, remove, or stop use of equipment that does not meet ignition controls in the affected tank headspace and connected enclosed spaces.

The flammable gas concentration controls selected as an acceptable method to implement this TSR for modified sluicing operations are :

1. Develop process controls such that the anticipated flammable gas concentration in Waste Group B SSTs is maintained $\leq 25 \%$ of the LFL for modified sluicing operations. (Note: Active ventilation may be used to maintain the flammable gas concentration $\leq 25 \%$ of the LFL.)

2. Periodically monitor the flammable gas concentration in the tank headspace to verify that it is $\leq 25 \%$ of the LFL during modified sluicing operations in Waste Group B SSTs. If the flammable gas concentration is $>25 \%$ of the LFL, take the actions prescribed in the TSR. (Note: Actions taken if the flammable gas concentration is $>25 \%$ of the LFL include stopping modified sluicing operations.)

Note: There are no Waste Group A SSTs, and there is no induced GRE flammable gas hazard in Waste Group C SSTs (i.e., there is insufficient retained gas to achieve $100 \%$ of the LFL if $100 \%$ of the retained gas was instantaneously released) and, therefore, induced GRE flammable gas concentration controls are not required.

The specific process controls to maintain the flammable gas concentration $\leq 25 \%$ of the LFL (e.g., active ventilation) and the periodicity for monitoring the flammable gas concentration in the tank headspace will be specified in the process control plan. The flammable gas monitoring frequency will be based on a conservative evaluation of the time for the flammable gas concentration to increase by $25 \%$ of the LFL (e.g., PNNL-14271). For example, based on the evaluation of SST 241-S-112 in PNNL-14271 (see Section 4.1.1.2), the frequency of flammable gas monitoring would be at least once every $8 \mathrm{hr}$. Periodic flammable gas monitoring would also continue after shutdown of modified sluicing operations until a downward trend is observed that demonstrates that $25 \%$ of the LFL will not be exceeded.

In addition to the above flammable gas concentration controls, if active ventilation is required to maintain the flammable gas concentration $\leq 25 \%$ of the LFL, process controls will be developed such that the flammable gas concentration is maintained $\leq 100 \%$ of the LFL following the loss of active ventilation and shutdown of modified sluicing operations. The specific process controls (e.g., maximum allowable tank inventory of process water and minimum level of liquid in the central pool derived in the PNNL-14271 evaluation) will be specified in the process control plan. 


\subsubsection{Conclusions}

Potential flammable gas hazards caused by modified sluicing operations are addressed and bounded by the DSA representative accidents. Postulated flammable gas accidents are also acceptably controlled by existing safety SSCs and TSRs, and no additional controls are necessary. Specific flammable gas concentration controls to implement the existing TSR requirement for induced flammable gas hazard controls have been defined.

\subsubsection{Criticality}

\subsubsection{DSA Representative Accident}

The DSA-related representative accident is 02 (Candidate Accident 01), Nuclear Criticality. The technical basis for the nuclear criticality safety of waste stored in underground tanks at the Hanford Site is summarized in DSA Section 3.3.2.4.2, "Nuclear Criticality." The DSA analysis postulated a mistransfer of waste from the Plutonium Finishing Plant that was routed to a DST where a criticality occurred.

The DSA indicates that no credible scenario has been identified for a criticality in a waste tank because of normal operations of waste storage. The potential for a criticality as a result of a mistransfer was analyzed. The potential for an accidental criticality without controls was estimated to be "beyond extremely unlikely." The criticality accident onsite radiological and onsite and offsite toxicological consequences are "low" (i.e., < 25 rem, < TEEL-1, and $<$ TEEL-2, respectively). Based on the estimated consequences and qualitative judgment, all the exposure categories were assigned to Risk Bin IV, which typically do not require safety SSC or TSR-level controls. However, one TSR-level control was selected to protect the frequency assumption as described in the DSA.

\subsubsection{Waste Retrieval System Operations Hazardous Conditions}

The modified sluicing waste retrieval system HAZOP concluded the potential for a criticality in the source SST and the receiving DST to remain in Risk Bin IV.

\subsubsection{Accident Frequency Comparison}

RPP-7475, Criticality Safety Evaluation of Hanford Site Tank Farm Facility, Section 2.8, "Sludge Retrieval Process Description," describes tank farm waste retrieval operations. Criticality concerns associated with sludge retrieval operations were evaluated in RPP-7475, Section 6.13, "Sludge Retrieval." The tank sludge contains most of the plutonium inventory of the tanks, which could create a criticality concern. Sludge retrieval operations involving waste retrieval modified sluicing operations were evaluated in RPP-7475. It was concluded that criticality due to sludge retrieval operations was not a concern. Sludge retrieval operations were considered to be the same as previously analyzed fluid dynamic sludge systems, specifically mixer pumps, air lift circulators, or sluicing relative to potential to create a criticality. Based on the evaluation in RPP-7475, it is concluded that criticality due to waste retrieval modified sluicing system operations remains "beyond extremely unlikely" without application of controls, 


\section{RPP-17965 REV 5}

and therefore, there is no increase in the frequency of a criticality accident as analyzed in the DSA.

\subsubsection{Accident Consequence Comparison}

The consequence of an unplanned nuclear criticality in a waste tank includes release of fission gases, small amounts of aerosolized plutonium, and tank waste (DSA, Section 3.3.2.4.2.3).

A criticality due to modified sluicing system operations would not result in an increase in SST source term considering the MAR, leak path factors (LPF), airborne release fractions (ARF), or respirable fraction (RF). As such, there would be no increase in potential radiological dose consequences from the SST being retrieved. A qualitative evaluation of the consequences of a nuclear criticality accident is described in RPP-12371, Technical Basis for the Nuclear Criticality Accident and Associated Represented Hazardous Conditions. Based on a review of this document, it is concluded that the DSA analysis unit-liter dose (ULD) values bound the ULD values of DST liquids and the ULD of the slurry mixture to be transferred from the 100 -series SSTs. As such, the DSA representative accident analysis radiological dose consequences remain bounding for a criticality from modified sluicing system operations.

\subsubsection{Safety SSCs and TSR Controls}

Administrative Control (AC) 5.7, "Safety Management Programs," Section 5.7.2, Program Key Element " $a$ " requires that the safety management programs (SMP) of DSA Chapters 6.0 through 17.0 to be established, implemented, and maintained. Chapter 6.0 of the DSA outlines the criticality safety program, which protects the assumptions on the current configuration of the tank waste with respect to criticality by establishing waste acceptance criteria (e.g., limits on fissile material concentration and alkalinity) for wastes entering the tank farms from outside sources. The criticality safety program also requires that criticality safety evaluations be performed for proposed tank farm operations that could change the form of the fissile material (e.g., dissociation of the fissile material from bound neutron absorbers by acid additions) or the distribution of the fissile material in the tanks (e.g., concentration of the fissile material).

\subsubsection{Conclusions}

A criticality evaluation of modified sluicing waste retrieval system operations concluded that a criticality was not credible. TSR controls are in place to ensure that the assumptions used to derive this conclusion remain valid. As such, the DSA representative accident remains bounding and no additional controls are necessary.

\subsubsection{Release from Contaminated Facility}

The DSA, Section 3.3.2.4.4, "Release from Contaminated Facility," provides the evaluation of this representative accident. Numerous contaminated areas exist within the tank farm facilities that are susceptible to releasing hazardous material, specifically during a fire. Contamination of tank farm facilities occurs from various operations required to manage tank waste.

Contaminated facilities at the tank farms include waste transfer-associated structures (e.g., valve pits, pump pits, diversion boxes, clean-out boxes), 244-CR Vault cells, 242-T Evaporator, etc. 
The hazard analysis performed for tank farm facilities and operations, including HNF-SD-WM-FHA-020, Tank Farms Fire Hazards Analysis (FHA), identify energy sources that could result in the uncontrolled release of radioactive and other hazardous material from contaminated tank farm facilities.

A qualitative evaluation of the frequency, consequences, and risk bin without controls for postulated release accidents from contaminated facilities, and the controls (i.e., safety SSCs and TSRs) selected to prevent or mitigate these previously analyzed accidents, are described in RPP-13354, Technical Basis for the Release from Contaminated Facility Representative Accident and Associated Represented Hazardous Conditions. These qualitative evaluations and the resulting controls for the uncontrolled release of radioactive and other hazardous material from contaminated facilities are addressed in Section 3.3.2.4.4 of the DSA.

\subsubsection{DSA Representative Accident}

A flammable gas deflagration in a waste transfer-associated structure is considered the bounding representative accident for a Release from a Contaminated Facility as discussed in the DSA. In this bounding accident scenario, flammable gases from a connected tank (e.g., DST, SST) or from waste present in the structure accumulate to the LFL and are ignited. Other identified energy sources that could result in uncontrolled releases from waste transfer-associated structures or other contaminated facilities include load-handling (e.g., load drop) accidents, compressed gas system failures, and other fires. Postulated causes of these other fires include electrical fires; fires due to maintenance activities (e.g., cutting, grinding, welding) and transient combustibles; and vehicle fuel fires. The FHA provides a complete description of the hazards investigated.

\subsubsection{Waste Retrieval System Operations Hazardous Conditions}

The waste retrieval modified sluicing system design introduces sluice nozzles and actuators that are hydraulically driven. These hydraulic lines, if ruptured, could leak into a pit and could be subject to internal fires (e.g., electrical or fluid) or exposed to vehicle fuel fires or other external fires (e.g., range fires or lighting initiated fires).

A HAZOP was performed to identify and evaluate potential hazards associated with SST waste retrieval modified sluicing system. The results of the HAZOP were reviewed to determine potential hazardous conditions created by the waste retrieval modified sluicing system and to identify potential hazardous conditions that may not be adequately bounded by current tank farms (DSA) analyzed representative accidents.

Hazardous conditions involving energy sources that could result in the uncontrolled release of radioactive and other hazardous material from contaminated tank farm facilities similar to those associated with the waste retrieval modified sluicing system have previously been considered in the DSA as Representative Accident Number 4 (Candidate Accident 7). A total of 11 hazardous conditions involving releases from contaminated facilities associated with the waste retrieval modified sluicing system operations were identified via the HAZOP process. The hazardous conditions expected during conduct of the waste retrieval modified sluicing system operations are similar to those previously identified in the tank farm operations hazards analysis database, Section 3.3.1.7, "Hazard Analysis Database," with the exception of the additional hydraulic line 
rupture leaking hydraulic fluid into a pit. Three of these hazardous conditions were identified as having characteristics sufficiently different from the hazardous conditions in the DSA hazard evaluation database to warrant further evaluation (i.e., MODSLUIC-C-031, MODSLUIC-D-003a, and MODSLUIC-D-003b).

\subsubsection{Accident Frequency Comparison}

The frequency of a postulated fire within a contaminated structure without controls is dependent on the cause of the fire. An electrical fire, or fire due to maintenance activities or transient combustibles in a contaminated facility without controls, is also qualitatively estimated as "anticipated" based on operating experience. Since, the DSA estimated frequency for these accident scenarios is already "anticipated" without controls, the uncontrolled accident frequency cannot be increased by modified sluicing waste retrieval system operations. A frequency of "unlikely" however was determined qualitatively for this postulated hazardous condition and therefore bounded by the DSA estimated frequency of "anticipated." "Unlikely" was chosen because the hydraulic fluid is limited to approximately 150 gal and has a high flashpoint (e.g., $>380^{\circ} \mathrm{F}$, and a NFPA Fire Rating of 1 ).

\subsubsection{Accident Consequence Comparison}

To estimate the potential consequences of a fire in a contaminated facility, the MAR is conservatively assumed in the DSA to be the equivalent of between 10 and $100 \mathrm{~L}$ of tank waste with solids fractions ranging from $1 \%$ to $10 \%$.

The ARF and RF used to determine the amount of respirable material released during a fire in a contaminated facility are from DOE-HDBK-3010-94, Airborne Release Fractions/Rates and Respirable Fractions for Nonreactor Nuclear Facilities. An ARF of 0.2 and an RF of 0.3 for an aqueous solution or air-dried salts under a gasoline fire on a surface that is a strong conductor of heat (i.e., metal) are considered to conservatively bound releases from a fire.

Based on the above MAR and release fractions, the total amount of respirable material suspended by a fire in a contaminated facility represented by a waste transfer-associated structure is conservatively estimated to be between a few $\mathrm{mL}$ and $2.5 \mathrm{~L}$, depending on the release mechanism. Radiological and toxicological consequences for this material release are estimated using the bounding radiological ULD for all tank wastes, the bounding toxicological sum of fraction (SOF) values for all tank wastes, and the accident analysis methodology described in RPP-13354. For the fire, a conservative release duration of 15 min was assumed for estimating consequences. In addition, the fire analysis included the thermal (buoyant) effects of the fire when determining the atmospheric dispersion coefficients.

The radiological consequences to the onsite worker and toxicological consequences to the offsite public are "low" ( $<25 \mathrm{rem},<$ TEEL-1, and $<$ TEEL-2, respectively) based on the conservative calculations in RPP-13354 for fires in contaminated facilities (see DSA Table 3.3.2.4.4-1).

The waste retrieval modified sluicing system design uses existing tank farm pits with drains. Hence, little to no accumulation of wastes is expected within the pits as a result of a spill or leak. The 42-L of MAR previously analyzed in the DSA is considered bounding for this scenario. Additionally, a review of the waste retrieval modified sluicing system indicates that only a 
limited amount of combustibles may be available to burn from a hydraulic oil rupture (approximately $150 \mathrm{gal}$ ) and the hydraulic oil has a high flashpoint (e.g., $>380^{\circ} \mathrm{F}$, and NFPA Fire Rating of 1). Therefore, the DSA consequences for a "Release from Contaminated Facility" would remain bounding.

\subsubsection{Safety SSCs and TSR Controls}

Based on the low offsite and onsite consequences, there are no TSR and/or safety SSC controls required for this postulated accident.

\subsubsection{Conclusions}

Based upon this safety evaluation, the DSA representative accident for "Release from Contaminated Facility" adequately bounds the frequency and consequences of similar hazards (e.g., fires) involving the waste retrieval modified sluicing system operations, when considering the application of current TSR controls.

No additional controls are necessary to prevent and/or mitigate releases from contaminated facilities due to waste retrieval modified sluicing operations.

\subsubsection{Waste Transfer Leaks}

\subsubsection{DSA Representative Accidents}

The DSA representative accidents are the "fine spray into the air" scenario and the "large pipe break into a pit" scenario. The fine spray into the air scenario assumes that a small width crack (the optimal width for producing fine aerosol) has occurred in a waste transfer line, and that waste slurry is spraying into the air under maximum available pump pressure. The large pipe break into a pit scenario assumes that a large pipe break has occurred, and that waste is leaking into an open pit at the maximum flow rate of the transfer pump. DSA Section 3.3.2.4.13, "Waste Transfer Leak," addresses these hazardous conditions. The DSA section also addresses several other accident scenarios, but the fine spray into the air and the large pipe break into a pit scenario are the limiting scenarios. The DSA estimates the frequency of the fine spray into the air scenario to be "unlikely," and the large pipe break into a pit scenario to be "anticipated." The onsite radiological and toxicological guidelines are exceeded for the two representative accident scenarios, and safety SSCs and/or TSR controls are required. The offsite radiological and toxicological guidelines are not exceeded.

\subsubsection{Waste Retrieval System Operations Hazardous Conditions}

The waste retrieval modified sluicing system HAZOP identified numerous hazardous conditions that could occur during modified sluicing system operations that would result in waste transfer leaks. These conditions involve leaks occurring in transfer lines at various locations and in various configurations. All of these scenarios are similar to scenarios already evaluated in DSA Section 3.3.2.4.13. The significant analysis parameters that differ in value between modified sluicing and the existing DSA include ULDs, SOFs, ${ }^{137} \mathrm{Cs}$ and ${ }^{90} \mathrm{Sr}$ concentrations, maximum transfer pump pressure, and maximum transfer pump flow rate. Other parameters significant to 
the calculation of radiological dose and toxicological exposure values are expected to be the same for modified sluicing and the DSA (e.g., $\chi / Q$ atmospheric dispersion values). If the values of all of these parameters for the modified sluicing system are bounded by the values of these parameters used for the current DSA analysis, then it may be concluded that modified sluicing is bounded by the current DSA.

Tables 4-1 and 4-2 provide a comparison of the analysis parameter values for properties associated with the waste (ULDs, SOFs, ${ }^{137} \mathrm{Cs}$ and ${ }^{90} \mathrm{Sr}$ concentrations), and for properties associated with the transfer pumps (maximum transfer pump pressure, and maximum transfer pump flow rate) for modified sluicing and the existing DSA analyses. Table 4-3 provides a comparison of radiological and toxicological consequence values specifically for the Seepex ${ }^{1}$ positive displacement pump.

Properties Associated with the Waste

The DSA used values for ULD, SOF, ${ }^{137} \mathrm{Cs}$ concentration and ${ }^{90} \mathrm{Sr}$ concentration that are bounding for all tanks in tank farms. Therefore, it is necessarily true that these values bound those associated with modified sluicing, which are based on the limiting values for 100 -series SSTs. However, the DSA assumes that the maximum insoluble solids concentration of a pumped waste stream will be $25 \mathrm{vol} \%$. It has been identified that during modified sluicing, an insoluble solids concentration as high as $30 \mathrm{vol} \%$ may be achieved for short periods of time. Consequently, Table 4-1 presents a comparison of analysis parameter values for properties associated with the waste, including waste slurry properties for $30 \mathrm{vol} \%$ insoluble solids.

Table 4-1. Properties Associated with the Waste. (2 sheets)

\begin{tabular}{|c|l|l|}
\hline \multicolumn{1}{|c|}{ Description } & \multicolumn{1}{|c|}{ DSA $^{(1)}$} & $\begin{array}{l}\text { Bounding 100-series SSTs (Modified } \\
\text { Sluicing) } \\
\text { (2) } \\
\text { [the bounding tank from which the } \\
\text { parameter value is taken is shown below } \\
\text { the parameter] }\end{array}$ \\
\hline Onsite ULD Liquid & $1.0 \mathrm{E}+3 \mathrm{~Sv} / \mathrm{L}$ & $\begin{array}{l}4.5 \mathrm{E}+2 \\
(\mathrm{U}-106)\end{array}$ \\
\hline Onsite ULD Solids & $1.9 \mathrm{E}+5 \mathrm{~Sv} / \mathrm{L}$ & $\begin{array}{l}1.4 \mathrm{E}+5 \mathrm{~Sv} / \mathrm{L} \\
(\mathrm{AX}-104)\end{array}$ \\
\hline Onsite Slurry ULD & $4.8 \mathrm{E}+4 \mathrm{~Sv} / \mathrm{L}(25 \mathrm{vol} \%)$ & $4.2 \mathrm{E}+4(30 \mathrm{vol} \%)$ \\
\hline Offsite ULD Liquid & $1.5 \mathrm{E}+3 \mathrm{~Sv} / \mathrm{L}$ & $\begin{array}{l}6.0 \mathrm{E}+2 \\
(\mathrm{U}-106)\end{array}$ \\
\hline Offsite ULD Solids & $2.9 \mathrm{E}+5 \mathrm{~Sv} / \mathrm{L}$ & $\begin{array}{l}1.9 \mathrm{E}+5 \mathrm{~Sv} / \mathrm{L} \\
(\mathrm{AX}-104)\end{array}$ \\
\hline Offsite Slurry ULD & $7.4 \mathrm{E}+4 \mathrm{~Sv} / \mathrm{L}(25 \mathrm{vol} \%)$ & $\begin{array}{l}5.7 \mathrm{E}+4 \mathrm{~Sv} / \mathrm{L}(30 \mathrm{vol} \%) \\
(\mathrm{A}-106)\end{array}$ \\
\hline Onsite SOF Liquid & $5.8 \mathrm{E}+8(\mathrm{TEEL}-2)$ & $\begin{array}{l}6.28 \mathrm{E}+8(\mathrm{TEEL}-2) \\
(\mathrm{A}-102)\end{array}$ \\
\hline Onsite SOF Solids & $3.9 \mathrm{E}+9(\mathrm{TEEL}-2)$ & \\
\hline
\end{tabular}

\footnotetext{
${ }^{1}$ Seepex is a registered trademark of Seeberger GmbH and Company, Germany.
} 


\section{RPP-17965 REV 5}

Table 4-1. Properties Associated with the Waste. (2 sheets)

\begin{tabular}{|c|c|c|}
\hline Description & $\mathbf{D S A}^{(1)}$ & $\begin{array}{l}\text { Bounding 100-series SSTs (Modified } \\
\text { Sluicing) } \\
\text { [the bounding tank from which the } \\
\text { parameter value is taken is shown below } \\
\text { the parameter] }\end{array}$ \\
\hline Onsite Slurry SOF & $1.4 \mathrm{E}+9(25 \mathrm{vol} \%)$ & $5.9 \mathrm{E}+8(30 \mathrm{vol} \%)$ \\
\hline Offsite SOF Liquid & $7.9 \mathrm{E}+9(\mathrm{TEEL}-1)$ & $\begin{array}{l}3.71 \mathrm{E}+9 \\
(\mathrm{~A}-106)\end{array}$ \\
\hline Offsite SOF Solids & $3.8 \mathrm{E}+9(\mathrm{TEEL}-1)$ & $\begin{array}{l}2.21 \mathrm{E}+9(\mathrm{TEEL}-1) \\
(\mathrm{TY}-102)\end{array}$ \\
\hline Offsite Slurry SOF & $6.9 \mathrm{E}+9(25$ vol\% $)$ & $3.3 \mathrm{E}+9(30 \mathrm{vol} \%)$ \\
\hline${ }^{137}$ Cs Solids & $7.0 \mathrm{E}+10 \mathrm{~Bq} / \mathrm{L}$ & $\begin{array}{l}1.9 \mathrm{E}+6 \mathrm{uCi} / \mathrm{L}^{(3)} \\
7.0 \mathrm{E}+10 \mathrm{~Bq} / \mathrm{L} \\
(\mathrm{AX}-104)\end{array}$ \\
\hline${ }^{137} \mathrm{Cs}$ Liquid & $5.9 \mathrm{E}+10 \mathrm{~Bq} / \mathrm{L}$ & $\begin{array}{l}5.3 \mathrm{E}+5 \mathrm{uCi} / \mathrm{L}^{(3)} \\
2.0 \mathrm{E}+10 \mathrm{~Bq} / \mathrm{L} \\
(\mathrm{A}-102)\end{array}$ \\
\hline Slurry Cs-137 & $6.2 \mathrm{E}+10 \mathrm{~Bq} / \mathrm{L}(25 \mathrm{vol} \%)$ & $3.5 \mathrm{E}+10 \mathrm{~Bq} / \mathrm{L}(30 \mathrm{vol} \%)$ \\
\hline${ }^{90} \mathrm{Sr}$ Solids & $2.9 \mathrm{E}+12 \mathrm{~Bq} / \mathrm{L}$ & $\begin{array}{l}7.9 \mathrm{E}+7 \mathrm{uCi} / \mathrm{L}^{(3)} \\
2.9 \mathrm{E}+12 \mathrm{~Bq} / \mathrm{L} \\
(\mathrm{AX}-104)\end{array}$ \\
\hline${ }^{90} \mathrm{Sr}$ Liquid & $3.5 \mathrm{E}+9 \mathrm{~Bq} / \mathrm{L}$ & $\begin{array}{l}5.9 \mathrm{E}+4 \mathrm{uCi} / \mathrm{L}^{(3)} \\
2.2 \mathrm{E}+9 \mathrm{~Bq} / \mathrm{L} \\
(\mathrm{U}-106)\end{array}$ \\
\hline Slurry Sr-90 & $7.3 \mathrm{E}+11 \mathrm{~Bq} / \mathrm{L}(25 \mathrm{vol} \%)$ & $8.7 \mathrm{E}+11 \mathrm{~Bq} / \mathrm{L}(30 \mathrm{vol} \%)$ \\
\hline
\end{tabular}

Notes:

$\mathrm{DSA}=$ documented safety analysis

TEEL $=$ Temporary Emergency Exposure Limit.

SOF $=$ sum of fractions.

$\mathrm{ULD}=$ unit-liter dose.

SST $=$ single-shell tank.

(1) Onsite radiological data and onsite and offsite toxicological data from RPP-13750, Waste Transfer Leaks Technical Basis Document. Offsite radiological data from RPP-14499, Offsite Radiological Consequence Analysis for the Waste Transfer Leak.

${ }^{(2)}$ Radiological data from RPP-5924, Radiological Source Terms for Tank Farms Safety Analysis, Rev.3, unless otherwise noted. Toxicological data from RPP-8369, Chemical Source Terms for Tank Farms Safety Analyses, Rev. 1.

${ }^{(3) 137} \mathrm{Cs}$ and ${ }^{90} \mathrm{Sr}$ data are from the July 10,2003 download of the Best-Basis Inventory. This is the same download that was used as the basis for RPP-5924 Rev.3. The Best-Basis Inventory is maintained at http://twins.pnl.gov/twins.htm. Pacific Northwest Laboratory, Richland, Washington.

Table 4-1 indicates that waste transfer leak analysis properties associated with the waste to be transferred during modified sluicing are bounded by the values of these properties assumed in the DSA analysis, except for the ${ }^{90} \mathrm{Sr}$ concentration. The ${ }^{90} \mathrm{Sr}$ concentration in the slurry exceeds the maximum DSA value for slurries if the insoluble solids concentration is greater than approximately 25 vol\% insoluble solids. However, the ${ }^{137} \mathrm{Cs}$ concentration and the ${ }^{90} \mathrm{Sr}$ concentration are always used together and are only used to calculate the direct radiation dose from a surface pool for the onsite receptor (direct shine does not affect an offsite receptor). Consequently, the lower concentration of ${ }^{137} \mathrm{Cs}$ for sluicing tends to compensate for the higher concentration of ${ }^{90} \mathrm{Sr}$. This can be seen by comparing the direct shine dose for the fine spray and the large break representative accidents as calculated for the DSA (assuming $25 \mathrm{vol} \%$ solids), 
with the same values calculated using the ${ }^{137} \mathrm{Cs}$ and ${ }^{90} \mathrm{Sr}$ concentrations from Table 4-1 (assuming $30 \mathrm{vol} \%$ solids). The result is that, for the large pipe break scenario, the DSA value for direct shine dose is $3.6 \mathrm{E}+2$ rem (RPP-13750, Table A6-5) and the direct shine dose using modified sluicing values for ${ }^{137} \mathrm{Cs}$ and ${ }^{90} \mathrm{Sr}$ concentrations is also $3.6 \mathrm{E}+2$ rem (from Excel model Large Break $8 \mathrm{hr} 30 \%$ modified sluicing (9-26-03).xls). Similarly, for the fine spray representative accident, both the DSA case for $25 \mathrm{vol} \%$ solids and the modified sluicing case for 30 vol\% solids give a direct shine dose of $2.2 \mathrm{E}+1 \mathrm{rem}$ (see RPP-1370 Table A6-1 and Excel model Fine Spray $8 \mathrm{hr}$ 30\% modified sluicing (9-26-03).xls). From these results it is concluded that, while the ${ }^{90} \mathrm{Sr}$ concentration for modified sluicing assuming $30 \mathrm{vol} \%$ solids is not bounded by the ${ }^{90} \mathrm{Sr}$ concentration used for the DSA analysis which assumes a maximum of $25 \mathrm{vol} \%$ solids, the combination of ${ }^{137} \mathrm{Cs}$ and ${ }^{90} \mathrm{Sr}$ concentrations for modified sluicing is within the envelop of the values assumed for purposes of the DSA analyses. All of the other waste properties used for modified sluicing are individually bounded by the values of those properties assumed in the DSA analysis.

The other modified sluicing properties that are important for the waste transfer leak analysis are those associated with the waste transfer pumps.

\section{Properties Associated with the Transfer Pumps}

Two types of waste transfer pumps are currently planned for use for modified sluicing. The Lawrence pump configuration consists of an immersible (also referred to as "submersible") pump that provides positive suction head to a vertical inline "booster" pump. These two pumps are centrifugal pumps. This configuration was selected to bound the pump configuration that will be used for modified sluicing because the final pump configuration has not yet been selected.

The other transfer pump configuration planned for use during modified sluicing consists of a single Seepex positive displacement pump. A positive displacement pump is especially appropriate for pumping higher solids content waste material.

Table 4-2 compares the transfer pump properties with those assumed in the DSA.

A composite pump curve is not available for the Lawrence Centrifugal Pump configuration. Therefore, the maximum pressures from the two individual pump curves (i.e., the submersible pump and the vertical inline pump) were added to produce an approximate bounding maximum pressure for the two pumps operating in series. The maximum flow rate for the two pumps operating in series was taken to be the maximum flow rate for the vertical inline pump, since it has the lower maximum flow rate of the two pumps and would therefore be limiting. As Table 4-2 shows, the Lawrence Centrifugal Pump configuration pump parameters are bounded by the pump parameters assumed in the DSA analysis. 
Table 4-2. Properties Associated with the Transfer Pumps.

\begin{tabular}{|l|l|l|l|}
\hline \multicolumn{1}{|c|}{ DSA } & $\begin{array}{c}\text { Lawrence centrifugal } \\
\text { pump configuration }\end{array}$ & \multicolumn{1}{|c|}{$\begin{array}{c}\text { Seepex positive } \\
\text { displacement pump }\end{array}$} \\
\hline Max. Flow Rate & $790 \mathrm{gal} / \mathrm{min}$ & $\sim 685 \mathrm{gal} / \mathrm{min}^{(1)}$ & $521 \mathrm{gal} / \mathrm{min}^{(4)}$ \\
\hline Max. Pressure & $\begin{array}{l}800 \mathrm{ft} \\
\text { (approx. } 460 \mathrm{lb} / \mathrm{in}^{2}\end{array}$ & $\begin{array}{l}153.5 \mathrm{ft}+550.1 \mathrm{ft}= \\
\text { gauge for } 7 \mathrm{vol} \% \\
\text { insoluble solids waste) }\end{array}$ & $480 \mathrm{lb} / \mathrm{in}^{2} \mathrm{gauge}^{(5)}$ \\
\hline
\end{tabular}

The Seepex pump is a positive displacement pump rather than a centrifugal pump and, consequently, it does not have a pump curve like a centrifugal pump. However, the uncontrolled maximum pump flow rate and the uncontrolled maximum pump discharge pressure can be estimated based on the point at which the pump motor is estimated to begin to fail (i.e., for the uncontrolled case, no credit is taken for the pressure relief valve or amperage limits that are normally associated with the pump). The Seepex pump electric motor has a nominal horsepower rating of $30 \mathrm{hp}$, based on Seepex Quality Inspection Certificates According to DIN 55 350-18-4.2.2 (CVI \#50253). The point at which motor failure begins is taken to be $115 \%$ of this value (the "nameplate value"), since typical industry standards (e.g., National Electrical Manufacturer's Association Safety Standard and Guide for Selection, Installation, and Use of Electric Motors and Generators, MG2-2001) specify that operation up to $115 \%$ of nominal rating shall not have an immediate damaging effect on motor operation. $115 \%$ of $30 \mathrm{HP}=$ $34.5 \mathrm{hp}$. This is the point for which maximum pump pressure and maximum pump flow rate are estimated.

The $34.5 \mathrm{hp}$ produces a maximum pump speed of approximately $650 \mathrm{rpm}$ in a no backpressure condition. Based on $650 \mathrm{rpm}$, a maximum flow rate of approximately $521 \mathrm{gal} / \mathrm{min}$ is estimated by extrapolation of the pump performance curves in Seepex Operating and Maintenance Instruction for Progressive Cavity Pump BE 55-24, Serial Numbers 806306 and 806307, Section 9 - Auxiliary Documentation.

Based on pump test data included in vendor file CVI \#50253 $34.5 \mathrm{hp}$ motor operation suggests a maximum pump pressure of approximately $480 \mathrm{lb} / \mathrm{in}^{2}$ gauge. 
As Table 4-2 indicates, the maximum flow rate for the Seepex pump is bounded by the DSA assumed maximum flow rate, while the maximum pressure may not be bounded. However, recalculation of the bounding onsite and offsite radiological and toxicological consequences using the waste properties from Table 4-1, together with an assumed $480 \mathrm{lb} / \mathrm{in}^{2}$ gauge pump pressure, produces the following results (Table 4-3).

Table 4-3. Seepex Pump Maximum Pressure Exposure Comparison.

\begin{tabular}{|c|c|c|}
\hline & DSA & $480 \mathrm{lb} / \mathrm{in}^{2}$ gauge pressure \\
\hline Onsite radiological exposure & Moderate risk bin ${ }^{(1)}$ & Moderate risk bin ${ }^{(3)}$ \\
\hline Onsite toxicological exposure & High risk bin ${ }^{(1)}$ & High risk bin ${ }^{(3)}$ \\
\hline Offsite radiological exposure & $1.4 \mathrm{E}-1 \mathrm{rem}^{(2)}$ & $9.6 \mathrm{E}-2 \mathrm{rem}^{(3)}$ \\
\hline Offsite toxicological exposure & Low risk bin ${ }^{(1)}$ & Low risk bin ${ }^{(3)}$ \\
\hline $\begin{array}{l}\text { Notes: } \\
\text { DSA = documented safety analy } \\
\text { (1) RPP-13750, Waste Transfer } \\
\text { (2) RPP-14499, Offsite Radiologi } \\
\text { (3) Based on the same calculation } \\
\text { RPP-13750 and RPP-14499. } \\
\text { Calculations of the results for } 48 \\
\text { Fine Spray } 8 \mathrm{hr} 0 \% 480 \text { psig } \\
\text { Fine Spray } 8 \mathrm{hr} 7 \% 480 \text { psig } \\
\text { Fine Spray } 8 \mathrm{hr} 15 \% 480 \text { psig } \\
\text { Fine Spray } 8 \mathrm{hr} 25 \% 480 \text { psig } \\
\text { Fine Spray Offsite } 8 \mathrm{hr} 0 \% 48 \\
\text { Fine Spray Offsite } 8 \mathrm{hr} 7 \% 48 \\
\text { Fine Spray Offsite } 8 \mathrm{hr} 15 \% 4 \\
\text { Fine Spray Offsite } 8 \mathrm{hr} 25 \% 4 \\
\text { (note that } 30 \text { vol\% cases wer } \\
\text { 25 vol\%) }\end{array}$ & $\begin{array}{l} \\
\text { Consequence Analysis } f \\
\text { methodology as describe } \\
\text { b/in }{ }^{2} \text { gauge pressure are } \\
\text { 8-03).xls } \\
\text { 8-03).xls } \\
\text { 28-03).xls } \\
\text { 28-03).xls } \\
\text { ig (9-28-03).xls } \\
\text { ig (9-28-03).xls } \\
\text { osig (9-28-03).xls } \\
\text { t } 9-28-03) . x l s \\
\end{array}$ & $\begin{array}{l}\text { Insfer Leak. } \\
\text { ray accident scenario analyses in } \\
\text { following Excel spreadsheets: }\end{array}$ \\
\hline
\end{tabular}

Based on the information in Table 4-3, a maximum pump pressure of $480 \mathrm{lb} / \mathrm{in}^{2}$ gauge would produce consequences that are bounded by the current DSA analysis.

Based on informal discussion with the Seepex pump vendor, it is possible that a pressure spike greater than $480 \mathrm{lb} / \mathrm{in}^{2}$ gauge may occur for a short period of time. If the pressure is high enough (on the order of $2,000 \mathrm{lb} / \mathrm{in}^{2}$ gauge to $3,000 \mathrm{lb} / \mathrm{in}^{2}$ gauge) and a leak occurs, the offsite evaluation guideline could be exceeded. However, this would require a fine crack that has optimal width for producing fine spray to form and be maintained for an $8 \mathrm{hr}$ period. If such a crack did occur, it is very likely that it would quickly expand due to erosion by the high pressure of the leaking fluid. As the width of the crack increases from the optimal width for spray production, the amount of respirable size aerosol particles produced decreases rapidly, and the leak begins to more closely resemble the large pipe break into a pit scenario. Consequently, it is qualitatively judged that, even if a leak occurred at a pressure much higher than $480 \mathrm{lb} / \mathrm{in}^{2}$ gauge and a crack occurs that has the optimal width for production of fine aerosol, this crack configuration would not exist for an extended period of time (i.e., $8 \mathrm{hr}$ is assumed in the DSA analysis) and offsite radiological consequences would not challenge guidelines. Also, the leak scenario would become more like a large break scenario as the crack width increases due to erosion. For large break scenarios, the maximum pump flow rate is more important for determining consequences 
than the maximum pump pressure. As noted in Table 4-2, the maximum flow rate of the Seepex pump is bounded by the maximum flow rate assumed in the DSA. Also, the Seepex pump includes a relief valve. No credit is taken for this relief valve when estimating uncontrolled radiological and toxicological consequences. However, this relief valve is considered a defensein-depth feature for mitigation of accident scenarios involving high pump pressures. Vendor information file CVI \#50253 includes documentation from the manufacturer indicating that the valve is pressure tested to meet or exceed the pertinent requirements of ASME B\&PV Code Section VIII, Division 1, subsections UG-125 through UG-136.

\subsubsection{Safety SSCs and TSR Controls}

The discussion presented in Section 4.1.4.2 indicates that waste transfer leak accident scenarios associated with modified sluicing are bounded by those currently addressed in the DSA. Therefore, the controls specified in the TSRs for the waste transfer leak accident as analyzed in the DSA also provide adequate risk reduction to allow modified sluicing operations to be conducted safely. The current controls for waste transfer leak accident scenarios specified in the TSRs are as follows:

- LCO 3.1.1, "Transfer Leak Detection Systems"

- LCO 3.1.2, "Backflow Prevention Systems"

- AC 5.7, "Safety Management Programs"

- AC 5.8, "Emergency Preparedness"

- AC 5.11, "Transfer Controls "

- AC 5.12, "Administrative Lock Controls."

Applicable safety-significant SSCs include:

- Transfer Leak Detection Systems

- Hose-in-hose Transfer Line Systems

- Aboveground Transfer System Vehicle Barriers (if used to comply with AC 5.11)

- Service Water Pressure Detection Systems (if used to comply with LCO 3.1.2)

- Backflow Preventers (if used to comply with LCO 3.1.2).

It is assumed in this analysis that all transfer lines used for modified sluicing will be either underground or, if aboveground, will be safety-significant HIHTL systems.

As noted above, the relief valve installed on the Seepex positive displacement pump will be treated as a defense-in-depth feature.

\subsubsection{Conclusions}

The waste transfer leak accident scenarios associated with modified sluicing are bounded by those currently addressed in the DSA. Therefore, the controls specified in the TSRs for the waste transfer leak accident as analyzed in the DSA also provide adequate risk reduction for waste transfer leak accidents associated with modified sluicing operations. 
RPP-17965 REV 5

\subsection{EVALUATION OF RISK FROM MODFIED SLUICING OF WASTE FOR DSA CANDIDATE ACCIDENTS NOT SELECTED AS REPRESENTATIVE ACCIDENTS}

\subsubsection{Filtration Failures Leading to Unfiltered Releases}

\subsubsection{DSA Representative Accident}

There is no DSA representative accident because HEPA filter failures from exposure to high temperature or pressure were analyzed and binned in Risk Bin III (RPP-13437, Technical Basis Document for Ventilation System Filtration Failures Leading to Unfiltered Release). The analyses assume an event that results in failure of all prefilters, HEPA filters, and other filters (i.e., high-efficiency mist eliminators and high-efficiency gas adsorbers) present in the ventilation system. It is further assumed that a fraction of the inventory of tank waste accumulated on filters and ventilation system ductwork is released. Failure of the filters results in an unfiltered release that also contributes to the consequences of the event. Consequences of all HEPA filter failure and unfiltered release scenarios evaluated in RPP-13437 fall into the "low" category.

\subsubsection{Waste Retrieval System Operations Hazardous Conditions}

SST modified sluicing waste retrieval systems will retrieve waste from designated tanks and transfer the retrieved waste to the DST system. The SST modified sluicing waste retrieval system is designed to dissolve SST crystallized salt and to mobilize sludge through the application of high pressure water or supernatant spray to break down the waste salt, sludge, and solids and to direct the waste to the intake of a slurry transfer pump for transfer into the DST system. Various SST waste retrieval system sluicing designs may be used.

The SST waste retrieval system sluicing designs employ sluicing nozzles that are installed in the tank headspace via SST risers. The number of sluicing nozzles can vary depending on the amount and location of solidified waste within the SST. The nozzle system is designed to aim pressurized fluid (raw water or supernatant) that will break up, mobilize, and move the sludge and compacted solids slurry to a location where they are picked up by a slurry transfer pump.

The SST modified sluicing HAZOP identified potential SST HEPA failures and unfiltered releases from various initiators such as moisture buildup, dome cracking, vapor condensation resulting in a vacuum, and sluice water evaporation resulting in headspace pressurization.

Sluicing operations have the potential to increase the aerosol content of the headspace beyond what is currently evaluated in the DSA. Therefore the effect of the increased aerosol loading requires further evaluation.

\subsubsection{Accident Frequency Comparison}

Aerosol generation and moisture buildup causing HEPA filter failure has been previously identified and documented in the hazard analysis database. The assigned frequency for these 
conditions is "anticipated" in RPP-13437. Since that is the highest frequency category, the SST modified sluicing operations cannot exceed this frequency.

\subsubsection{Accident Consequence Comparison}

The source terms (including ULD, ARF, and RF) for HEPA filter failure during SST modified sluicing operations would not be different from those currently considered in RPP-13437, since the waste composition will not change and the HEPA filter loading parameters remain the same.

There are no mechanisms during SST modified sluicing operations that would cause an increase in the radiological dose or toxicological consequences from the release of material from the HEPA filters or ducting during a HEPA filter failure over that analyzed in support of the DSA (RPP-13437). However, the unfiltered release portion of the event during modified sluicing operations was postulated to have consequences higher than those evaluated in RPP-13437 because of the potentially high aerosol loading in the headspace of the tank being retrieved.

4.2.1.4.1 Reasonably Conservative Base Case. This case assumes that one ventilation system is operating at the maximum ventilation runout flow of a portable exhauster with a variable frequency drive at the normal $60 \mathrm{~Hz}$ set point (RPP-CALC-24575, Assessment of Maximum Ventilation Flow Rates for VFD Driven Portable Exhausters for SST Ventilation). Tank waste releases are qualitatively estimated at $10 \%$ SST solids and $90 \%$ SST liquids from experience from sluicing SST 241-C-106 (RPP-19919, Campaign Report for the Retrieval of Waste Heel from Tank 241-C-106) and past sluicing campaigns (SD-WM-TI-302, Hanford Waste Tank Sluicing History). An aerosol partition fraction of $2 \times 10^{-8} \mathrm{~L}$ waste/ $\mathrm{L}$ for air lift circulator operation is used. This is conservative compared to the measured aerosol partition fraction during a waste transfer of $2 \times 10^{-9} \mathrm{~L}$ waste/L (RPP-13437).

4.2.1.4.1.1 Toxicological Consequences of an Unfiltered Release. The aerosol release rate can be calculated as follows:

$$
\begin{aligned}
& \left(1,304 \mathrm{ft}^{3} / \mathrm{min}\right)(1 \mathrm{~min} / 60 \mathrm{sec})\left(28.3 \mathrm{~L} / \mathrm{ft}^{3}\right)\left(2 \times 10^{-8} \mathrm{~L} \text { waste } / \mathrm{L} \text { air }\right) \\
& =1.23 \times 10^{-5} \mathrm{~L} / \mathrm{sec}
\end{aligned}
$$

where:

$1,304 \mathrm{ft}^{3} / \mathrm{min}$ is the maximum ventilation exhaust flowrate for a portable exhauster for SST retrieval ventilation (RPP-CALC-24575)

$28.3 \mathrm{~L} / \mathrm{ft}^{3}$ is a conversion factor (Weast 1981, CRC Handbook of Chemistry and Physics)

$2 \times 10^{-8} \mathrm{~L}$ waste/ $\mathrm{L}$ air is the partition fraction of waste in the headspace air during air lift circulator operation which is a conservative selection since the measured partition fraction during a waste transfer is $2 \times 10^{-9} \mathrm{~L}$ waste/ $\mathrm{L}$ air (RPP-13437).

4.2.1.4.1.2 Onsite Toxicological Consequences. Calculating the TEEL-2 SOF multiplier for an onsite release assuming 10\% SST solids and 90\% SST liquids:

$(0.90)\left(5.73 \times 10^{8}\right)+(0.10)\left(6.28 \times 10^{8}\right)=5.79 \times 10^{8}$ 


\section{RPP-17965 REV 5}

where:

$5.73 \times 10^{8}$ is the bounding liquid TEEL-2 SOF multiplier for 100-series SSTs (RPP-8369, Chemical Source Terms for Tank Farms Safety Analysis)

$6.28 \times 10^{8}$ is the bounding solid TEEL-2 SOF multiplier for 100-series SSTs (RPP-8369).

Calculating the onsite moderate toxicological consequences:

$$
\begin{aligned}
\text { Onsite, moderate SOF } & =(\text { aerosol release rate })(\text { onsite } \chi / \mathrm{Q})(\text { TEEL-2 SOF multiplier }) \\
\text { Onsite, moderate SOF } & =\left(1.23 \times 10^{-5} \mathrm{~L} / \mathrm{sec}\right)\left(3.28 \times 10^{-2} \mathrm{sec} / \mathrm{m}^{3}\right)\left(5.79 \times 10^{8}\right) /\left(1,000 \mathrm{~L} / \mathrm{m}^{3}\right) \\
& =2.3 \times 10^{-1}
\end{aligned}
$$

where:

$3.28 \times 10^{-2} \mathrm{sec} / \mathrm{m}^{3}$ is the bounding onsite $\chi / \mathrm{Q}$ for a ground level release (RPP-13482)

$1,000 \mathrm{~L} / \mathrm{m}^{3}$ is a volumetric conversion factor.

4.2.1.4.1.3 Offsite Toxicological Consequences. Calculating the TEEL-1 SOF multiplier for an offsite release assuming $10 \%$ SST solids and $90 \%$ SST liquids:

$(0.90)\left(3.71 \times 10^{9}\right)+(0.10)\left(2.21 \times 10^{9}\right)=3.56 \times 10^{9}$

where:

$3.71 \times 10^{9}$ is the bounding liquid TEEL-1 SOF multiplier for 100-series SSTs (RPP-8369)

$2.21 \times 10^{9}$ is the bounding solid TEEL-1 SOF multiplier for 100-series SSTs (RPP-8369).

Calculating the offsite moderate toxicological consequences:

Offsite, moderate SOF $=($ aerosol release rate $)($ offsite $\chi / \mathrm{Q})($ TEEL-1 SOF multiplier $)$

Offsite, moderate SOF $=\left(1.23 \times 10^{-5} \mathrm{~L} / \mathrm{sec}\right)\left(2.22 \times 10^{-5} \mathrm{sec} / \mathrm{m}^{3}\right)\left(3.56 \times 10^{9}\right) /\left(1,000 \mathrm{~L} / \mathrm{m}^{3}\right)$ $=9.7 \times 10^{-4}$

where:

$2.22 \times 10^{-5} \mathrm{sec} / \mathrm{m}^{3}$ is the bounding offsite $\chi / \mathrm{Q}$ for a ground level release (RPP-13482).

4.2.1.4.1.4 Radiological Consequences of an 8-hr Unfiltered Release. The total release over the 8 -hr period can be found by:

$\left(1.23 \times 10^{-5} \mathrm{~L} / \mathrm{sec}\right)(60 \mathrm{sec} / \mathrm{min})(60 \mathrm{~min} / \mathrm{h})(8 \mathrm{hr})=3.54 \times 10^{-1} \mathrm{~L}$

Calculating the onsite ULD for an onsite release assuming 10\% SST sludge and $90 \%$ supernatant:

$(0.90)\left(4.5 \times 10^{2} \mathrm{~Sv} / \mathrm{L}\right)+(0.10)\left(1.4 \times 10^{5} \mathrm{~Sv} / \mathrm{L}\right)=1.4 \times 10^{4} \mathrm{~Sv} / \mathrm{L}$ 


\section{RPP-17965 REV 5}

where:

$4.5 \times 10^{2} \mathrm{~Sv} / \mathrm{L}$ is the bounding ULD for supernatant in 100-series SSTs (RPP-5924)

$1.4 \times 10^{5} \mathrm{~Sv} / \mathrm{L}$ is the bounding ULD for sludge in 100-series SSTs (RPP-5924).

Calculating the onsite radiological dose:

$$
\begin{aligned}
\text { Onsite Dose } & =(\text { aerosol released })(\text { onsite } \chi / \mathrm{Q})(\text { onsite ULD) (breathing rate }) \\
\text { Onsite Dose } & =\left(3.54 \times 10^{-1} \mathrm{~L}\right)\left(5.58 \times 10^{-3} \mathrm{sec} / \mathrm{m}^{3}\right)\left(1.4 \times 10^{4} \mathrm{~Sv} / \mathrm{L}\right)\left(3.33 \times 10^{-4} \mathrm{~m}^{3} / \mathrm{sec}\right) \\
& =9.2 \times 10^{-3} \mathrm{~Sv} \\
& =9.2 \times 10^{-1} \mathrm{rem}
\end{aligned}
$$

where:

$5.58 \times 10^{-3} \mathrm{sec} / \mathrm{m}^{3}$ is the onsite 8-hr $\chi / \mathrm{Q}$ including plume meander (RPP-13482)

$3.33 \times 10^{-4} \mathrm{~m}^{3} / \mathrm{sec}$ is the breathing rate (RPP-5924).

It can be seen that the consequences for the unfiltered release accident are below the moderate risk guidelines ( 1.0 is the toxicological guideline and $25 \mathrm{rem}$ is the radiological guideline). Even when the consequences for the bounding HEPA filter failure are added to the unfiltered release the guidelines are not challenged. The contribution to the toxicological consequences due to high pressure failure of the HEPA filters is $3.1 \times 10^{-3}$ for onsite and $4.2 \times 10^{-6}$ for offsite releases while the bounding contribution to the radiological consequences is $2.2 \times 10^{-4} \mathrm{rem}$ (RPP-13437). The resultant risk bin is III for an accident with a frequency of "anticipated."

\subsection{Sensitivity Case 1 (30\% Solids Loading)}

4.2.1.4.2.1 Toxicological Consequences of an Unfiltered Release. The aerosol release rate can be calculated as follows:

$$
\begin{aligned}
& \left(1,304 \mathrm{ft}^{3} / \mathrm{min}\right)(1 \mathrm{~min} / 60 \mathrm{sec})\left(28.3 \mathrm{~L} / \mathrm{ft}^{3}\right)\left(2 \times 10^{-8} \mathrm{~L} \text { waste } / \mathrm{L} \text { air }\right) \\
& =1.23 \times 10^{-5} \mathrm{~L} / \mathrm{sec}
\end{aligned}
$$

where:

$1,304 \mathrm{ft}^{3} / \mathrm{min}$ is the maximum ventilation exhaust flowrate for a portable exhauster for SST retrieval ventilation (RPP-CALC-24575)

$28.3 \mathrm{~L} / \mathrm{ft}^{3}$ is a conversion factor (Weast 1981)

$2 \times 10^{-8} \mathrm{~L}$ waste/ $\mathrm{L}$ air is the partition fraction of waste in the headspace air during air lift circulator operation which is a conservative selection since the measured partition fraction during a waste transfer is $2 \times 10^{-9} \mathrm{~L}$ waste/L air (RPP-13437).

4.2.1.4.2.2 Onsite Toxicological Consequences. Calculating the TEEL-2 SOF multiplier for an onsite release assuming 30\% SST solids and 70\% SST liquids (RPP-13437):

$(0.70)\left(5.73 \times 10^{8}\right)+(0.30)\left(6.28 \times 10^{8}\right)=5.89 \times 10^{8}$ 


\section{RPP-17965 REV 5}

where:

$5.73 \times 10^{8}$ is the bounding liquid TEEL-2 SOF multiplier for 100 -series SSTs (RPP-8369)

$6.28 \times 10^{8}$ is the bounding solid TEEL-2 SOF multiplier for 100-series SSTs (RPP-8369).

Calculating the onsite moderate toxicological consequences:

Onsite, moderate SOF $=($ aerosol release rate) (onsite $\chi / \mathrm{Q})($ TEEL-2 SOF multiplier)

Onsite, moderate SOF $=\left(1.23 \times 10^{-5} \mathrm{~L} / \mathrm{sec}\right)\left(3.28 \times 10^{-2} \mathrm{sec} / \mathrm{m}^{3}\right)\left(5.89 \times 10^{8}\right) /\left(1,000 \mathrm{~L} / \mathrm{m}^{3}\right)$ $=2.4 \times 10^{-1}$

where:

$3.28 \times 10^{-2} \mathrm{sec} / \mathrm{m}^{3}$ is the bounding onsite $\chi / \mathrm{Q}$ for a ground level release (RPP-13482) $1,000 \mathrm{~L} / \mathrm{m}^{3}$ is a volumetric conversion factor.

4.2.1.4.2.3 Offsite Toxicological Consequences. Calculating the TEEL-1 SOF multiplier for an offsite release assuming $30 \%$ SST solids and 70\% SST liquids (RPP-13437):

$(0.70)\left(3.71 \times 10^{9}\right)+(0.30)\left(2.21 \times 10^{9}\right)=3.26 \times 10^{9}$

where:

$3.71 \times 10^{9}$ is the bounding liquid TEEL-1 SOF multiplier for 100-series SSTs (RPP-8369)

$2.21 \times 10^{9}$ is the bounding solid TEEL-1 SOF multiplier for 100-series SSTs (RPP-8369).

Calculating the offsite moderate toxicological consequences:

Offsite, moderate SOF $=($ aerosol release rate) $($ offsite $\chi / \mathrm{Q})($ TEEL-1 SOF multiplier $)$

Offsite, moderate SOF $=\left(1.23 \times 10^{-5} \mathrm{~L} / \mathrm{sec}\right)\left(2.22 \times 10^{-5} \mathrm{sec} / \mathrm{m}^{3}\right)\left(3.26 \times 10^{9}\right) /\left(1000 \mathrm{~L} / \mathrm{m}^{3}\right)$

$$
=8.9 \times 10^{-4}
$$

where:

$2.22 \times 10^{-5} \mathrm{sec} / \mathrm{m}^{3}$ is the bounding offsite $\chi / \mathrm{Q}$ for a ground level release (RPP-13482).

4.2.1.4.2.4 Radiological Consequences of an 8-hr Unfiltered Release. The total release over the 8-hr period can be found by:

$\left(1.23 \times 10^{-5} \mathrm{~L} / \mathrm{sec}\right)(60 \mathrm{sec} / \mathrm{min})(60 \mathrm{~min} / \mathrm{h})(8 \mathrm{hr})=3.54 \times 10^{-1} \mathrm{~L}$

Calculating the onsite ULD for an onsite release assuming 30\% SST sludge and $70 \%$ supernatant (RPP-13437):

$(0.70)\left(4.5 \times 10^{2} \mathrm{~Sv} / \mathrm{L}\right)+(0.30)\left(1.4 \times 10^{5} \mathrm{~Sv} / \mathrm{L}\right)=4.2 \times 10^{4} \mathrm{~Sv} / \mathrm{L}$ 


\section{RPP-17965 REV 5}

where:

$4.4 \times 10^{2} \mathrm{~Sv} / \mathrm{L}$ is the bounding ULD for supernatant in 100-series SSTs (RPP-5924)

$1.4 \times 10^{5} \mathrm{~Sv} / \mathrm{L}$ is the bounding ULD for sludge in 100-series SSTs (RPP-5924).

Calculating the onsite radiological dose:

$$
\begin{aligned}
\text { Onsite Dose } & =(\text { aerosol released })(\text { onsite } \chi / \mathrm{Q})(\text { onsite ULD })(\text { breathing rate }) \\
\text { Onsite Dose } & =\left(3.54 \times 10^{-1} \mathrm{~L}\right)\left(5.58 \times 10^{-3} \mathrm{sec} / \mathrm{m}^{3}\right)\left(4.2 \times 10^{4} \mathrm{~Sv} / \mathrm{L}\right)\left(3.33 \times 10^{-4} \mathrm{~m}^{3} / \mathrm{sec}\right) \\
& =2.8 \times 10^{-2} \mathrm{~Sv} \\
& =2.8 \mathrm{rem}
\end{aligned}
$$

where:

$5.58 \times 10^{-3} \mathrm{sec} / \mathrm{m}^{3}$ is the onsite $8-\mathrm{hr} \chi / \mathrm{Q}$ including plume meander (RPP-13482)

$3.33 \times 10^{-4} \mathrm{~m}^{3} / \mathrm{sec}$ is the breathing rate (RPP-5924).

It can be seen that the consequences for the unfiltered release accident are below the moderate risk guidelines (1.0 is the toxicological guideline and $25 \mathrm{rem}$ is the radiological guideline). Even when $30 \%$ SST solids are assumed and the consequences for the bounding HEPA filter failure are added to the unfiltered release the guidelines are not challenged. The contribution to the toxicological consequences due to high pressure failure of the HEPA filters is $3.1 \times 10^{-3}$ for onsite and $4.2 \times 10^{-6}$ for offsite releases while the bounding contribution to the radiological consequences is $2.2 \times 10^{-4} \mathrm{rem}$ (RPP-13437). The resultant risk bin is III for an accident with a frequency of "anticipated."

4.2.1.4.3 Sensitivity Case 2 (Maximum Allowable Ventilation Flow Rate). The purpose of this sensitivity case is to back calculate the maximum ventilation flow rate during modified sluicing operations that is within the DSA guidelines. This is done by calculating the aerosol release rate using the onsite moderate guideline SOF of 1 and then calculating the maximum ventilation flow rate.

The aerosol release rate is calculated by:

Aerosol release rate $=($ Onsite, moderate $\mathrm{SOF}) /($ onsite $\chi / \mathrm{Q})(\mathrm{TEEL}-2 \mathrm{SOF}$ multiplier $)$

Aerosol release rate $=(1)\left(1,000 \mathrm{~L} / \mathrm{m}^{3}\right) /\left(3.28 \times 10^{-2} \mathrm{sec} / \mathrm{m}^{3}\right)\left(5.79 \times 10^{8}\right)$

$$
=5.27 \times 10^{-5} \mathrm{~L} / \mathrm{sec}
$$

where:

$3.28 \times 10^{-2} \mathrm{sec} / \mathrm{m}^{3}$ is the bounding onsite $\chi / \mathrm{Q}$ for a ground level release (RPP-13482)

$1,000 \mathrm{~L} / \mathrm{m}^{3}$ is a volumetric conversion factor.

$5.79 \times 10^{8}$ is the TEEL-2 SOF multiplier for an onsite release assuming $10 \%$ SST solids and $90 \%$ SST liquids (RPP-13437):

$(0.90)\left(5.73 \times 10^{8}\right)+(0.10)\left(6.28 \times 10^{8}\right)=5.79 \times 10^{8}$ 
where:

$5.73 \times 10^{8}$ is the bounding liquid TEEL-2 SOF multiplier for 100-series SSTs (RPP-8369)

$6.28 \times 10^{8}$ is the bounding solid TEEL-2 SOF multiplier for 100-series SSTs (RPP-8369). The maximum ventilation flow rate is:

$$
\begin{aligned}
& =5.26 \times 10^{-5} \mathrm{~L} / \mathrm{sec} /(1 \mathrm{~min} / 60 \mathrm{sec})\left(28.3 \mathrm{~L} / \mathrm{ft}^{3}\right)\left(2 \times 10^{-8} \mathrm{~L} \text { waste } / \mathrm{L} \text { air }\right) \\
& =5,600 \mathrm{ft}^{3} / \mathrm{min}
\end{aligned}
$$

where:

28.3 $\mathrm{L} / \mathrm{ft}^{3}$ is a conversion factor (Weast 1981)

$2 \times 10^{-8} \mathrm{~L}$ waste/ $\mathrm{L}$ air is the partition fraction of waste in the headspace air during air lift circulator operation which is a conservative selection since the measured partition fraction during a waste transfer is $2 \times 10^{-9} \mathrm{~L}$ waste/L air (RPP-13437).

\subsubsection{Safety SSCs and TSR Controls}

Currently the DSA has no TSR-level controls for HEPA filter failures or unfiltered releases, nor are any additional controls required for SST modified sluicing conditions. Since SST modified sluicing conditions remain Risk Bin III, they do not require the identification of additional controls beyond existing SMPs.

\subsubsection{Conclusions}

Filtration system failure accidents that could be initiated during SST modified sluicing operations are adequately analyzed and bounded by conditions currently identified in the hazards analysis database and the DSA technical basis documents. No additional controls are necessary. Sensitivity cases show that the conclusions are not very sensitive to ventilation flow rate and percent solids. 


\section{RPP-17965 REV 5}

\subsection{CONTROLS}

Based on the hazard and accident analysis of modified sluicing operations, no new accidents were identified, and the existing DSA analyses were found to be encompassing and bounding. The DSA controls (i.e., safety SSCs and TSRs) were also found to acceptably prevent or mitigate potential hazardous conditions and postulated accidents for modified sluicing operations. Although the waste transfer spray leak accident caused by the high pressures possible with progressive cavity pumps was determined to be bounded by the DSA analysis and mitigated by the selected DSA controls (e.g., waste transfer-associated covers) and additional defense-indepth feature was identified for this accident scenario. The defense-in-depth feature is the pressure limiter (e.g., pressure relief valve) for progressive cavity pumps that is designed to prevent pressures exceeding the design pressure of the waste transfer system. 


\section{RPP-17965 REV 5}

\section{This page intentionally left blank.}




\section{RPP-17965 REV 5}

\subsection{REFERENCES}

03-TED-029, 2003, “Approval of Interim Authorization Using Alternate Controls Related to the Operation of Active Ventilation on Single-Shell Tank (SST) 241-C-106 During Accelerated Waste Retrieval," Letter dated March 5, to E. S. Aromi, CH2M HILL Hanford Group, Inc., from R. J. Schepens, U.S. Department of Energy, Office of River Protection, Richland, Washington.

03-TED-066, 2003, "Safety Evaluation Report (SER) for Approval of Justification for Continued Operation (JCO) for Tank Farms Single-Shell Tank (SST) Retrieval/Closure Modified Sluicing," Letter dated June 2, to E. S. Aromi, CH2M HILL Hanford Group, Inc., from R. J. Schepens, U.S. Department of Energy, Office of River Protection, Richland, Washington.

Best Basis Inventory, available at: http://twins.pnl.gov/twins.htm, Pacific Northwest National Laboratory, Richland, Washington. Queries executed on September 9, 2003.

CVI \#22668 Supplement No. 147, Quality Documentation Plan, Purchase Order W-78259-Z4, Lawrence Pumps, Inc., Lawrence Mass [no date].

CVI \#50253, 2003, Section 21, Seepex Quality Inspection Certificates According to DIN 55 350-18-4.2.2, CH2M HILL Hanford Group, Inc., Richland, Washington.

MG2-2001, 2001, National Electrical Manufacturer's Association Safety Standard and Guide for Selection, Installation, and Use of Electric Motors and Generators, Rosslyn, Virginia.

PNNL-13781, 2003, Effects of Globally Waste-Disturbing Activities on Gas Generation, Retention, and Release in Hanford Waste Tanks, Rev. 2, Pacific Northwest National Laboratory, Richland, Washington.

PNNL-14271, 2003, Flammable Gas Release Estimates for Modified Sluicing Retrieval of Waste from Selected Hanford Single-Shell Tanks, Rev. 0, Pacific Northwest National Laboratory, Richland, Washington.

RPP-CALC-24575, 2005, Assessment of Maximum Ventilation Flow Rates for VFD Driven Portable Exhausters for SST Ventilation, Rev. 0, CH2M HILL Hanford Group, Inc., Richland, Washington.

RPP-19919, 2004, Campaign Report for the Retrieval of Waste Heel from Tank 241-C-106, Rev. 0, CH2M HILL Hanford Group, Inc., Richland, Washington.

RPP-5924, 2003, Radiological Source Terms for Tank Farms Safety Analysis, Rev. 3, CH2M HILL Hanford Group, Inc., Richland, Washington. 


\section{RPP-17965 REV 5}

RPP-5926, 2003, Steady-State Flammable Gas Release Rate and Lower Flammability Level Evaluation for Hanford Tank Waste, Rev. 3, CH2M HILL Hanford Group, Inc., Richland, Washington.

RPP-7475, 2002, Criticality Safety Evaluation of Hanford Tank Farm Facility, Rev. 1, CH2M HILL Hanford Group, Inc., Richland, Washington.

RPP-7689, 2003, Hazard Evaluation for Single-Shell Retrieval Via Salt Cake Dissolution Proof of Concept in Tank 241-U-107, Rev. 0A, CH2M HILL Hanford Group, Inc., Richland, Washington.

RPP-8369, 2003, Chemical Source Terms for Tank Farms Safety Analyses, Rev. 2, CH2M HILL Hanford Group, Inc., Richland, Washington.

RPP-9014, 2002, Process Hazard Evaluation for the S-112 Saltcake Waste Retrieval Technology Demonstration Project Preconceptual Design, Rev. 0, CH2M HILL Hanford Group, Inc., Richland, Washington.

RPP-12371, 2003, Technical Basis for the Nuclear Criticality Representative Accident and Associated Represented Hazardous Conditions, Rev. 1, CH2M HILL Hanford Group, Inc., Richland, Washington.

RPP-13354, 2003, Technical Basis for the Release from Contaminated Facility Representative Accident and Associated Represented Hazardous Conditions, Rev. 1, CH2M HILL Hanford Group, Inc., Richland, Washington.

RPP-13437, 2003, Technical Basis Document for Ventilation System Filtration Failures Leading to an Unfiltered Release, Rev. 0, CH2M HILL Hanford Group, Inc., Richland, Washington.

RPP-13482, 2003, Atmospheric Dispersion Coefficients and Radiological/Toxicological Exposure Methodology for Use in Tank Farms, Rev. 2, CH2M HILL Hanford Group, Inc., Richland, Washington.

RPP-13557, 2003, Safety Evaluation of Phase 1 Retrieval of 241-C-106 for Closure, Rev. 0, CH2M HILL Hanford Group, Inc., Richland, Washington.

RPP-13750, 2003, Waste Transfer Leaks Technical Basis Document, Rev. 1, CH2M HILL Hanford Group, Inc., Richland, Washington.

RPP-13978, 2003, Technical Basis for the Transportation-Related Handling Accidents and Associated Representative Hazardous Conditions, Rev. 1, CH2M HILL Hanford Group, Inc., Richland, Washington.

RPP-14499, 2003, Offsite Radiological Consequence Analysis for the Waste Transfer Leak, Rev.1, CH2M HILL Hanford Group, Inc., Richland, Washington. 


\section{RPP-17965 REV 5}

SD-WM-TI-302, 1987, Hanford Waste Tank Sluicing History, Rev. 0, Westinghouse Hanford Company, Richland, Washington.

Weast, R. C., 1981, CRC Handbook of Chemistry and Physics, CRC Press, Inc., Boca Raton, Florida. 


\section{RPP-17965 REV 5}

This page intentionally left blank. 
RPP-17965 REV 5

APPENDIX A

TEAM MEMBER ROSTER

A-i 
RPP-17965 REV 5
RP

This page intentionally left blank. 
RPP-17965 REV 5

Hazards Analysis Team Meeting Attendance Sheet Meeting Subject: Nootified S/wicing $\frac{\text { Date }}{\text { Name }}$ Phone $/ 19 / 23$

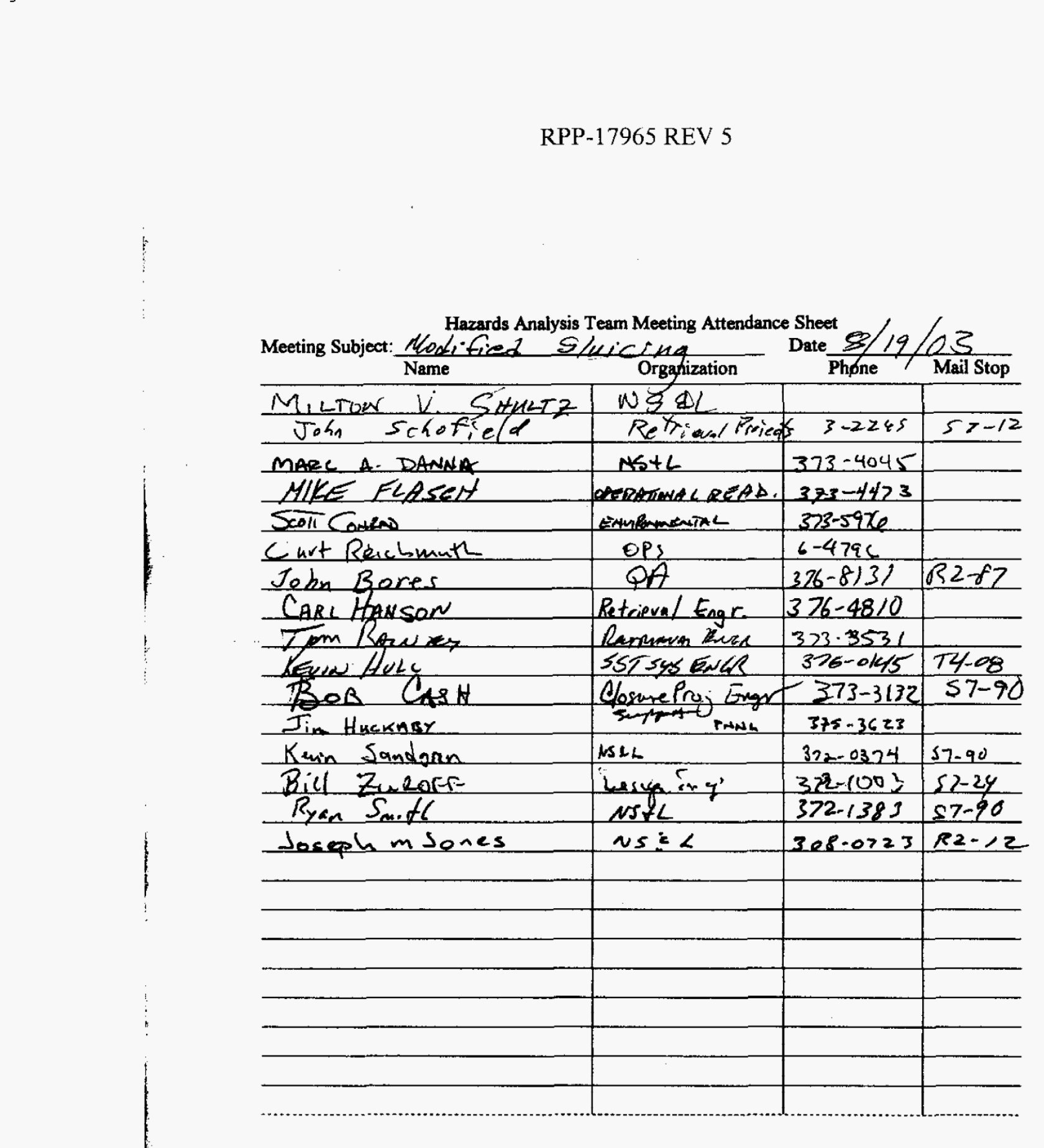

(n)

.

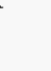


RPP-17965 REV 5

This page intentionally left blank.

A-2 
RPP-17965 REV 5

\section{5} i

s


RPP-17965 REV 5

This page intentionally left blank.

B-ii 
Definitions of information listed in Table 3-X and C-1:

- ID: The item identification (ID); used to record a unique identifier for the hazardous condition.

- Node: The division of a process or activity into discrete segments is called a node. Each node represents a specific part of the process or activity. This division into nodes is designed to facilitate the hazard identification process.

- Process Variable: The characteristics of a process, such as flow, pressure, or temperature, which are used to define proper operation.

- Deviation: The deviation is the description of the divergence from the desired value for a given process variable, such as "low temperature" to describe temperature below normal or optimum.

- Hazardous Condition: The hardware failures, operational faults, or conditions that could result in undesired consequences. The Hazardous Condition is a concise statement combining the Cause, Consequence, and Mode of radioactive material release.

- Possible Causes of Deviation: The causes that lead to the deviation from the process variable and resultant Hazardous Condition.

- Consequence: The potential consequences that could result from the postulated deviation.

- Potential Engineered Features: Potential SSCs are existing engineered features (hardware items) identified by the hazard and operability study (HAZOP) team that have the potential to mitigate or prevent the hazardous condition of concern. The engineered features are candidates for designation as safety-significant items for hazardous conditions that pose a significant threat to the health of facility workers and onsite personnel or safety class for hazards that pose a significant threat to offsite individuals. These items should not be construed as being the "official" controls that would eventually be credited in the safety basis.

- Potential Administrative Controls: Technical safety requirements are existing controls identified by the HAZOP team that have the potential to mitigate or prevent the hazardous condition of concern. These items should not be construed as being the "official" administrative features that would eventually be credited in the safety basis.

- NC Consequence Category (NC Offsite Rad, NC Offsite Tox, NC Onsite Rad, NC Onsite Tox, NC FW Cons): The consequence category is a code designator for the level of safety consequence associated with a specific class of receptor, material of concern (radioactive or toxic material), and the hazardous condition. The consequence assignment is a "first cut," qualitative estimate of the safety severity of the consequences assuming no controls are present. The criteria for determining the consequence 
designation is unique to the receptor. For the Offsite and Onsite receptor the consequence designators are low (L), moderate (M), and high $(\mathrm{H})$. The facility worker (FW) is assigned a $\mathrm{Y}$ or $\mathrm{N}$ based on whether the postulated event is estimated to result in severe injury or death. $\mathrm{Y}$ indicates there is a potential for significant $\mathrm{FW}$ impact and $\mathrm{N}$ indicates no potential. Table B-1 summarizes the criteria for Offsite receptors, Onsite receptors, and facility workers:

Table B-1. Consequence Levels and Risk Evaluation Guidelines.

\begin{tabular}{|c|c|c|c|}
\hline $\begin{array}{c}\text { Consequence } \\
\text { level }\end{array}$ & Offsite public & Onsite co-located worker & Site facility worker \\
\hline High & $\begin{array}{l}\text { Considerable offsite impacts } \\
\text { on people or the environs. } \\
\quad>25 \text { rem TEDE or } \\
>\text { ERPG-2/TEEL-2 }\end{array}$ & $\begin{array}{c}\text { Considerable onsite impacts } \\
\text { on people or the environs. } \\
\text { >100 rem TEDE or } \\
>\text { ERPG-3/TEEL - } 3\end{array}$ & \multirow{3}{*}{$\begin{array}{l}\text { All facility worker } \\
\text { hazards are assessed } \\
\text { for prompt death or } \\
\text { serious injury or } \\
\text { significant } \\
\text { radiological or } \\
\text { chemical exposure. }\end{array}$} \\
\hline Moderate & $\begin{array}{l}\text { Only minor offsite impact on } \\
\text { people or the environs. } \\
\quad \geq 1 \text { rem TEDE or } \\
>\text { ERPG-1/TEEL- } 1\end{array}$ & $\begin{array}{l}\text { Considerable onsite impact } \\
\text { on people or the environs. } \\
\quad \geq 25 \text { rem TEDE or } \\
>\text { ERPG-2/TEEL-2 }\end{array}$ & \\
\hline Low & $\begin{array}{l}\text { Negligible offsite impact on } \\
\text { people or the environs. } \\
\qquad<1 \text { rem or } \\
<\text { ERPG-1/TEEL-1 }\end{array}$ & $\begin{array}{l}\text { Minor onsite impact on } \\
\text { people or the environs. } \\
\qquad 25 \text { rem or } \\
<\text { ERPG-2/TEEL- } 2\end{array}$ & \\
\hline
\end{tabular}

- ENV Cons. The environmental consequence ranking is a "first cut," qualitative estimate of the environmental severity of the hazardous condition assuming no controls are present. The following system is used:

E0 No significant environmental effect outside the facility confinement systems.

E1 Limited environmental discharge of hazardous material outside the facility.

E2 Large environmental discharge of hazardous material within the plant site boundary.

E3 Significant environmental discharges of hazardous material outside the plant site boundary. 
- NC Frequency: The NC frequency is a "first cut," qualitative estimate of the likelihood of the hazardous condition assuming no controls are present. The following system is used:

A Events that are expected to occur one or more times during the lifetime of the facility, categorized as "anticipated" events. The frequency range associated with this category is $>1 \mathrm{E}-02 / \mathrm{yr}$.

U Events that could occur during the lifetime of the facility, but with low probability. Such events are categorized as "unlikely" and fall in the range of $1 \mathrm{E}-04 / \mathrm{yr}$ to $1 \mathrm{E}-02 / \mathrm{yr}$.

EU Events not expected to occur during the lifetime of the facility, categorized as "extremely unlikely." The frequency range associated with this category is $1 \mathrm{E}-06 / \mathrm{yr}$ to $1 \mathrm{E}-04 / \mathrm{yr}$.

BEU Events categorized as "beyond extremely unlikely," with a frequency less than $1 \mathrm{E}-06 / \mathrm{yr}$. Events in this category (such as meteor strike) are so unlikely they generally do not require special controls.

- Remarks: Miscellaneous observations or clarifying comments for a given item. 
RPP-17965 REV 5

This page intentionally left blank. 
RPP-17965 REV 5

APPENDIX C

HAZOP TABLE

C-i 
RPP-17965 REV 5

This page intentionally left blank.

C-ii 


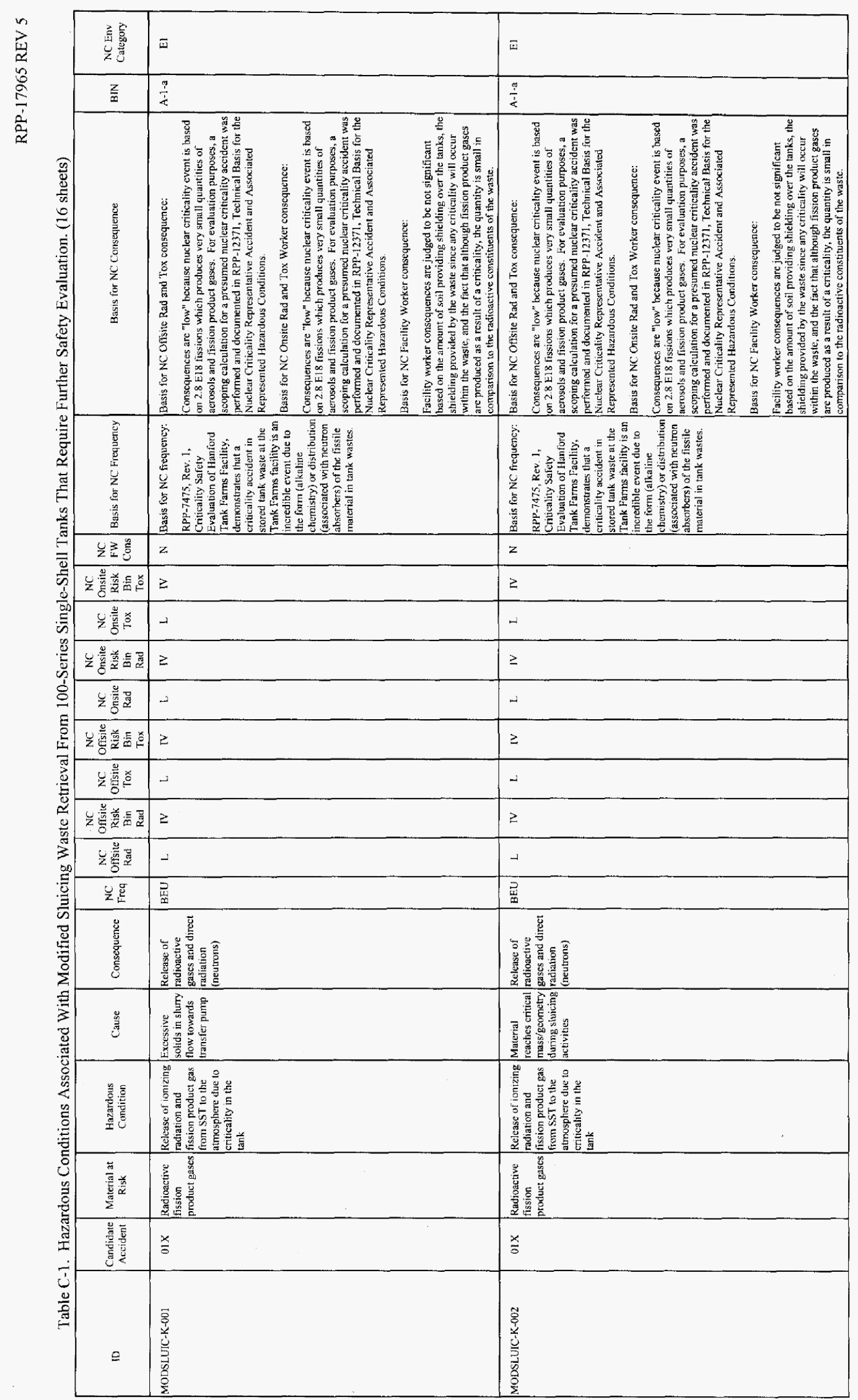




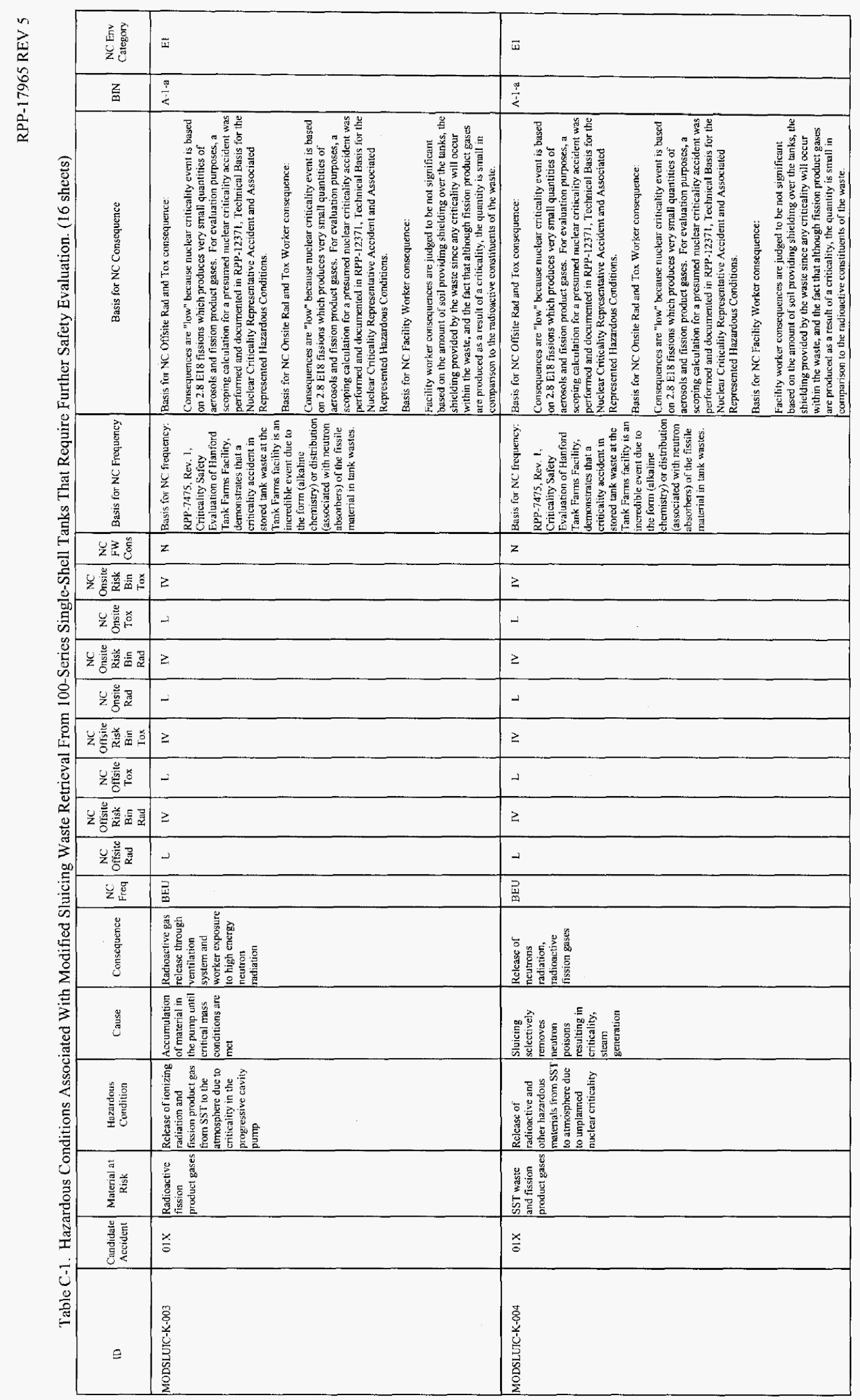




\begin{tabular}{|c|c|c|}
\hline 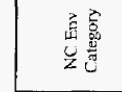 & $\bar{\square}$ & $\bar{\psi}$ \\
\hline z. & $\dot{3}$ & $\stackrel{8}{\dot{z}}$ \\
\hline 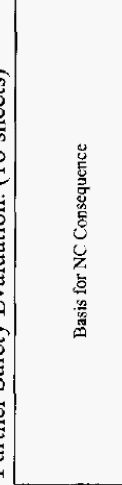 & 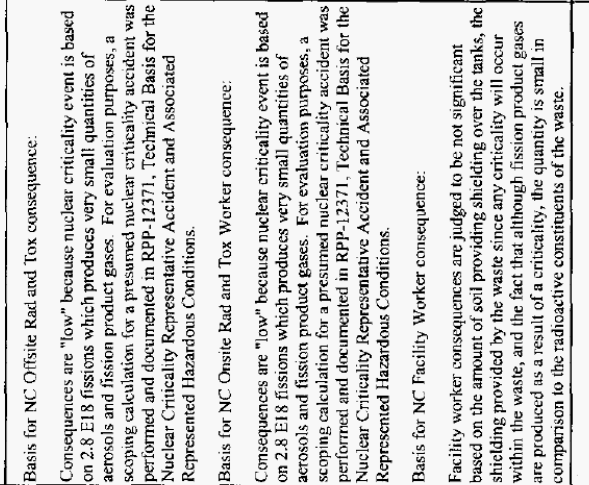 & 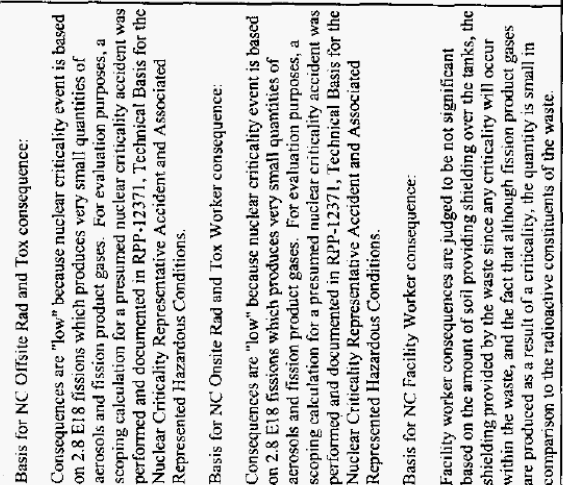 \\
\hline 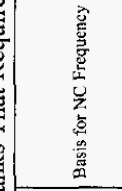 & 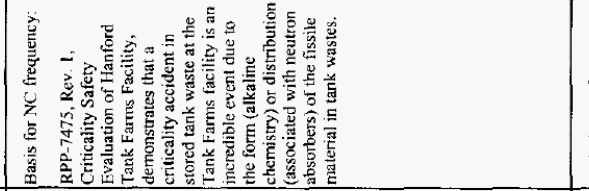 & 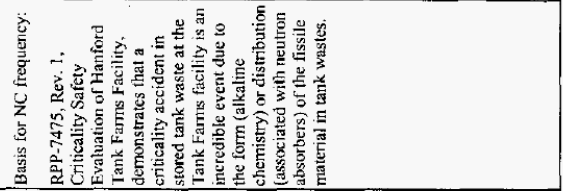 \\
\hline 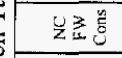 & $z$ & $\mathrm{z}$ \\
\hline$\frac{2}{2}$ & $\geq$ & $\geq$ \\
\hline 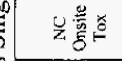 & - & \lrcorner \\
\hline 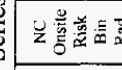 & $\geq$ & $\geq$ \\
\hline 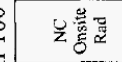 & I & \lrcorner \\
\hline $\begin{array}{ll}2 \\
z\end{array}$ & $\geq$ & $\geq$ \\
\hline 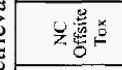 & 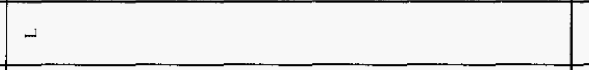 & \lrcorner \\
\hline 4 & $\geq$ & $z$ \\
\hline 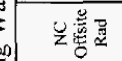 & 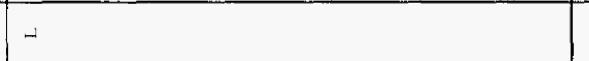 & I \\
\hline 缕 & \begin{tabular}{|l|} 
要 \\
\end{tabular} & 畐 \\
\hline 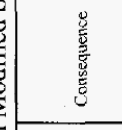 & 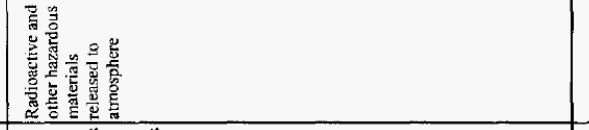 & \\
\hline 喜 & 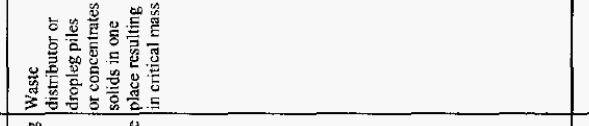 & 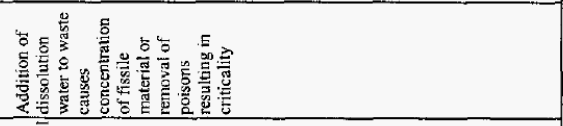 \\
\hline 高高 & 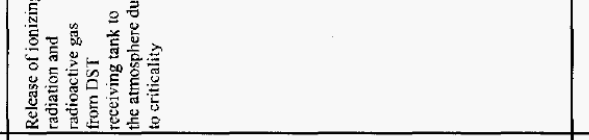 & \\
\hline 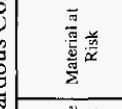 & 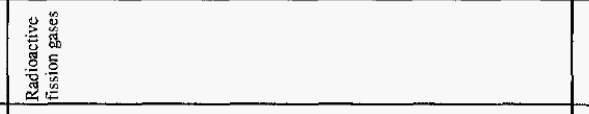 & 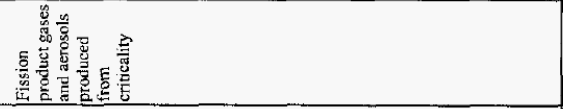 \\
\hline 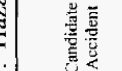 & 岸 & $\frac{x}{0}$ \\
\hline$\equiv$ & 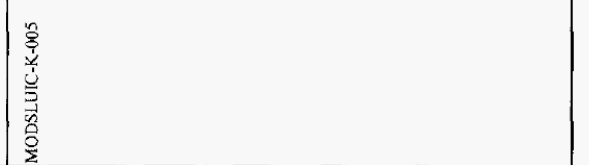 & \\
\hline
\end{tabular}




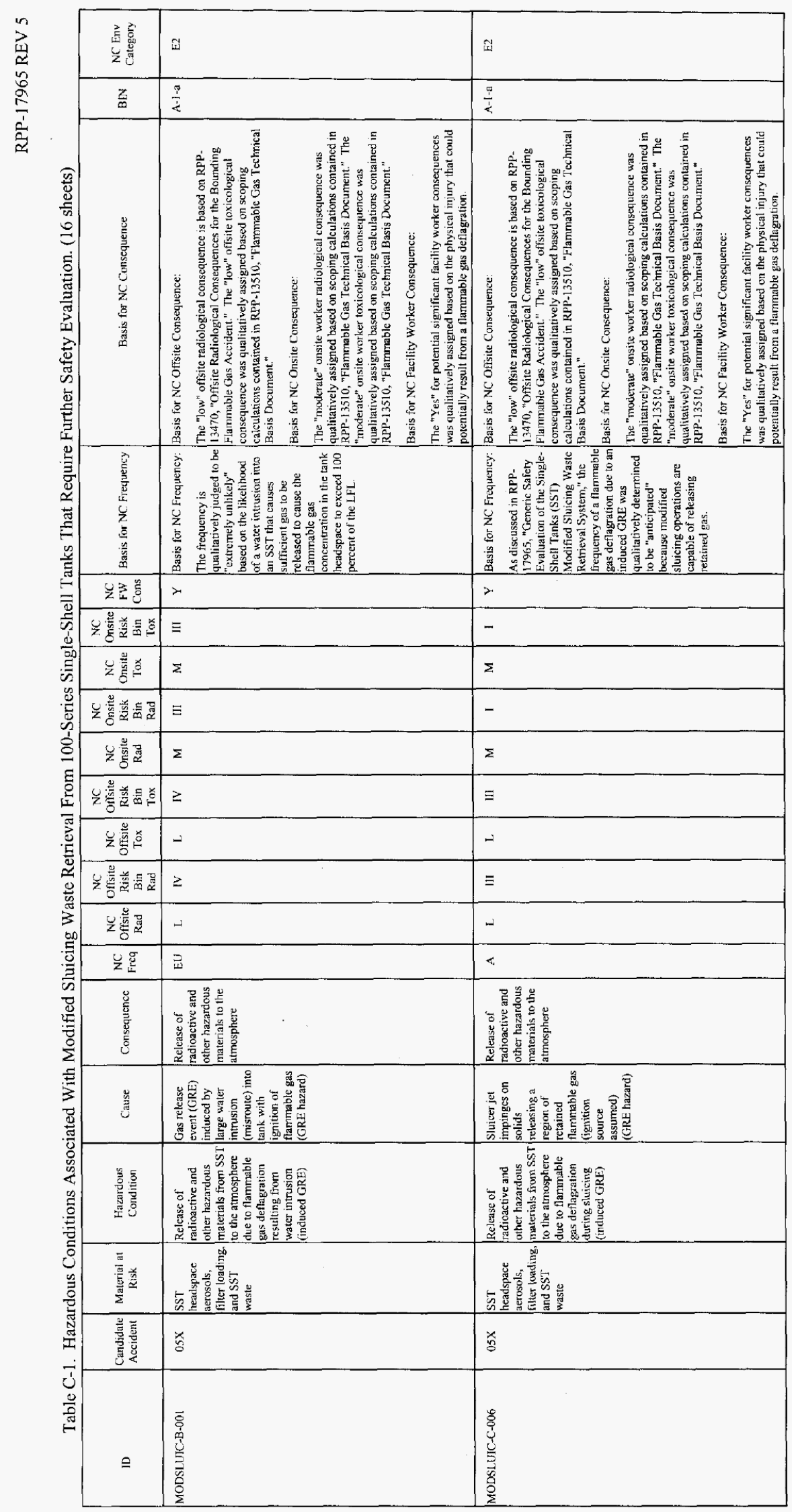




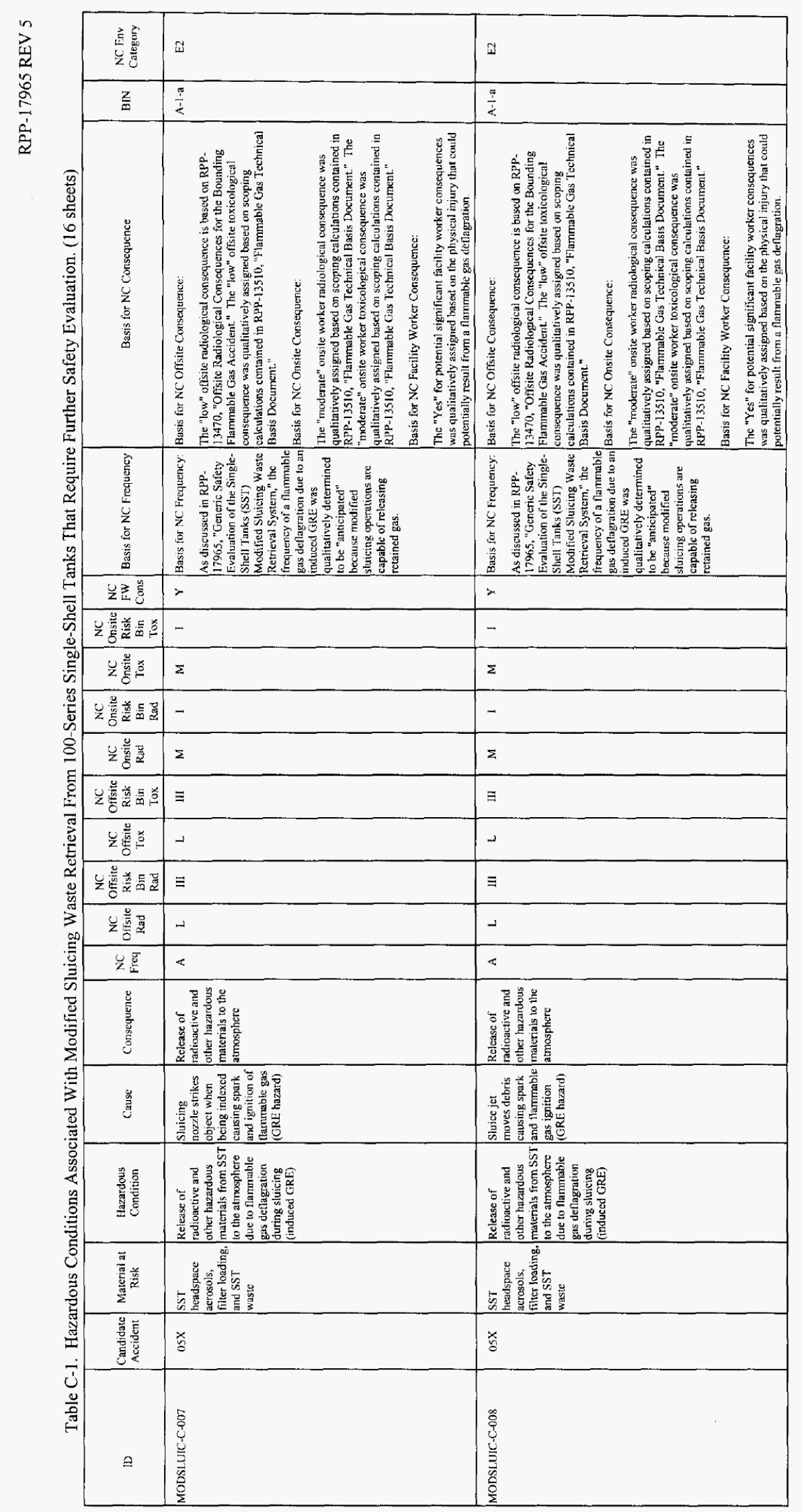




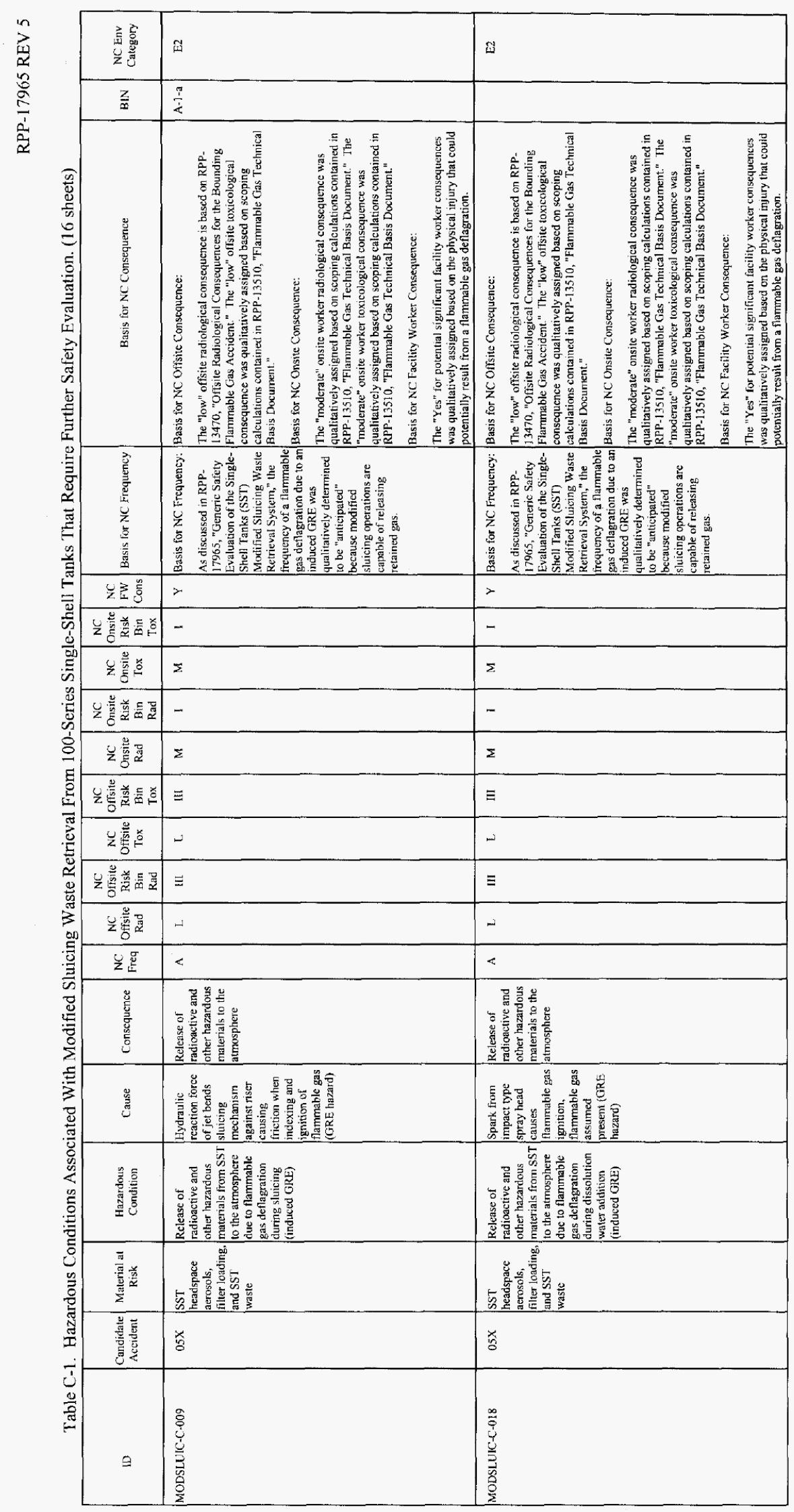




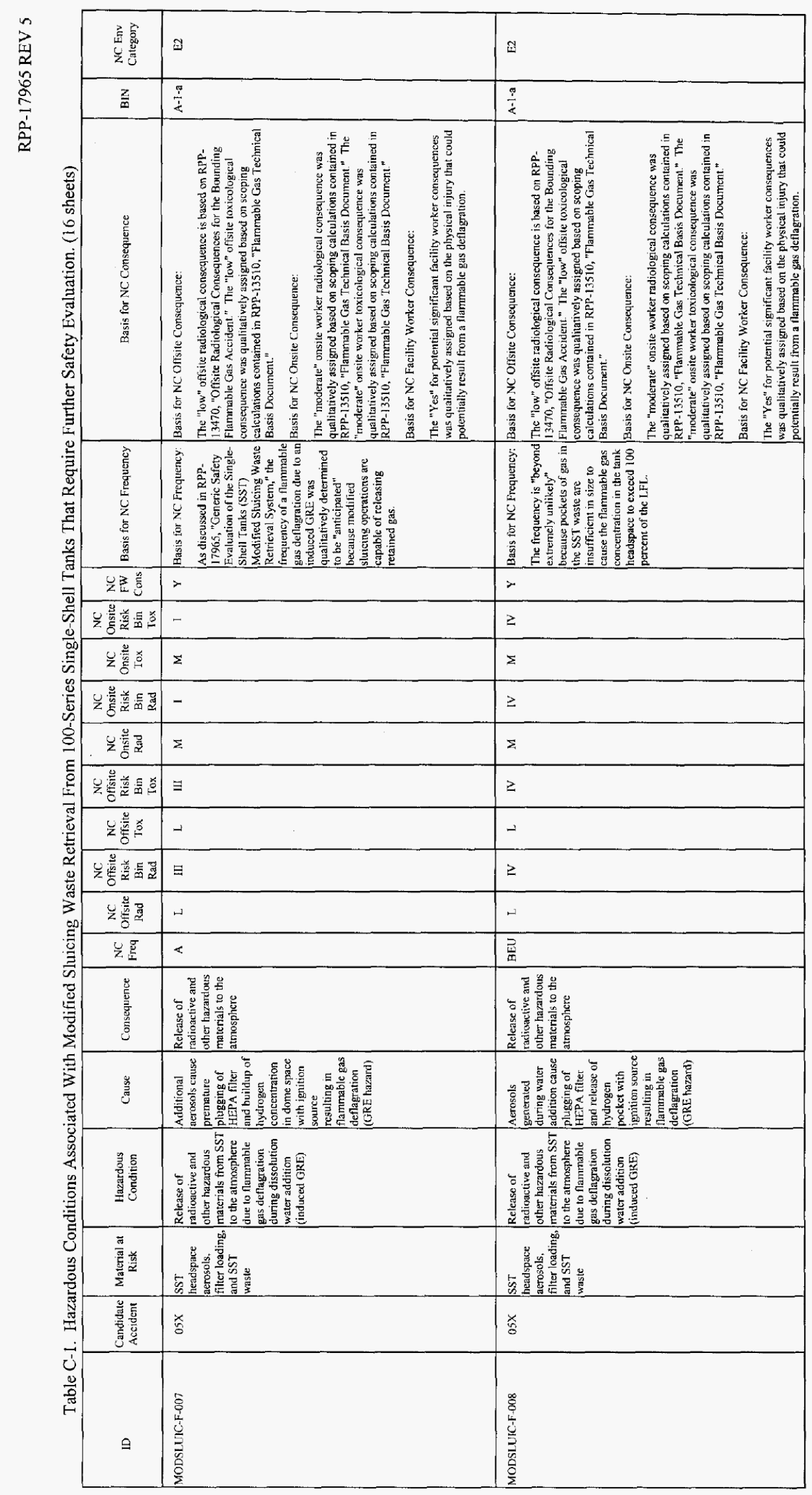

ن 


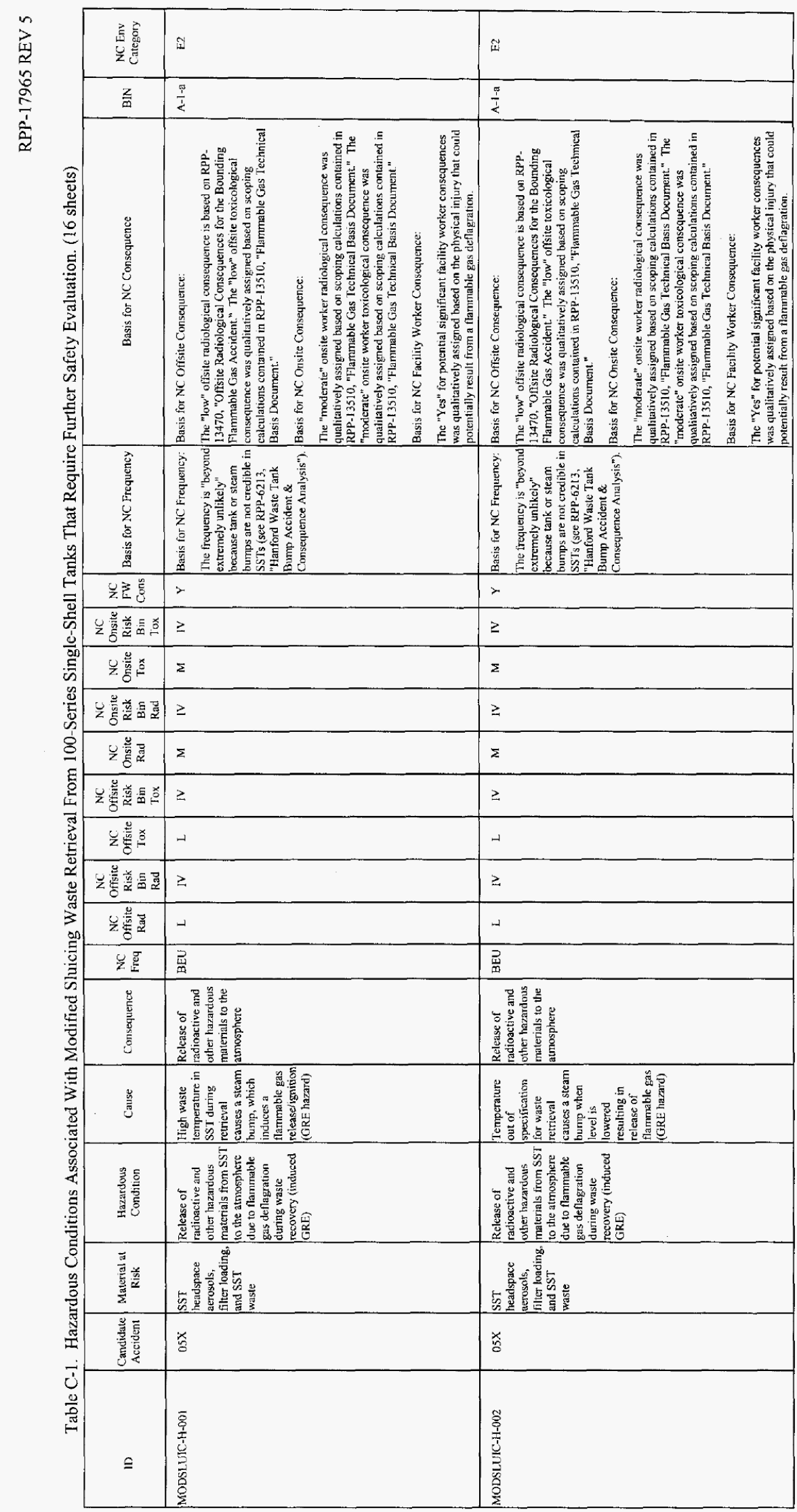

\begin{tabular}{|c|c|c|c|}
\hline & 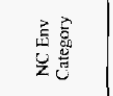 & i & $\ddot{\ddot{\mu}}$ \\
\hline & $\frac{z}{m}$ & $\frac{9}{\frac{P}{2}}$ & $\frac{F}{\dot{z}}$ \\
\hline & 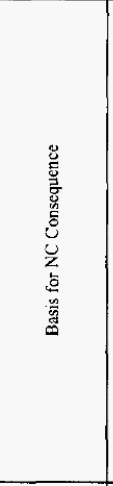 & 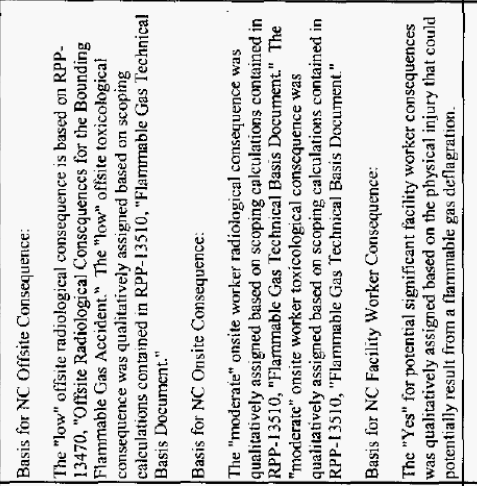 & 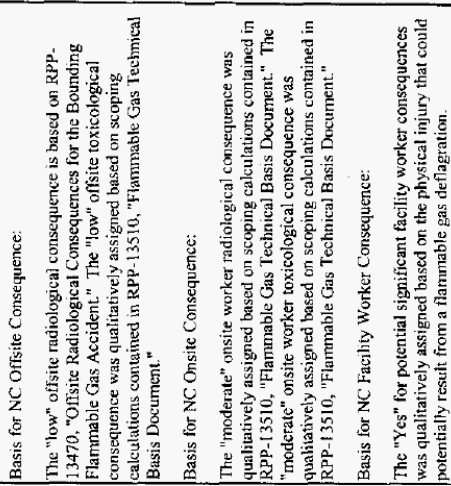 \\
\hline$\vec{\Phi}$ & 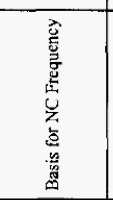 & 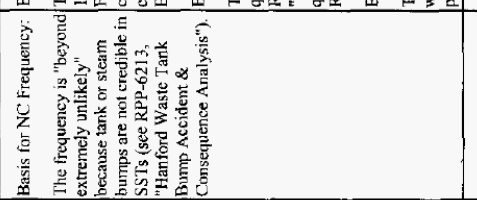 & 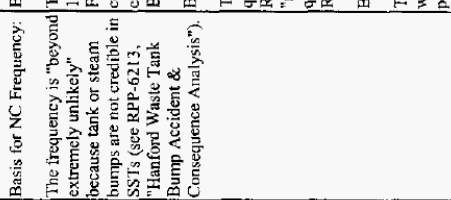 \\
\hline & 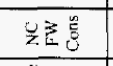 & 2 & $\frac{\infty}{2}=$ \\
\hline & 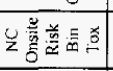 & $\geq$ & $z$ \\
\hline . & 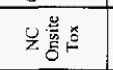 & $\Sigma$ & $\Sigma$ \\
\hline & 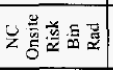 & $\geq$ & $\geq$ \\
\hline 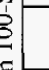 & 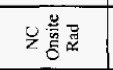 & $\Sigma$ & $\bar{z}$ \\
\hline 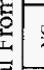 & 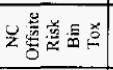 & $\geq$ & $\geq$ \\
\hline & 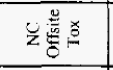 & - & \lrcorner \\
\hline & 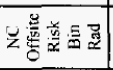 & $\geq$ & $z$ \\
\hline & 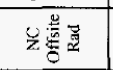 & \lrcorner & \lrcorner \\
\hline 館 & 采焉 & \begin{tabular}{|l|}
$\underline{m}$ \\
\end{tabular} & 畐 \\
\hline & 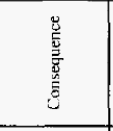 & 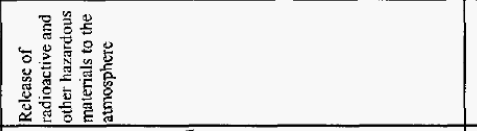 & 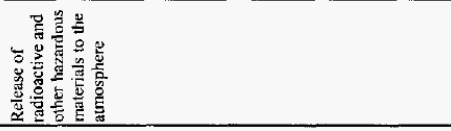 \\
\hline $\bar{\xi}$ & 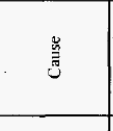 & 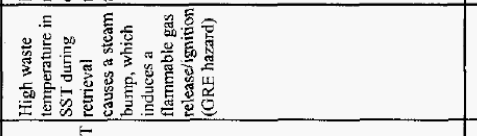 & 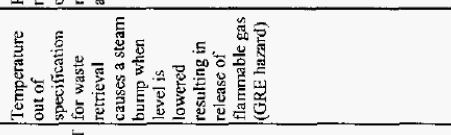 \\
\hline & 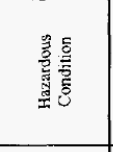 & 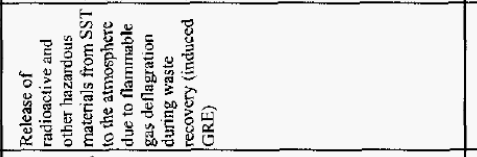 & 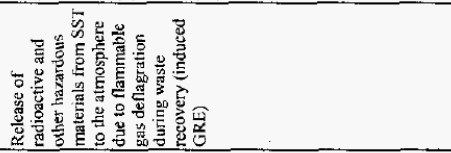 \\
\hline & 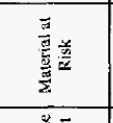 & 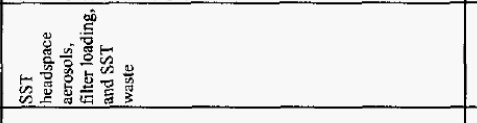 & \\
\hline 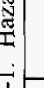 & 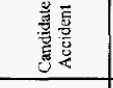 & 希 & 증 \\
\hline & $\cong$ & 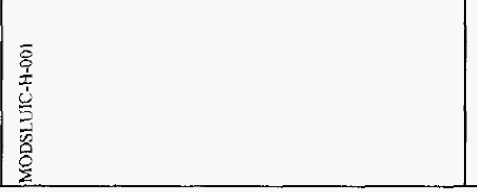 & \\
\hline
\end{tabular}




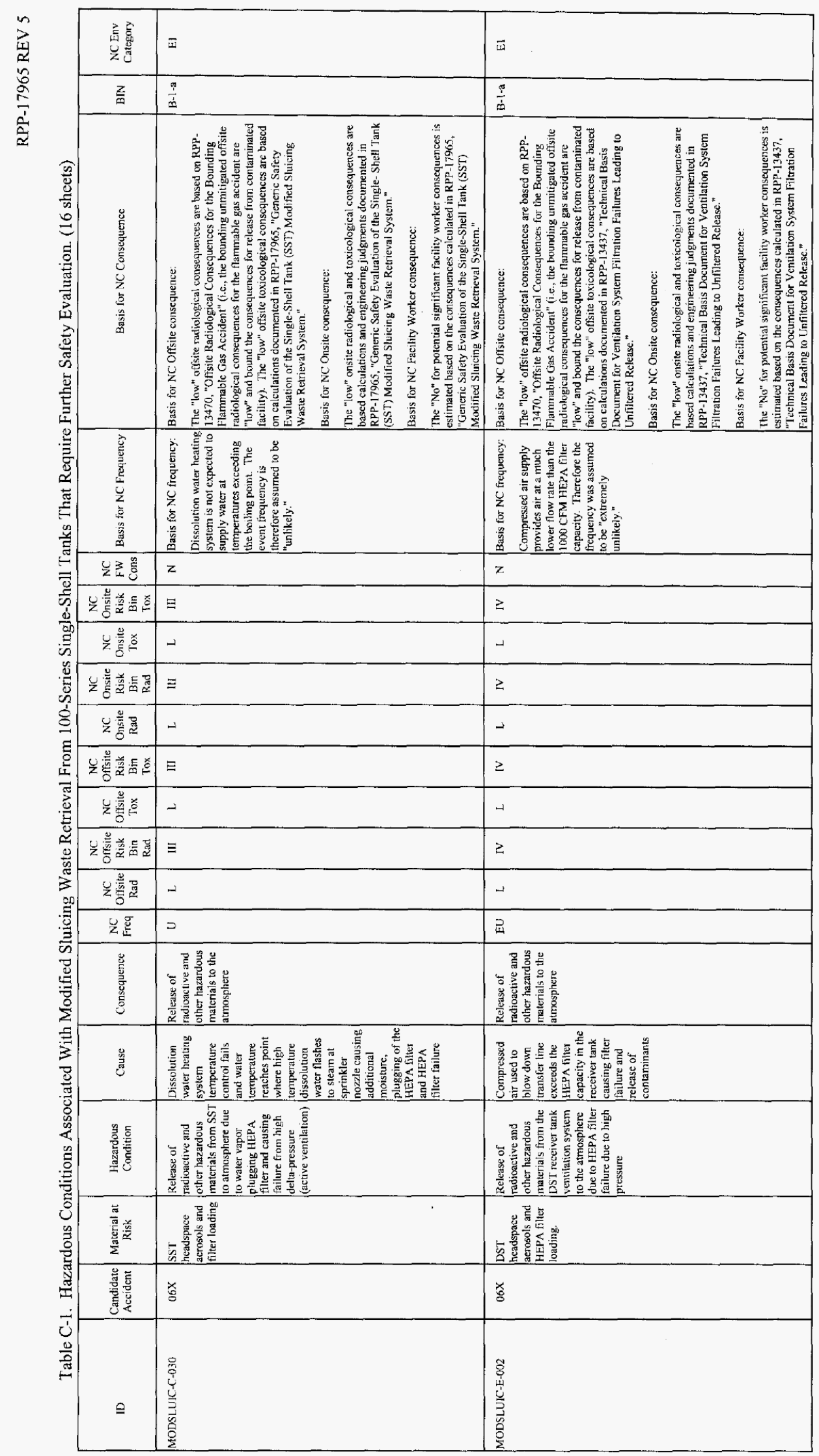




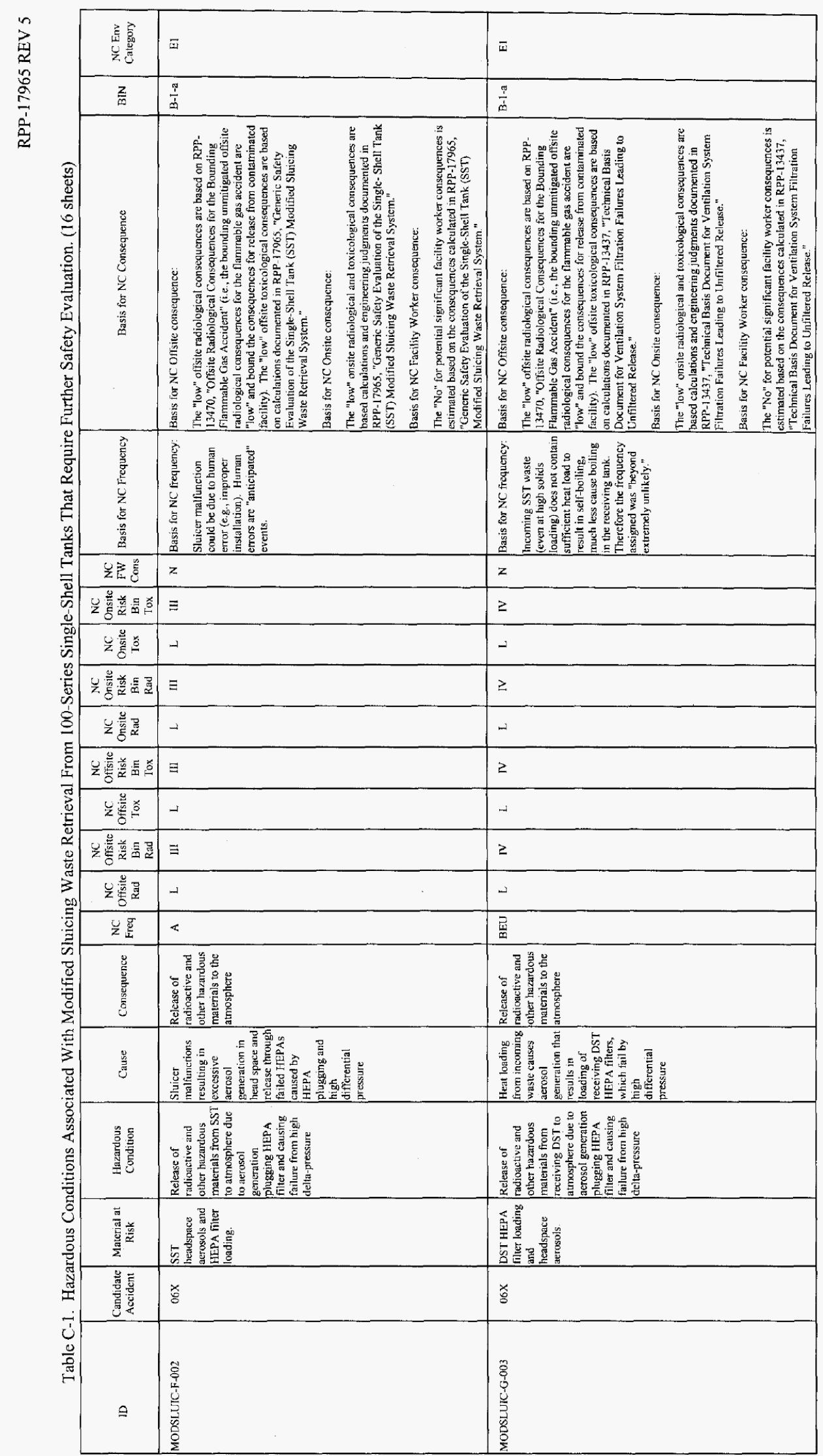

운 


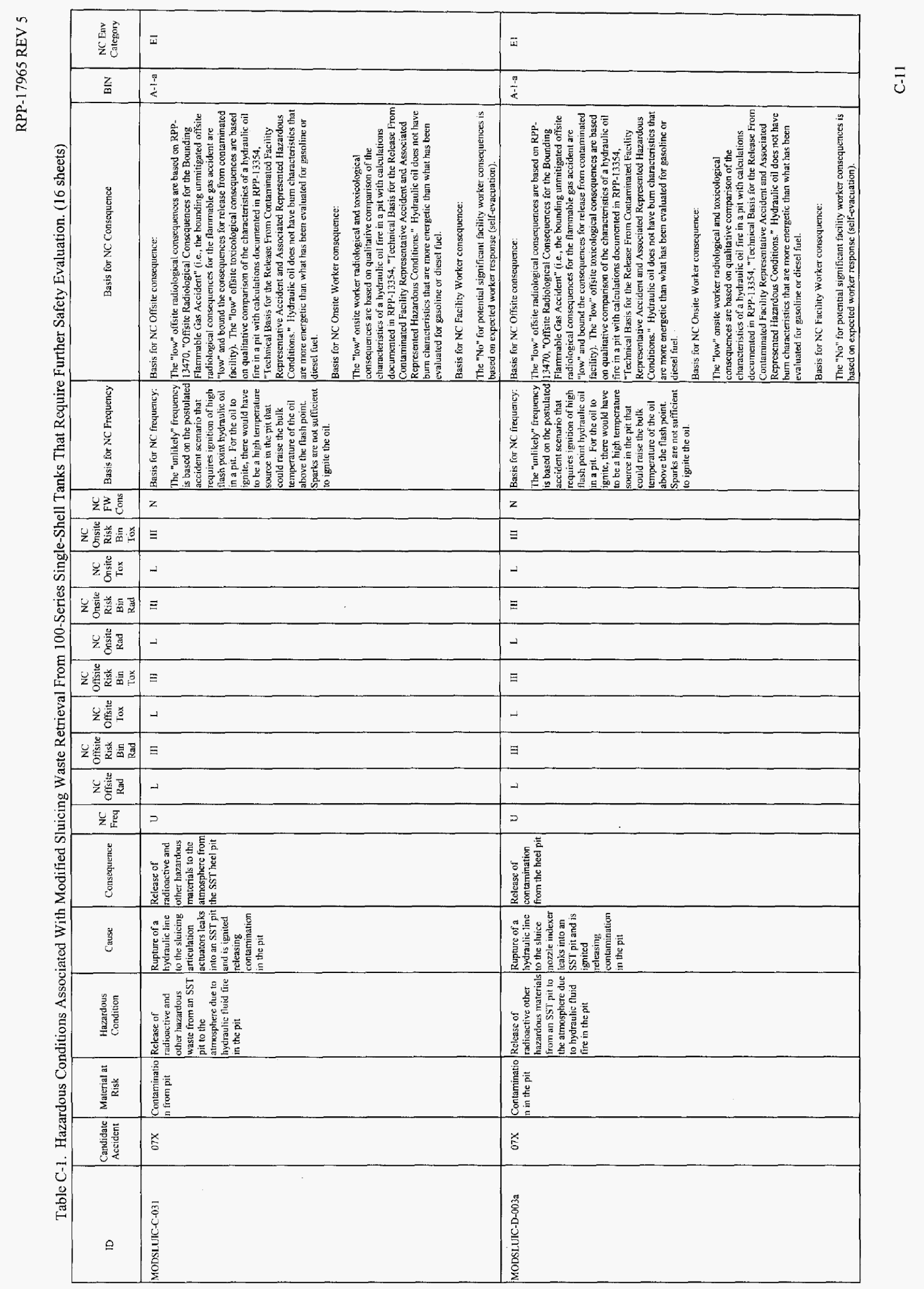




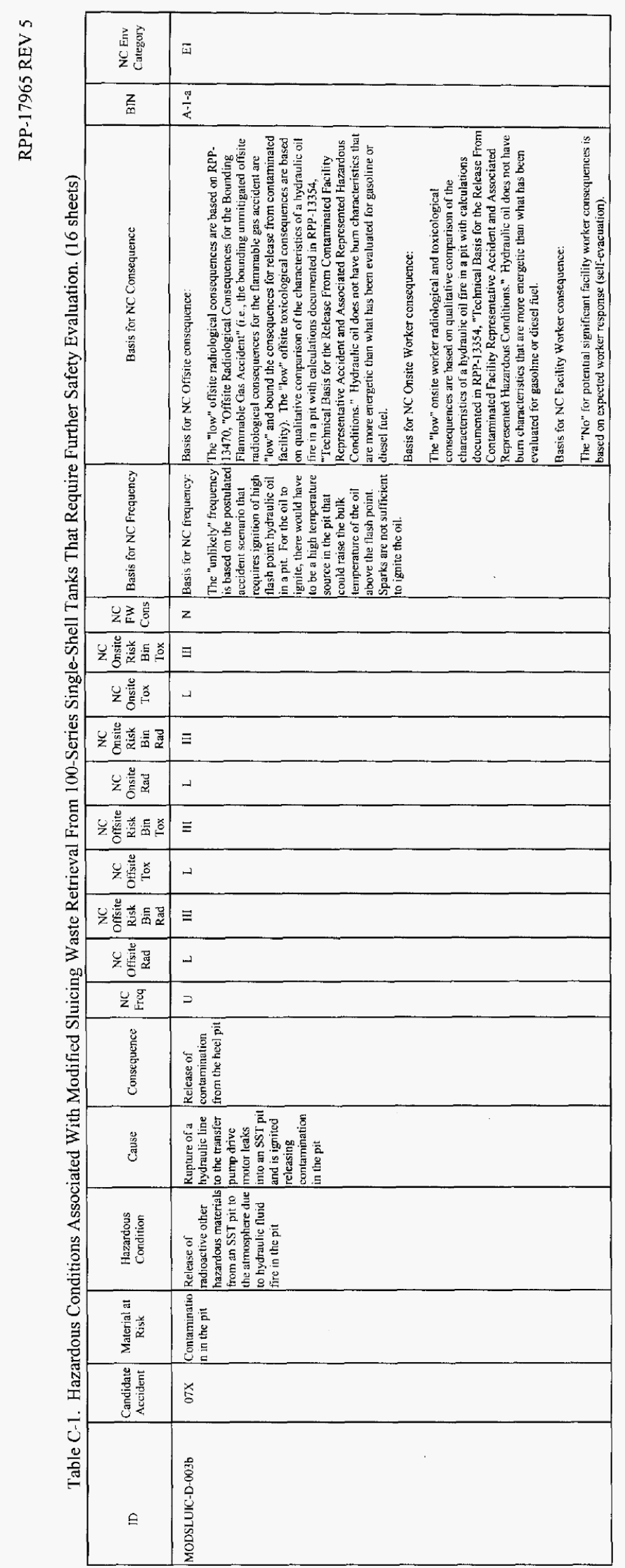

U 


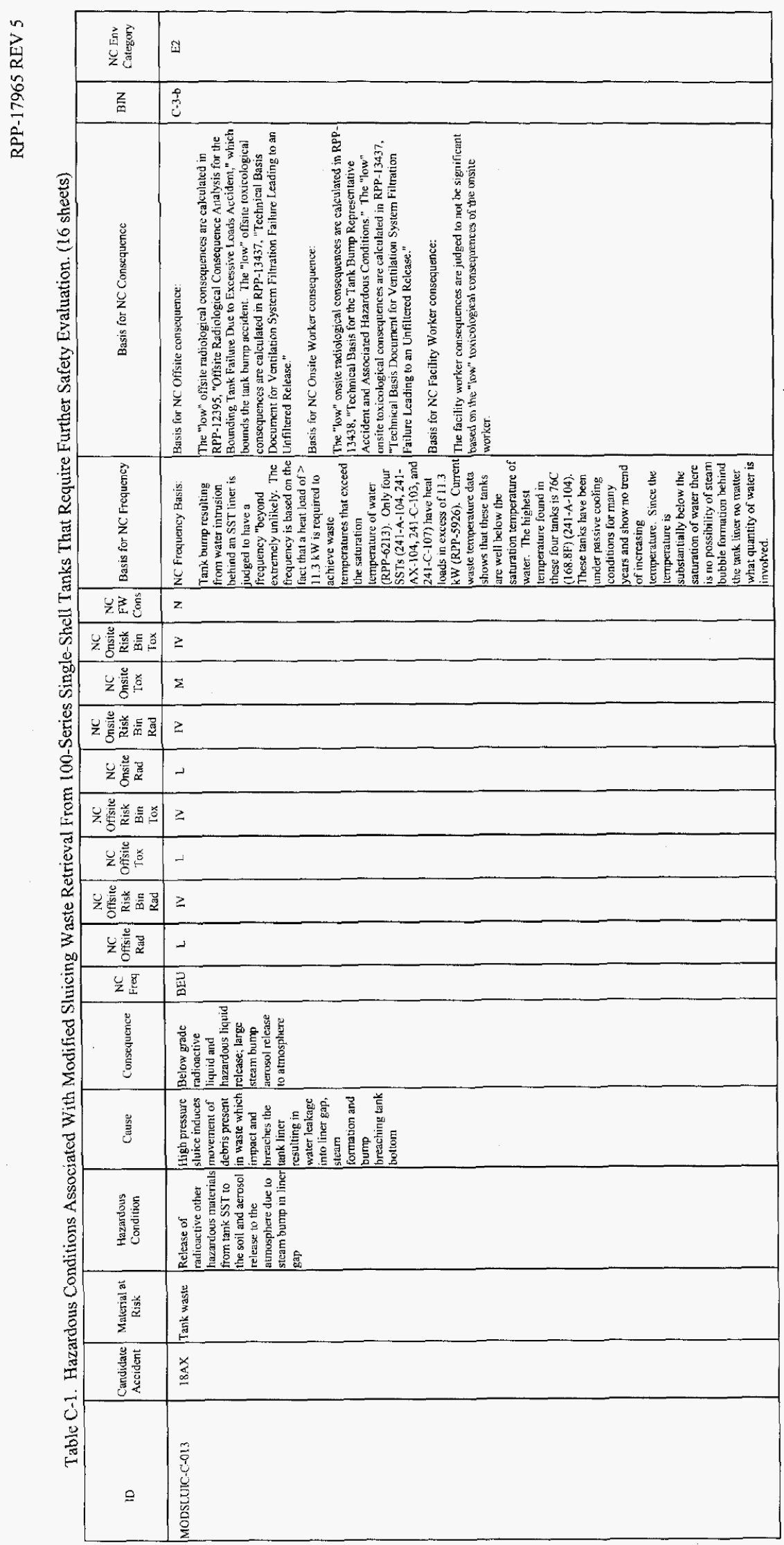




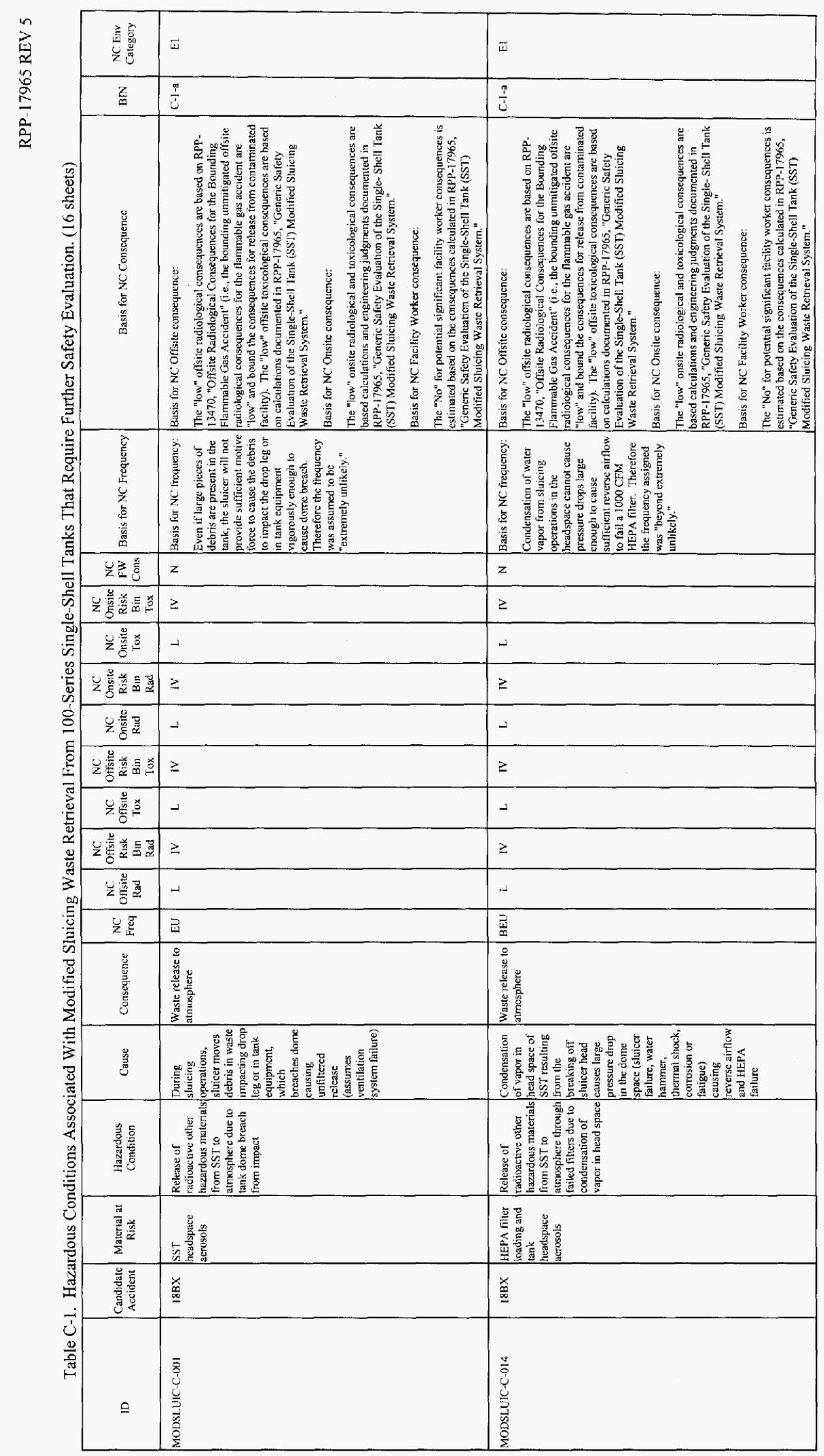




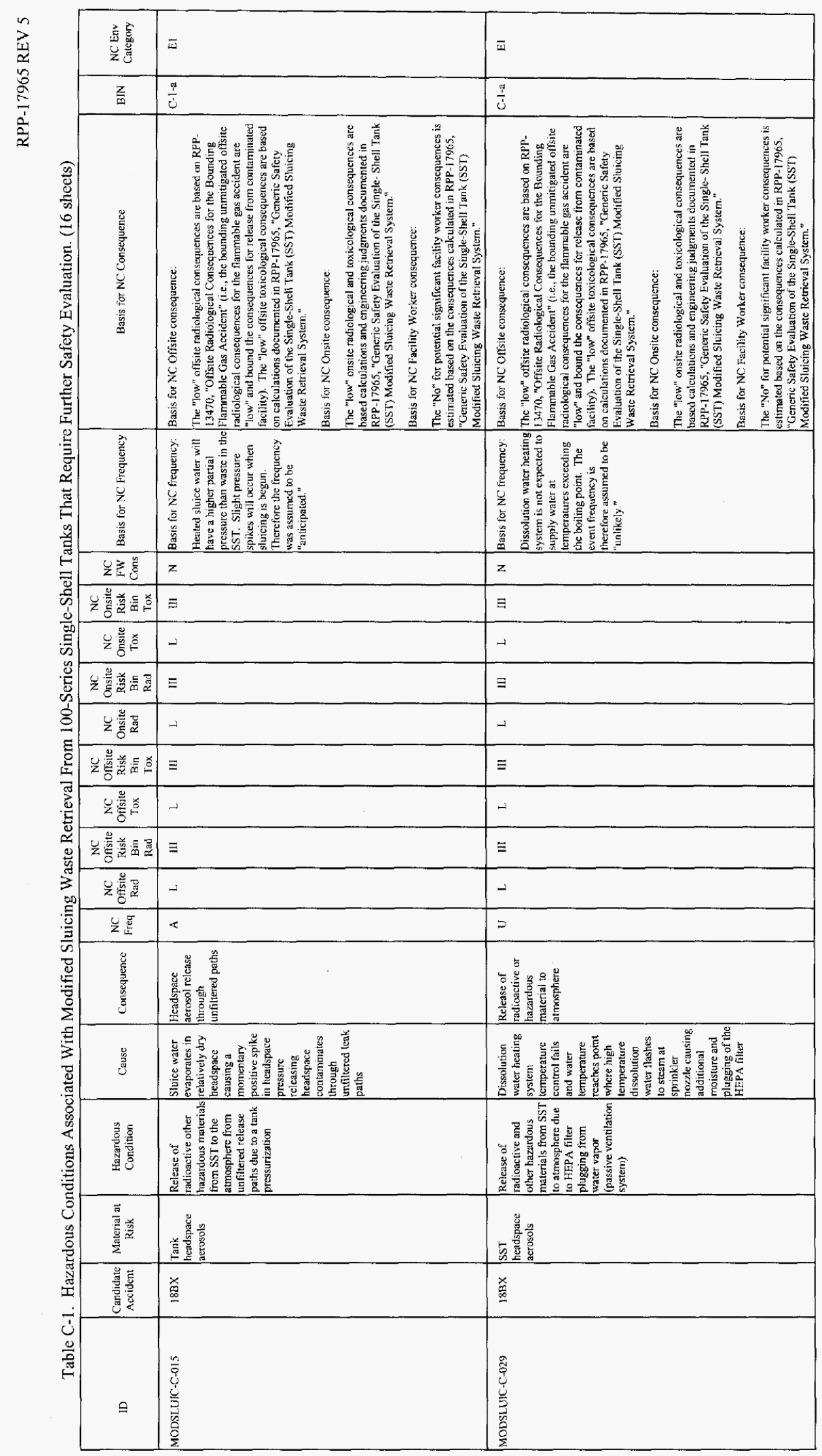

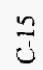




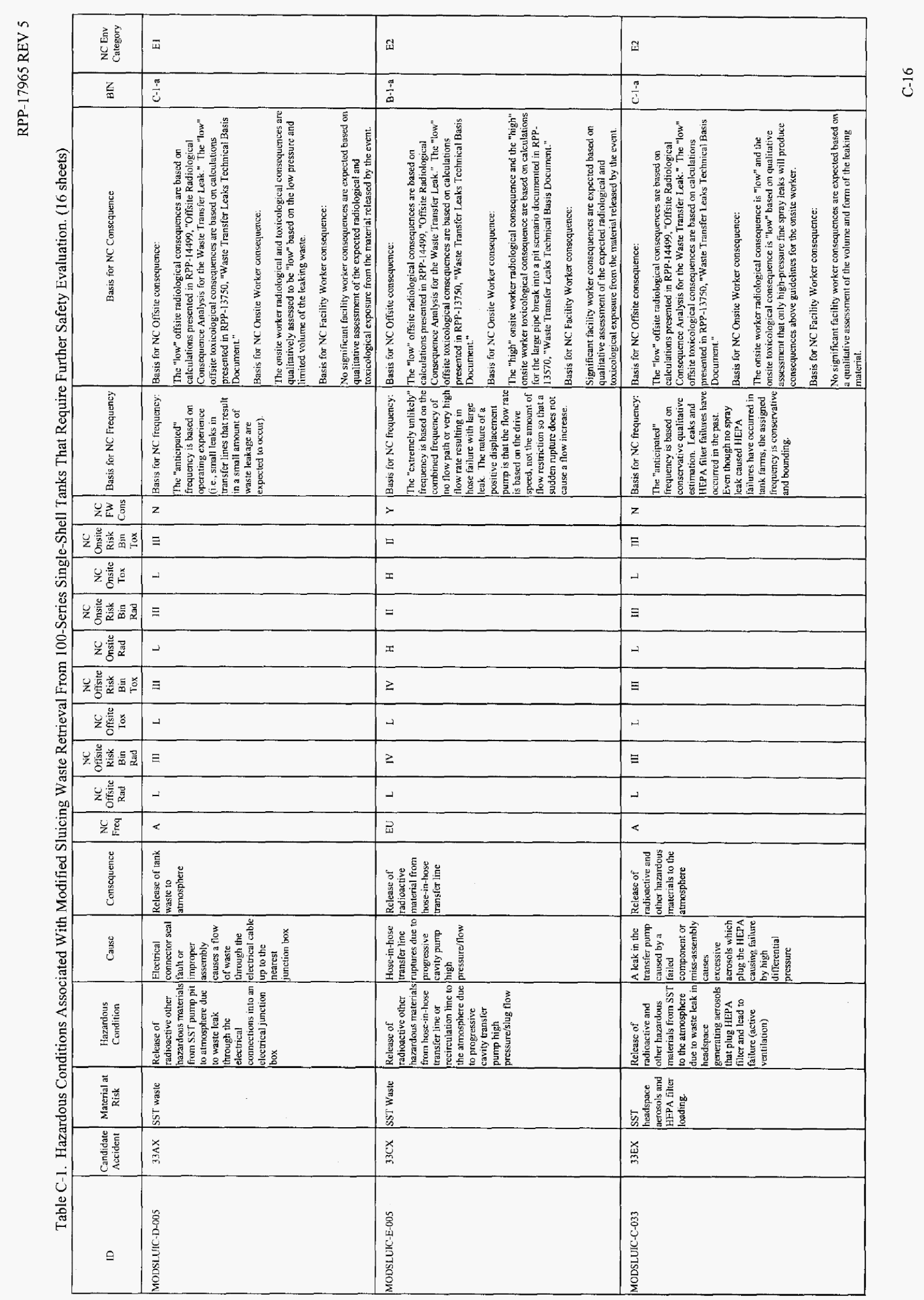

$\stackrel{0}{0}$ 
RPP-17965 REV 5

\section{APPENDIX D}

SAFETY EVALUATION FOR SLUICING IN SINGLE-SHELL TANK 241-S-102 WITH DOUBLE-SHELL TANK 241-SY-102 SUPERNATANT 
RPP-17965 REV 5

This page intentionally left blank.

D-ii 


\section{CONTENTS}

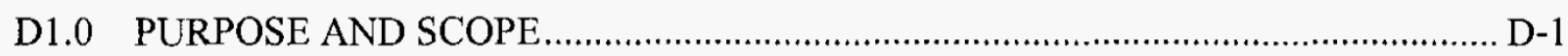

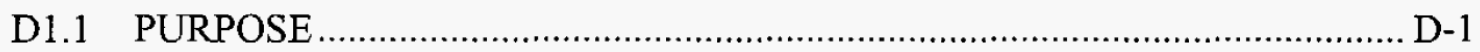

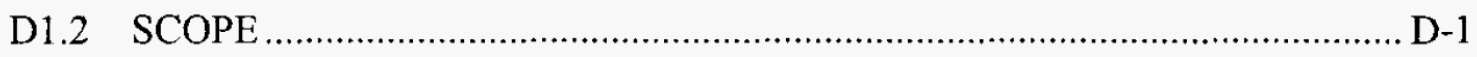

D2.0 DESCRIPTION OF THE SUPERNATANT SLUICING DESIGN AND

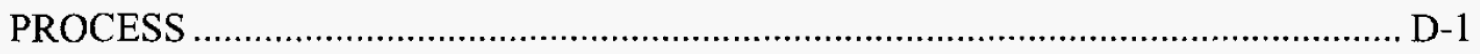

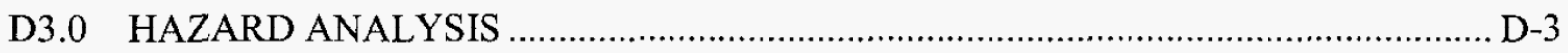

D3.1 HAZARD IDENTIFICATION AND EVALUATION ….......................... D-3

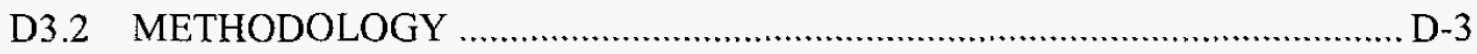

D3.3 HAZARDOUS CONDITION SCREENING ............................................ D-3

D4.0 ACCIDENT ANALYSIS................................................................................... D

D4.1 EVALUATION OF RISK FROM SLUICING WITH DOUBLE-SHELL

TANK SUPERNATANT FOR DSA REPRESENTATIVE ACCIDENTS ....... D-6

D4.1.1 Waste Transfer Leaks ...................................................................... D-6

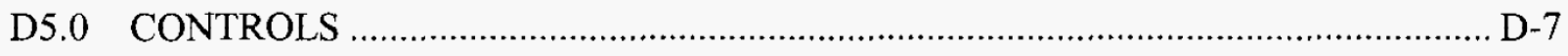

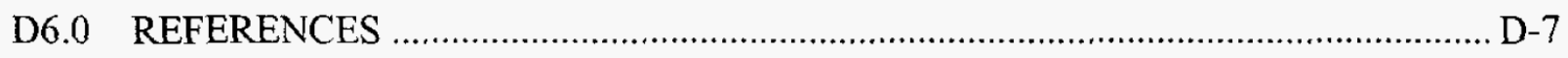

\section{ATTACHMENTS}

D1 HAZARD ANALYSIS AND CONTROL DECISION RECORD

TEAM MEMBER ROSTERS ...............................................................Attach D1-i

D2 HAZARD EVALUATION DATABASE TABLES .....................................Attach D2-i 


\section{RPP-17965 REV 5}

This page intentionally left blank.

\section{D-jv}


RPP-17965 REV 5

\section{D1.0 PURPOSE AND SCOPE}

\section{D1.1 PURPOSE}

The purpose of this appendix is to determine if the potential risk associated with using doubleshell tank (DST) supernatant to sluice single-shell tanks (SST) for retrieval of the SSTs in the tank farms is adequately addressed and bounded by the tank farms safety basis (RPP-13033, Tank Farms Documented Safety Analysis [DSA], and HNF-SD-WM-TSR-006, Tank Farms Technical Safety Requirements [TSR]) and to determine if additional controls may be required.

\section{D1.2 SCOPE}

The scope of this appendix is the SST modified sluicing waste retrieval system design that is planned for SST 241-S-102 with use of supernatant from DST 241-SY-102. Note that the general modified sluicing design has been previously evaluated in the main body of this document and this attachment only focuses on the unique aspects of using supernatant from DST 241-SY-102 for sluicing. Although this safety evaluation is based on the specific design for SST 241-S-102 retrieval to DST 241-SY-102, the design for use of supernatant as a sluice medium could be used in future SST retrievals. When the system designs and processes for the retrieval of these subsequent SSTs are established, the analysis contained in this appendix will be reviewed via the unreviewed safety question process to determine whether this analysis satisfactorily bounds the retrievals from these tanks.

\section{D2.0 DESCRIPTION OF THE SUPERNATANT SLUICING DESIGN AND PROCESS}

SST modified sluicing waste retrieval systems will retrieve waste from designated tanks to the extent needed for tank closure and transfer. The retrieved waste will be transferred to the DST system. The SST modified sluicing waste retrieval system is designed to dissolve SST crystallized salt and/or to mobilize sludge through the application of high pressure water or supernatant spray to break down the waste salt, sludge, and solids and to direct the waste to the intake of a slurry transfer pump for transfer into the DST system. Various SST waste retrieval system sluicing designs may be used. The designs may use sluice nozzles, DST supernatant pump, SST supernatant pump, waste transfer pump(s), monitoring and control systems, portable exhauster ventilation, and new as well as existing waste transfer systems. Support systems necessary for the sluicing design may include raw water and electrical supply. 


\section{RPP-17965 REV 5}

The sluicing design attributes unique to using DST 241-SY-102 supernatant as a sluice medium for retrieval of SST 241-S-102 are as follows.

- A supernatant pump is in DST 241-SY-102 that uses an existing underground transfer line to pump to the 241-SY-A valve pit, where it is then routed via a hose-in-hose transfer line (HIHTL) to the common riser extension (i.e., an aboveground waste-transfer associated structure located on top of riser) at riser 14 on SST $241-\mathrm{S}-102$. The supernatant is then introduced into the SST through electrically controlled sluice nozzles in riser 14 or redirected to sluice nozzle riser extensions in risers 11 and/or 16 via HIHTLs. The DST supernatant pump suction floats on the surface of the waste and the slurry distributor in the DST for returning retrieved SST waste is located in the supernatant to minimize disturbance of the DST settled solids.

- The sluice nozzle riser extensions are equipped with leak detectors and gravity drain directly into the SST. The riser extensions will be designed to be able to withstand a vehicle collision or vehicle barriers will protect them and the elevated abovegrade portions of HIHTLs from vehicle collisions.

- The sluice nozzles are connected to an electrically controlled pan and tilt mechanism and utilize supernatant or raw water for sluicing. The supernatant pump installed in DST 241-SY-102 maximum shutoff head and maximum runout are within the bounds of the DSA which are approximately $800 \mathrm{ft}$ and approximately $790 \mathrm{gal} / \mathrm{min}$, respectively. The sluice nozzles are directed from a control station that can be located inside or outside the tank farms fence area.

- Raw water is provided for flushing the waste transfer lines and sluice nozzles. A backflow prevention system is used to prevent or limit the backflow of waste and ensures that no contamination of the raw water supply can occur.

- The HIHTLs are equipped with leak detection at the DST 241-SY-102 central pump pit, $241-S Y-A$ valve pit, the riser extensions of the SST, and any existing tank farms physically connected waste transfer-associated structures. Material balance will be performed using waste level readings at DST 241-SY-102 and flow meter measurements at the common riser extension (riser 14). Radiation surveys will be relied upon between the common riser extension (riser 14) and the riser extensions on risers 11 and 16 to detect a waste transfer leak due to a common mode failure or misroute because (1) there are no flow metering devices at the riser extensions (risers 11 and 16) on the SST, (2) liquid level monitoring in the SST is not a reliable method of performing material balances in the SST (i.e., installed instrumentation locations and waste solid interference may not allow the instrumentation to extend to the bottom of the SST), and (3) instrument gauges could be damaged during sluicing operations in the SST. 


\section{D3.0 HAZARD ANALYSIS}

\section{D3.1 HAZARD IDENTIFICATION AND EVALUATION}

The graded approach was used to select the hazard identification and evaluation method. The goal of the graded approach is to select a method that does not create a large number of hazardous conditions redundant to those in the DSA hazard evaluation database (RPP-15188, Hazard Evaluation Database Report). The "delta" hazard analysis method was chosen. The "delta" hazard analysis method uses the concept of "deviations from a baseline" to identify hazardous conditions that require further evaluation.

\section{D3.2 METHODOLOGY}

SST modified sluicing operations using DST supernatant is an activity that has not been approved under the DSA. However, under the previous Basis for Interim Operation/Final Safety Analysis Report, supernatant for sluicing was authorized via the W-320 project. Therefore, as a starting point, the hazardous conditions identified for the W-320 project were reviewed to ensure the completeness of the hazard evaluation. A team composed of Nuclear Safety \& Licensing, Engineering, and Operations systematically evaluated sluicing using DST supernatant with the DSA representative and candidate accidents acting as study nodes. The attendance roster is included in Attachment D1 to document the presence of each team member.

\section{D3.3 HAZARDOUS CONDITION SCREENING}

Hazardous conditions involving exposure to radioactive and other hazardous materials were assigned a representative accident and/or a candidate accident designator. The representative accident designator allows cross reference to the appropriate analysis in the DSA. Candidate accident designators allow hazardous conditions to be compared with the hazardous conditions contained in the DSA hazard evaluation database.

Hazardous conditions were screened to determine if they potentially (1) are not represented by a DSA representative or candidate accident, (2) are similar to, but not bounded by a DSA representative or candidate accident, or (3) are similar to and bounded by a DSA representative or candidate accident but are unique in regard to phenomena or control applicability. Hazardous conditions meeting one or more of these criteria are further evaluated in Chapter 4.0. Only those hazardous conditions that are found to meet the screening criteria after further evaluation are incorporated into the DSA hazard evaluation database (see Attachment D2).

A general concern was identified with regards to the source term assumptions for all the DSA accident analyses. The specific concern was that the supporting calculations for the accidents postulated in the SSTs may have used SST source term values that may be challenged by the DST source term values due to the introduction of DST supernatant waste. Therefore, the following evaluation was performed. 
1. All applicable DSA SST accidents were reviewed to verify they used bounding SST source terms.

2. The SST bounding radiological and toxicological liquid source terms were obtained from RPP-5924, Radiological Source Terms for Tank Farms Safety Analysis, Rev. 4, and RPP-8369, Chemical Source Terms for Tank Farms Safety Analyses, Rev. 2, as reported in Table D-1.

3. The DST 241-SY-101, 241-SY-102, and 241-SY-103 liquid source terms were obtained from RPP 5924, Rev. 4, and RPP-8369, Rev. 2, as reported in Table D-1.

4. An evaluation was performed for planned operations in DSTs 241-SY-101, 241-SY-102, and 241-SY-103 to confirm that there are no planned waste transfers into these DSTs other than the sluicing retrieval operations for SSTs $241-\mathrm{S}-102$ and 241-S-112. The sluicing retrieval operations of SSTs $241-\mathrm{S}-102$ and $241-\mathrm{S}-112$ will only create more and more dilute supernatant each time the 241-SY DST is filled up and the supernatant is used for sluicing the SST 241-S-102. Additionally it can be assumed that only the most dilute DST supernatant will be used because it will be skimmed off the top of the DST waste via a flex and float supernatant pump. This verifies that the liquid source terms obtained from RPP 5924, Rev. 4, and RPP-8369, Rev. 2, are worst case source terms that could be introduced into $241-\mathrm{S}-102$.

5. A comparison of the DST liquid source terms with SST bounding source terms was made.

Table D-1. Liquid Unit Liter Doses and Sum of Fractions for 241-S-102 Waste Transfer.

\begin{tabular}{|l|c|c|c|c|c|}
\hline \multirow{2}{*}{ Tank } & Liquid ULD & Liquid ULD & & \multicolumn{3}{|c|}{ Liquid SOFs } \\
\cline { 3 - 6 } & Onsite & Offsite & $\begin{array}{c}\text { TEEL-1 Offsite } \\
\text { Mod }\end{array}$ & $\begin{array}{c}\text { TEEL-2 Onsite } \\
\text { Mod/Offsite } \\
\text { High }\end{array}$ & $\begin{array}{c}\text { TEEL-3 Onsite } \\
\text { High }\end{array}$ \\
\hline $241-S Y-101$ & $6.5 \mathrm{E}+01$ & $4.7 \mathrm{E}+01$ & $1.39 \mathrm{E}+09$ & $1.78 \mathrm{E}+08$ & $5.89 \mathrm{E}+06$ \\
\hline $241-\mathrm{SY}-102$ & $6.8 \mathrm{E}+01$ & $6.2 \mathrm{E}+01$ & $1.47 \mathrm{E}+09$ & $1.91 \mathrm{E}+08$ & $6.44 \mathrm{E}+06$ \\
\hline $241-\mathrm{SY}-103$ & $1.2 \mathrm{E}+02$ & $8.8 \mathrm{E}+01$ & $2.44 \mathrm{E}+09$ & $3.10 \mathrm{E}+08$ & $9.41 \mathrm{E}+06$ \\
\hline Bounding SST & $4.5 \mathrm{E}+02$ & $\begin{array}{c}6.0 \mathrm{E}+02 \\
(241-\mathrm{U}-106)\end{array}$ & $\begin{array}{c}3.71 \mathrm{E}+09 \\
(241-\mathrm{A}-106)\end{array}$ & $\begin{array}{c}5.73 \mathrm{E}+08 \\
(241-\mathrm{A}-106)\end{array}$ \\
\hline
\end{tabular}

Notes:

SST $=$ single-shell tank.

TEEL $=$ Temporary Emergency Exposure Limit.

$\mathrm{ULD}=$ unit liter dose.

The conclusion from this evaluation is that all SST accidents associated with modified sluicing in an SST bound the DST 241-SY-101, 241-SY-102, and 241-SY-103 liquid source terms and, therefore, this concern is not evaluated further in this document. 
RPP-17965 REV 5

\section{Representative Accident 1, Flammable Gas Accidents (Candidate Accidents 04/05)}

Hazardous conditions involving steady-state flammable gas releases and flammable gas release events (spontaneous and induced) were identified for SST sluicing operations using DST supernatant (i.e., the addition of DST waste to an SST). Review of these hazardous conditions determined that they were represented by existing hazardous conditions and bounded by the existing flammable gas accident analysis. The existing controls (safety structures, systems, and components [SSC] and TSR) were also determined to be applicable to prevent the postulated flammable gas accidents. Therefore, this representative accident is not evaluated further in this document.

\section{Representative Accident 2; Nuclear Criticality (Candidate Accident 01)}

Hazardous conditions involving nuclear criticality are identified in the DSA and are representative of hazardous conditions for this activity. The nuclear criticality safety management program has been identified in the DSA as the control to ensure that a nuclear criticality event remains "beyond extremely unlikely." The nuclear criticality safety program will review sluicing with supernatant and, if necessary, establish any required controls in tank farm procedures (e.g., criticality prevention specification). Therefore, this representative accident is not evaluated further in this document.

\section{Representative Accident 13, Waste Transfer Leak (Candidate Accidents 33A, 33C, 33D)}

Hazardous conditions involving waste leaks were identified as having characteristics similar to the hazardous conditions in the DSA hazard evaluation database. With respect to controls, however, it was identified that a material balance could not be performed that would detect waste leaks in all waste transfer route sections or detect all potential misroutes. Therefore, material balance controls were identified as needing to be further evaluated (see Section 4.1.1). Additionally, the supernatant waste transfer design was evaluated to verify that the configuration for a siphon event that could overfill a tank is "beyond extremely unlikely." The siphon event was a concern because the waste transfer slurry distributor is located below the waste surface and the sluice nozzles are located towards the bottom of SST 241-S-102. Based on RPP-CALC-23558, Tank 241-S-102 Retrieval Overfill Due To Siphoning Calculation, the siphon event is "beyond extremely unlikely" and, therefore, no further evaluation is required.

Identifiable to a Candidate Accident but DSA Hazardous Conditions Determined to be Risk Bin III or IV (i.e., no Representative Accident identified), Tank Bump (Candidate Accident 18A)

Hazardous conditions involving tank bump are identified in the DSA and are representative of hazardous conditions for this activity. Waste transfer controls have been established in the DSA to ensure that tank bump remains "beyond extremely unlikely." Therefore this representative accident is not evaluated further in this document. 


\section{D4.0 ACCIDENT ANALYSIS}

\section{D4.1 EVALUATION OF RISK FROM SLUICING WITH DOUBLE-SHELL TANK SUPERNATANT FOR DSA REPRESENTATIVE ACCIDENTS}

\section{D4.1.1 Waste Transfer Leaks}

\section{D4.1.1.1 DSA Representative Accidents}

The DSA-related representative accident is the "large pipe break into a pit" scenario. The large pipe break into a pit scenario assumes that a large pipe break has occurred, and that waste is leaking into an open pit at the maximum flow rate of the transfer pump. DSA Section 3.3.2.4.13, "Waste Transfer Leak," addresses this hazardous condition.

\section{D4.1.1.2 Waste Retrieval System Operations Hazardous Condition}

Based on the hazard identification and evaluation in Chapter 3.0, the potential waste transfer leak hazards for SST sluicing operations using DST supernatant are represented by existing hazardous conditions and bounded by existing waste transfer leak analysis. However, further evaluation of TSR Administrative Control (AC) 5.11 key element 5.11.2.b.1, "Material Balance," is needed because the implementation of the material balance controls for SST sluicing operations using DST supernatant is not possible or practicable for some sections of the planned waste transfer route.

For example, material balance monitoring covering all waste transfer route sections may not be possible during SST waste retrieval because of potential damage to SST waste level monitoring instrumentation during sluicing operations or because the location of SST waste level monitoring instrumentation or waste solid interference prevents accurate measurements when the SST waste volume is low. Material balance monitoring may also not be practical when there are significant as low as reasonably achievable (ALARA) concerns involving the installation, maintenance, or repair of instrumentation required for material balance monitoring (e.g., flow instrumentation) in contaminated waste transfer-associated structures. In addition, installing instrumentation required for performing material balance monitoring at the end of all waste transfer route sections may not be practical from an engineering perspective for waste transfer route sections that have no or limited misroute potential and where an alternative control equivalent to material balance monitoring is available. An example is the multiple HIHTL sections of an SST waste retrieval system between the waste transfer-associated structure located on or near the SST and the SST riser extensions or structures containing sluice nozzles. In this example, flow instrumentation would only be provided in the waste transfer-associated structure on or near the SST for performing material balance monitoring between this structure and the DST system, and radiation surveys would be performed in lieu of material balance monitoring to detect waste leaks in the HIHTL sections connecting this structure to the individual SST riser extensions or structures containing sluice nozzles. Therefore, the material balance control was revised to allow alternate means to detect and respond to waste leaks and misroutes. 


\section{RPP-17965 REV 5}

\section{D4.1.1.3 Conclusions}

An amendment for the DSA and TSRs has been developed to revise the material balance control (AC 5.11 key element 5.11.2.b.1). The revision allows for alternate material balance controls to be used for SST retrieval waste transfers when it is not possible or practical for material balance monitoring to detect waste leaks in all waste transfer route sections. Radiation surveys must be performed for sections of the waste transfer route where the material balance cannot detect waste leaks and there must be alternative methods to material balance monitoring for detecting misroutes.

The alternate material balance monitoring controls were selected based on the consensus of the decision team which was composed of Nuclear Safety \& Licensing, Engineering, and Operations personnel. The attendance roster and an e-mail from an operations representative are included in Attachment D1 to document the presence of each team member.

\section{D5.0 CONTROLS}

Based on the hazard and accident analyses of SST modified sluicing in SST 241-S-102 using DST 241-SY-102 supernatant, no new accidents were identified, and the existing DSA analyses were found to be encompassing and bounding. The DSA controls (i.e., safety SSCs and TSRs) were also found to acceptably prevent or mitigate potential hazardous conditions and postulated accidents with the exception of the TSR AC 5.11, material balance control (see Section 4.1.1). The AC 5.11 material balance control was revised to include alternate methods (radiation surveys) to detect waste leaks and misroutes during SST waste retrieval operations and activities.

\section{D6.0 REFERENCES}

HNF-SD-WM-TSR-006, 2004, Tank Farms Technical Safety Requirements, Rev. 4, CH2M HILL Hanford Group, Inc., Richland, Washington.

RPP-CALC-23558, 2004, Tank 241-S-102 Retrieval Overfill Due To Siphoning Calculation, Rev. 0, CH2M HILL Hanford Group, Inc., Richland, Washington.

RPP-5924, 2003, Radiological Source Terms for Tank Farms Safety Analysis, Rev. 4, CH2M HILL Hanford Group, Inc., Richland, Washington.

RPP-8369, 2003, Chemical Source Terms for Tank Farms Safety Analyses, Rev. 2, CH2M HILL Hanford Group, Inc., Richland, Washington.

RPP-13033, 2004, Tank Farms Documented Safety Analysis, Rev. 1, CH2M HILL Hanford Group, Inc., Richland, Washington.

RPP-13750, 2004, Waste Transfer Leaks Technical Basis Document, Rev. 10, CH2M HILL Hanford Group, Inc., Richland, Washington. 


\section{RPP-17965 REV 5}

RPP-14499, 2003, Offsite Radiological Consequence Analysis for the Waste Transfer Leak, Rev. 2, CH2M HILL Hanford Group, Inc., Richland, Washington.

RPP-15188, 2004, Hazard Evaluation Database Report, Rev. 7-B, CH2M HILL Hanford Group, Inc., Richland, Washington. 
RPP-17965 REV 5

ATTACHMENT D1

HAZARD ANALYSIS AND CONTROL DECISION RECORD

TEAM MEMBER ROSTERS

Attach D1-i 
Page 91 of 143 of DA02557226

\section{RPP-17965 REV 5}

This page intentionally left blank.

Attach D1-ii

-

This page intentionally left blank. 
RPP-17965 REV 5

Modified Sluicing - Recirculation Date $1 / / 3 / 03$

l lazard Evaluation Sessinn Amolance Sign In Sheet

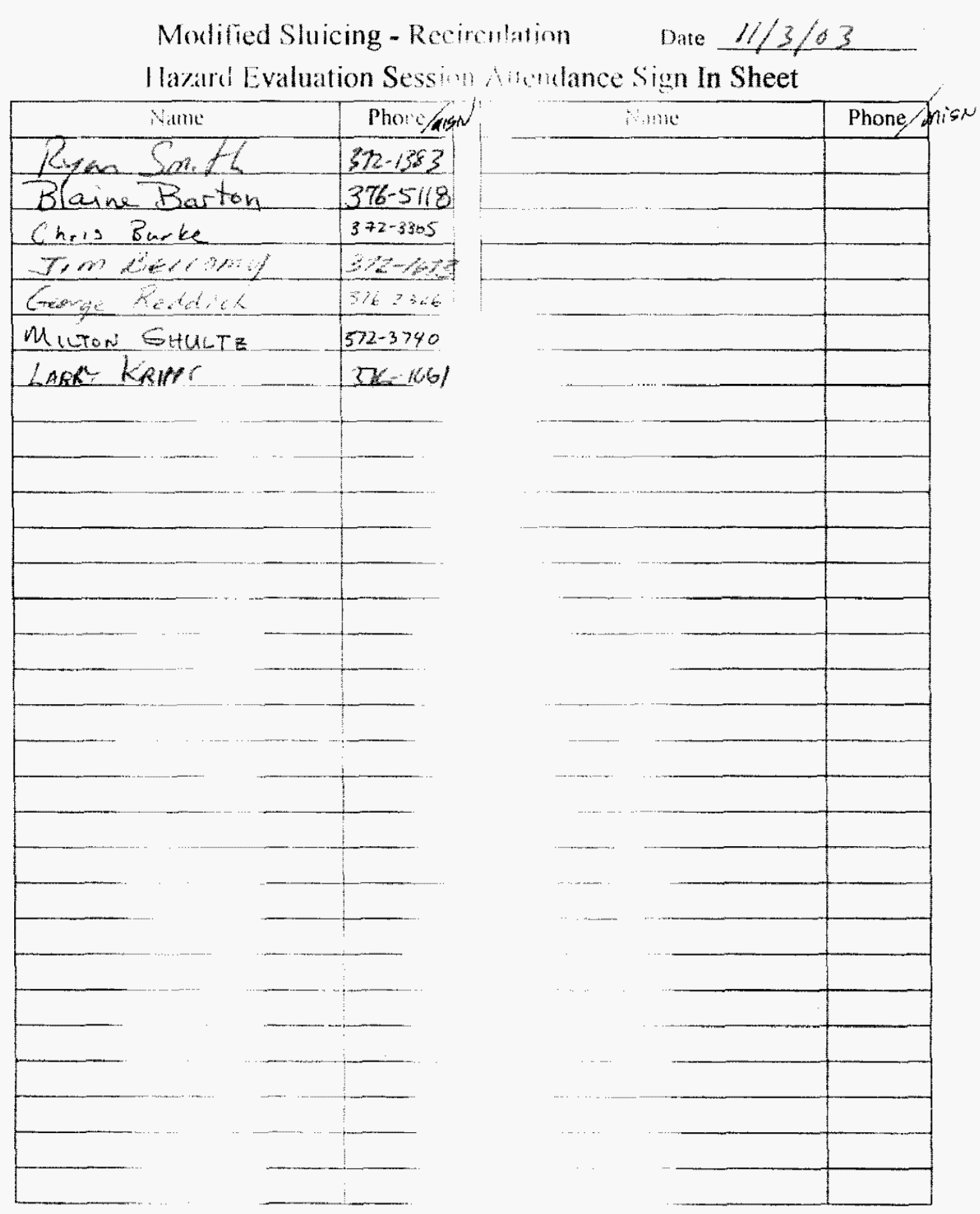


Page 93 of 143 of DA02557226

RPP-17965 REV 5

Hazards Evaluation Team Meeting Attendance Sheet

Meeting Subject: Waste Trash Condo Der sic-

Date $\frac{12 / 18 / 03}{\text { Name }}$

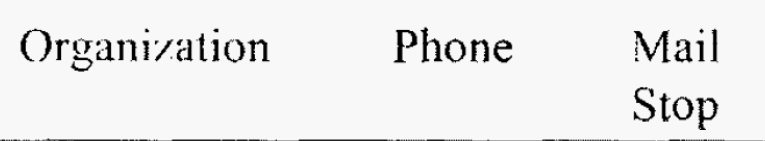

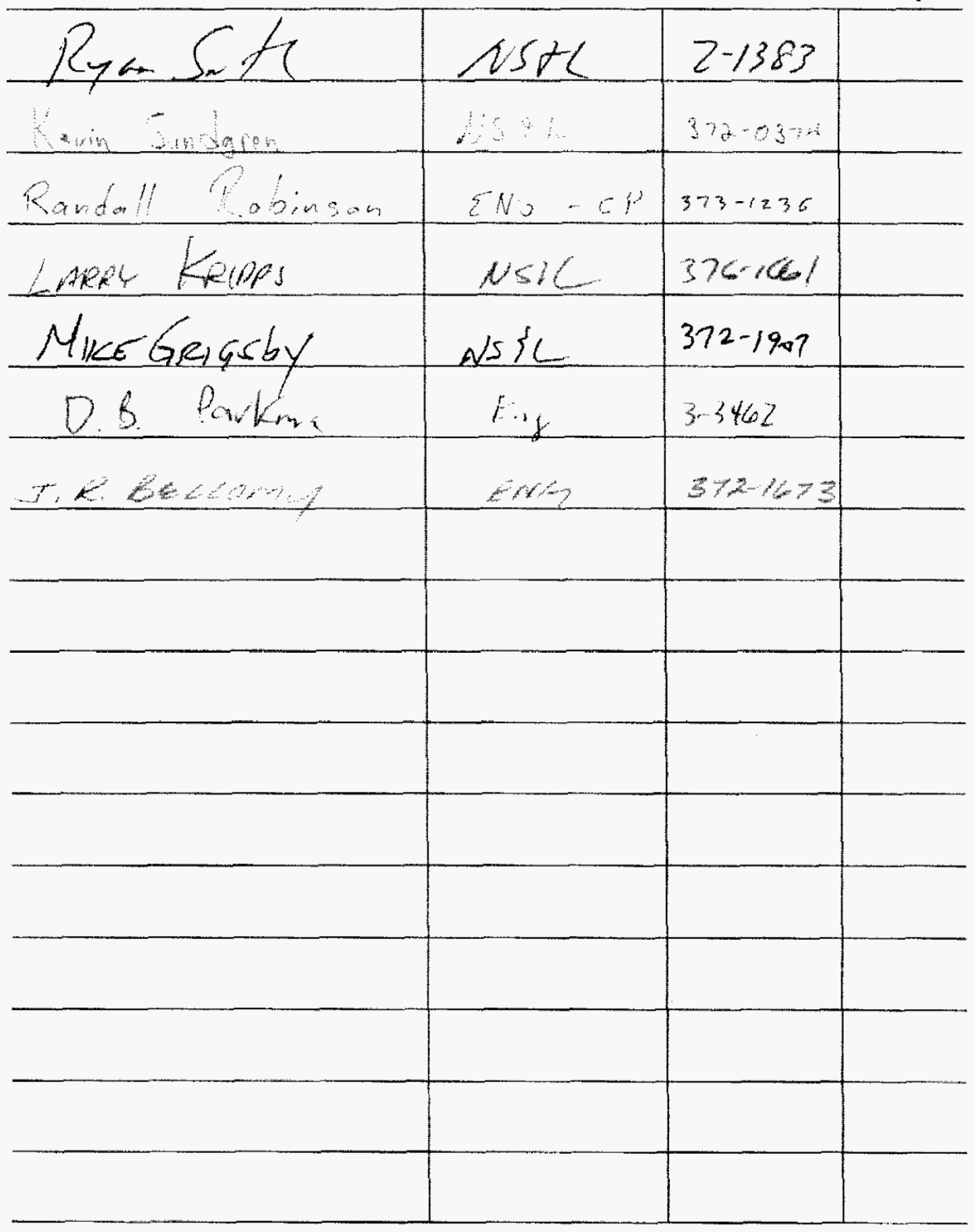

Attach D1-2 


\section{RPP-17965 REV 5}

\section{Smith, Ryan D}

$\begin{array}{ll}\text { From: } & \text { Hopkins, Gary P } \\ \text { Sent: } & \text { Friday, December 19, 2003 8:07 AM } \\ \text { To: } & \text { Smith, Ryan D, Saueressig, David J } \\ \text { Cc: } & \text { Burke, Christopher A: Grigsby, J M (Mike); Reichmuth, Curtis R } \\ \text { Subject: } & \text { RE: Waste Transfer Controls for Supernatant Re-circulation }\end{array}$

Ryan,

The rad survey is the preferred method for ease of operation and the entire route will be surveyed as a matter of normal operations.

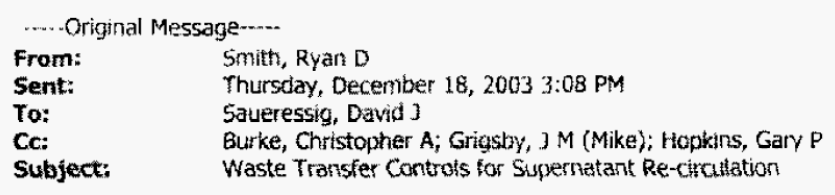

Dave.

Earlier today I conducted a Control Decision meeting to discuss alternate control strategies for sluicing in C-Farm using Supernatant from AN-106 with regards to Waste Transfer Leak Material Balance controls (required to mitigate a commonmode failure of the HIHTL). Based on the proposed engineering design there is no way of verifying that the supernatant from AN-106 reaches the C-Farm SST between the portable pit and the sluice pits on the SST. Control options that were discussed are as follows:

- Radiation Surveys

- Field Walk downs

- Visual inspection of sluice medium in SST by Camera systems

- Pressure Indicators from instrumentation

- Flow meters in sluice pits

Of these options the two that seemed most reasonable to implement were Rad Surveys (able to detect a large pool) or installing Flow meters in the sluice pits. Since the sluice pits tend to be highly contaminated and are difficult to do maintenance work in (ALARA concerns) the control decision team felt the Rad Surveys would be the better option Additionally the team assumed the operations staff would be performing surveys anyways so there would be minimal impact on resources and cost for implementation. The Rad Surveys would only need to be performed on dedicated portions of the HIHTL. that don't have flow meter indicators as long as no other waste transfer lines are physically connected and the frequency would be consistent with the current Material Balance control frequency based on pump flow rates, allowing for time to shut down the waste transfer pumps and evacuate personnel.

Since no one from operations was able to attend the meeting. I would like to obtain your concurrence for Operations on this decision. If you have any questions please let me know so we can discuss in further detail

Thanks

Ryan D. Smith, NS\&L Engineer

Phone: $372-1383$

Pager: $85-9030$

Location: 2704HV/200E/E215 (Mail Stop: 57-90)

E-mail: Ryan_D_Smith@rl.gov 
RPP-17965 REV 5

This page intentionally left blank.

Attach D1-4 
Page 96 of 143 of DA02557226

RPP-17965 REV 5

ATTACHMENT D2

HAZARD EVALUATION DATABASE TABLES

Attach D2-i 
RPP-17965 REV 5

This page intentionally left blank.

Attach D2-ii 

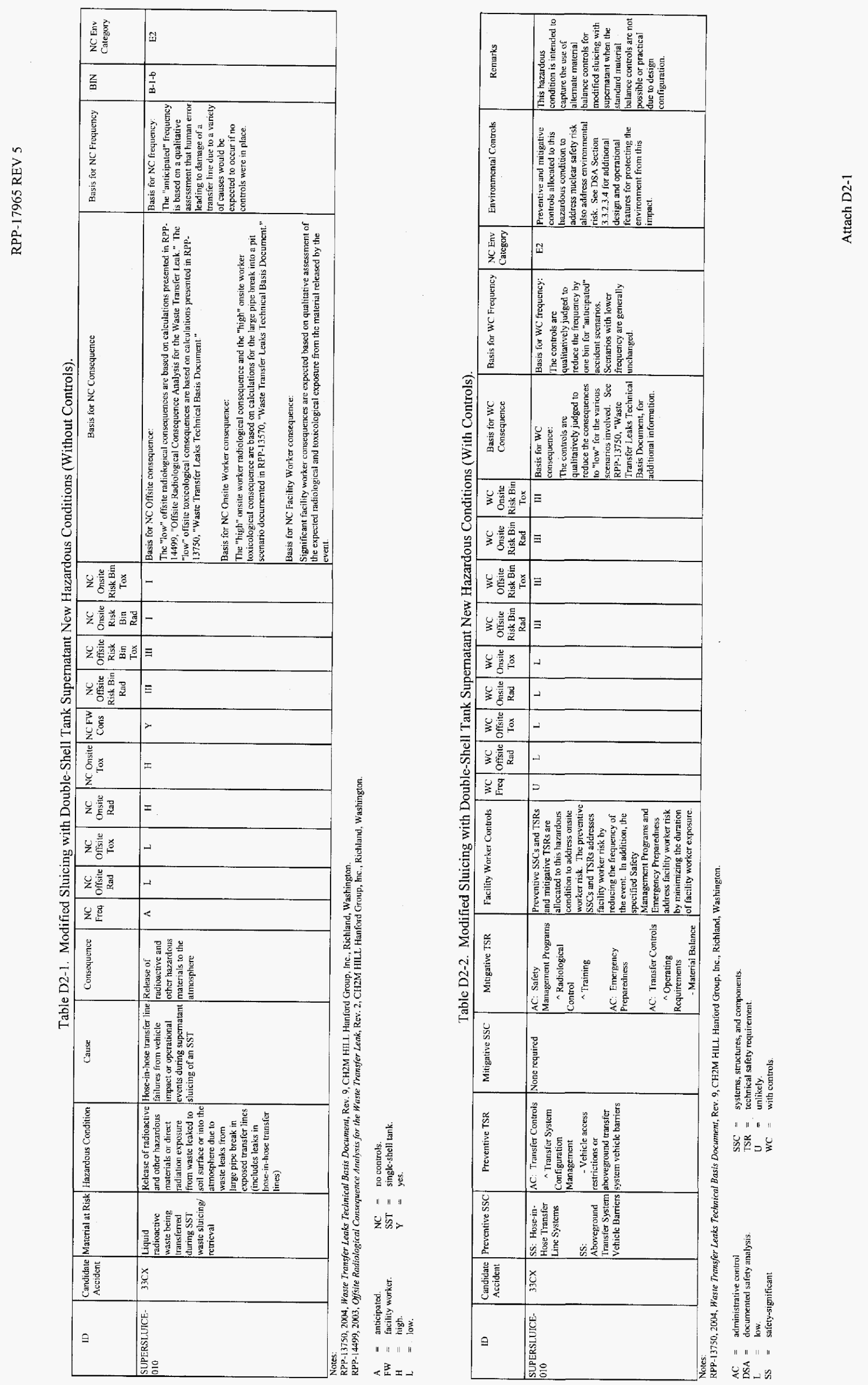

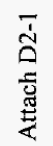


RPP-17965 REV 5

This page intentionally left blank.

Attach D2-2 
RPP-17965 REV 5

APPENDIX E

SAFETY EVALUATION FOR SLUICING IN SINGLE-SHELL TANK 241-C-103 WITH DOUBLE-SHELL TANK 241-AN-106 SUPERNATANT

E-i 


\section{RPP-17965 REV 5}

This page intentionally left blank.

E-ii 


\section{RPP-17965 REV 5}

\section{CONTENTS}

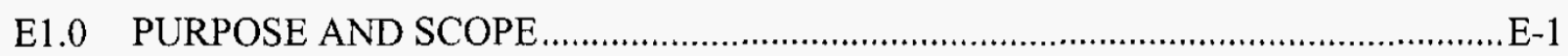

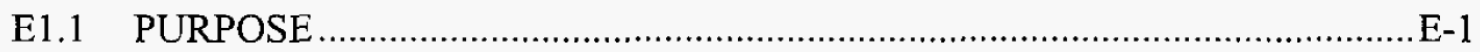

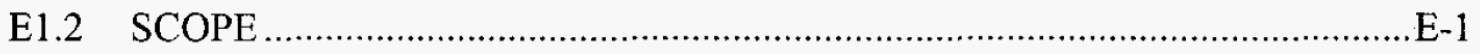

E2.0 DESCRIPTION OF THE SUPERNATANT SLUICING DESIGN AND

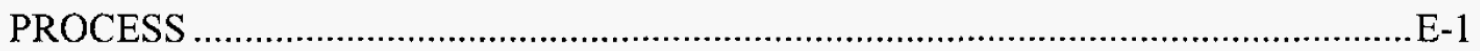

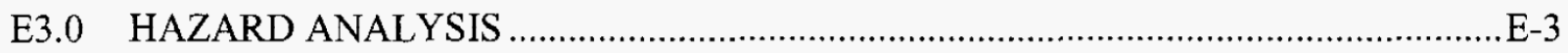

E3.1 HAZARD IDENTIFICATION AND EVALUATION ….................................

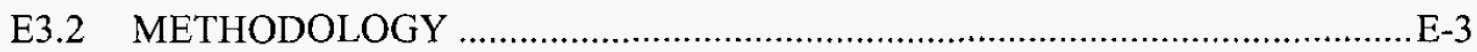

E3.3 HAZARDOUS CONDITION SCREENING .................................................

E4.0 ACCIDENT ANALYSIS .................................................................................... E-5

E4.1 EVALUATION OF RISK FROM SLUICING WITH DOUBLE-SHELL

TANK SUPERNATANT FOR DSA REPRESENTATIVE ACCIDENTS .........E-5

E4.1.1 Mixing of Incompatible Materials .........................................................

E4.1.2 Waste Transfer Leaks ........................................................................ E-6

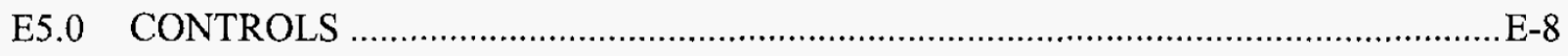

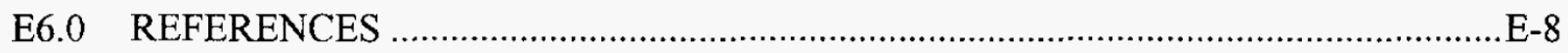

\section{ATTACHMENT}

E1 HAZARD EVALUATION DATABASE TABLES

Attach E1-i 


\section{RPP-17965 REV 5}

This page intentionally left blank. 
RPP-17965 REV 5

\section{E1.0 PURPOSE AND SCOPE}

\section{E1.1 PURPOSE}

The purpose of this appendix is to determine if the potential risk associated with using doubleshell tank (DST) supernatant to sluice single-shell tanks (SST) for retrieval of the SSTs in the tank farms is adequately addressed and bounded by the tank farms safety basis (RPP-13033, Tank Farms Documented Safety Analysis [DSA], and HNF-SD-WM-TSR-006, Tank Farms Technical Safety Requirements [TSR]) and to determine if additional controls may be required.

\section{E1.2 SCOPE}

The scope of this appendix is the SST modified sluicing waste retrieval system design that is planned for SST 241-C-103 with use of supernatant from DST 241-AN-106. Note that the general modified sluicing design has been previously evaluated in the main body of this document and the sluicing design with DST supernatant in 241-S-102 has been previously evaluated in Appendix D of this document. This attachment only focuses on the unique aspects of the 241-C-103 design and the use of supernatant from DST 241-AN-106 for sluicing. Although this safety evaluation is based on the specific design for SST 241-C-103 retrieval to DST 241-AN-106, this design could be used in future SST retrievals. When the system designs and processes for the retrieval of these subsequent SSTs are established, the analysis contained in this safety evaluation, including this appendix will be reviewed via the unreviewed safety question process to determine whether this analysis satisfactorily bounds the retrievals from these tanks.

\section{E2.0 DESCRIPTION OF THE SUPERNATANT SLUICING DESIGN AND PROCESS}

SST modified sluicing waste retrieval systems will retrieve waste from designated tanks to the extent needed for tank closure and transfer. The retrieved waste will be transferred to the DST system. The SST modified sluicing waste retrieval system is designed to dissolve SST crystallized salt and/or to mobilize sludge through the application of high pressure water or supernatant spray to break down the waste salt, sludge, and solids and to direct the waste to the intake of a slurry transfer pump for transfer into the DST system. Various SST waste retrieval system sluicing designs may be used. The designs may use sluice nozzles, DST supernatant pump, SST supernatant pump, waste transfer pump(s), monitoring and control systems, portable exhauster ventilation, and new as well as existing waste transfer systems. Support systems necessary for the sluicing design may include raw water and electrical supply. 


\section{RPP-17965 REV 5}

The sluicing design attributes unique to using DST 241-AN-106 supernatant as a sluice medium for retrieval of SST 241-C-103 are as follows.

- Supernatant is pumped from DST 241-AN-106 through a hose-in-hose transfer line (HIHTL) to the 241-C Tank Farm portable valve and instrument pit where it will be routed to the sluicer nozzles in the SSTs through other sections of HIHTL. The supernatant pump is a Floway centrifugal pump. The pumping performance has been evaluated and determined to be bounded by the DSA using the pumping curves in RPP-19618, AN-106 Supernatant Pump Process Flow for C-103 Sluicing.

- The portable valve and instrument pit is located in 241-C Tank Farm and is a fully abovegrade assembly that serves the same function as a belowgrade valve pit. The portable valve and instrument pit does not drain directly to an SST, therefore, a sump pump provides the mechanism to pump waste through one of the HIHTLs to the SST in the case of a leak. Leak detectors are located in the pit. Vehicle barriers will protect it and the abovegrade portions of hoses from vehicle collisions.

- The sluice nozzles, located in the SST 241-C-103 sluice and pump pits, are connected to a hydraulically controlled pan and tilt mechanism and utilize supernatant or raw water for sluicing. The SST retrieval pump is a Gorman-Rupp ${ }^{1}$ centrifugal pump located in the heel pit. The pumping performance has been evaluated and determined to be bounded by the DSA using the pumping curves in RPP-19621, C-103 Slurry Pump Process Flow Calculation.

- The raw water connection for flushing or sluicing is located on a skid outside the portable valve and instrument pit. Two waste transfer system valves will provide physical disconnection of the raw water line where it exits the portable valve and instrument pit.

- Transfer leak detection systems are installed at the DST 241-AN-106 central pump pit, 241-C Tank Farm portable valve and instrument pit, heel pit, sluice pit, and pump pit. The leak detectors located in the sluice and pump pits (where there is potential for hydraulic oil to be present) are TraceTek ${ }^{2}$ leak detector systems that use electrical conductivity probes that remain operable in Mobile, Quaker Quintolubric 8-33-EHC, and Shell Tellus ${ }^{3}$ Plus 46 hydraulic oil (RPP-19524, Hydraulic Fluid Compatibility with TraceTek Leak Detection System and Mini-Probe).

- Material balance will be performed by level readings at DST 241-AN-106 and flow meter measurements at the 241-C Tank Farm portable valve and instrument pit. There are no flow metering devices at the heel pit, sluice pit, or pump pit of the SSTs and liquid level monitoring in the SST is not practical or possible. Therefore, radiation survey controls (as developed in Appendix D for the 241-S-102 design) will be relied upon in addition to material balance controls to detect and mitigate a waste transfer leak or misroute.

\footnotetext{
${ }^{1}$ Gorman-Rupp is a trademark of Gorman-Rupp Company.

${ }^{2}$ TraceTek is a trademark of Raychem Corporation.

${ }^{3}$ Tellus is a trademark of Shell Company.
} 
- There is a large elevation difference between SST 241-C-103 and DST 241-AN-106 and, therefore, the DST supernatant pump and DST waste discharge drop leg have a siphon break to prevent an overfill of SST 241-C-103.

\section{E3.0 HAZARD ANALYSIS}

\section{E3.1 HAZARD IDENTIFICATION AND EVALUATION}

The graded approach was used to select the hazard identification and evaluation method. The goal of the graded approach is to select a method that does not create a large number of hazardous conditions redundant to those in the DSA hazard evaluation database (RPP-15188, Hazard Evaluation Database Report). The "delta" hazard analysis method was chosen. The "delta" hazard analysis method uses the concept of "deviations from a baseline" to identify hazardous conditions that require further evaluation.

\section{E3.2 METHODOLOGY}

The hazard evaluation performed for the SST 241-C-103 design is the same one that is documented in Appendix D and, therefore, only the unique hazardous conditions associated with the SST 241-C-103 to DST 241-AN-106 transfer are included and evaluated in this appendix.

\section{E3.3 HAZARDOUS CONDITION SCREENING}

Hazardous conditions involving exposure to radioactive and other hazardous materials were assigned a representative accident and/or a candidate accident designator. The representative accident designator allows cross reference to the appropriate analysis in the DSA. Candidate accident designators allow hazardous conditions to be compared with the hazardous conditions contained in the DSA hazard evaluation database.

Hazardous conditions were screened to determine if they potentially (1) are not represented by a DSA representative or candidate accident, (2) are similar to, but not bounded by a DSA representative or candidate accident, or (3) are similar to and bounded by a DSA representative or candidate accident but are unique in regard to phenomena or control applicability. Hazardous conditions meeting one or more of these criteria are further evaluated in Chapter 4.0. Only those hazardous conditions that are found to meet the screening criteria after further evaluation are incorporated into the DSA hazard evaluation database (see Attachment E1).

The same general concern that was identified for SST 241-S-102 in Appendix D with regards to the source term assumptions for all the DSA accident analyses was also identified for 241-C-103. The specific concern was that the supporting calculations for the accidents postulated in the SSTs may have used SST source term values that may be challenged by the DST source term values due to the introduction of DST supernatant waste. Since there is uncertainty associated with the DST 241-AN-106 supernatant waste inventory that may be present at the start of operations of 
SST 241-C-103 retrieval, a TSR control was developed to verify that DST waste additions to SSTs are bounded by the source term assumptions used in the accident analysis that are impacted by the waste addition. The current bounding 100 -series SST radiological and toxicological liquid source terms obtained from RPP-5924, Radiological Source Terms for Tank Farms Safety Analysis, and RPP-8369, Chemical Source Terms for Tank Farms Safety Analyses, are reported in Table E-1.

Table E-1. Unit Liter Dose and Sum of Fractions for the Bounding Single-Shell Tank 100-Series Waste.

\begin{tabular}{|c|c|c|c|c|c|}
\hline \multirow{2}{*}{ Tank } & \multirow{2}{*}{$\begin{array}{c}\text { Liquid ULD } \\
\text { Onsite }\end{array}$} & $\begin{array}{c}\text { Liquid ULD } \\
\text { Offsite }\end{array}$ & \multicolumn{3}{|c|}{ Liquid SOFs } \\
\cline { 3 - 6 } & & TEEL-1 & TEEL-2 & TEEL-3 \\
\hline Bounding SST & $4.5 \mathrm{E}+02$ & $6.0 \mathrm{E}+02$ & $3.71 \mathrm{E}+09$ & $5.73 \mathrm{E}+08$ & $1.25 \mathrm{E}+07$ \\
& $(241-\mathrm{U}-106)$ & $(241-\mathrm{U}-106)$ & $(241-\mathrm{A}-106)$ & $(241-\mathrm{A}-106)$ & $(241-\mathrm{A}-106)$ \\
\hline
\end{tabular}

Notes:

SST $=$ single-shell tank.

TEEL $=\quad$ Temporary Emergency Exposure Limit.

ULD $=\quad$ unit liter dose.

\section{Representative Accident 11, Mixing of Incompatible Materials (Candidate Accidents 03/23)}

Hazardous conditions involving mixing of incompatible materials for tank pressurization are identified in the DSA and are representative of hazardous conditions for this activity. Hazardous conditions involving mixing of incompatible materials for toxic material release were identified as potentially being unique to the DST supernatant sluicing design and process and, therefore, a further evaluation was determined to be warranted. The specific concerns are due to the organic waste composition in the 241-C Tank Farm tanks potentially containing large amounts of organics and ammonia that could be released due to sluicing using DST supernatant.

\section{Representative Accident 13, Waste Transfer Leak (Candidate Accidents 33A, 33C, 33D)}

Hazardous conditions involving waste leaks were identified as having characteristics similar to the hazardous conditions in the DSA hazard evaluation database. However, a siphon event due to the elevation differences between the SST and DST was identified as a credible accident scenario and, therefore, a further evaluation was determined to be warranted. Additionally, the waste transfer controls were identified as needing further evaluation for the operation of the sump pump in the portable aboveground valve and instrument pit and for the operability of electrical conductivity probes in the presence of hydraulic fluid that could leak into the sluice and pump pits where the SST 241-C-103 sluice nozzles are located.

\section{Identifiable to a Candidate Accident but DSA Hazardous Conditions Determined to be Risk Bin III or IV (i.e., no Representative Accident identified), Tank Bump (Candidate Accident 18A)}

Hazardous conditions involving tank bump were identified as a potentially credible accident scenario based on the current DSA accident analysis. Based on RPP-6213, Hanford Waste Tank 
Bump Accident and Consequence Analysis, if at least one of the following criteria is met a tank bump accident is "beyond extremely unlikely."

1. Total tank heat load is $\leq 38,000 \mathrm{Btu} / \mathrm{h}$

2. Non-convective layer thickness is $\leq 12 \mathrm{in}$.

3. Supernatant depth is $\leq 40$ in.

4. The non-condensable gas generation rate in the non-convective layer is sufficiently low, such that the ratio of vertical void fraction profile to the neutral buoyant void fraction is $<1.0$.

Preliminary analysis based on 241-C Tank Farm retrieval planning as documented in RPP-21753, C-Farm 100 Series Tanks, Retrieval Process Flowsheet Description, has identified that during 241-C Tank Farm SST retrieval operations the heat load will exceed the 38,000 Btu/h in DSTs 241-AN-106 and 241-AY-101 and none of the other criteria will be met. Therefore, the tank bump accident may become credible. Although waste retrieval operations from SST 241-C-103 to DST 241-AN-106 will not challenge the $38,000 \mathrm{Btu} / \mathrm{h}$ heat load criteria, the technical supporting documentation (i.e., RPP-6213 and RPP-13438, Technical Basis for the Tank Bump Accident and Associated Representative Hazardous Conditions) and TSR page changes that support this change are being submitted with this amendment to raise the DST heat load required for a tank bump in support of future 241-C Tank Farm SST retrieval operations.

\section{E4.0 ACCIDENT ANALYSIS}

\section{E4.1 EVALUATION OF RISK FROM SLUICING WITH DOUBLE-SHELL TANK SUPERNATANT FOR DSA REPRESENTATIVE ACCIDENTS}

\section{E4.1.1 Mixing of Incompatible Materials}

\section{E4.1.1.1 DSA Representative Accidents}

The related DSA representative accident is 11 (candidate accidents 03 and 23), Mixing of Incompatible Materials. The technical basis for the mixing of incompatible materials analysis is summarized in DSA Section 3.3.2.4.11, "Mixing of Incompatible Materials."

\section{E4.1.1.2 Waste Retrieval System Operations Hazardous Conditions}

The hazard analysis postulated that the addition of DST 241-AN-106 supernatant into the organic bearing waste in the 241-C Tank Farm tanks could result in organic vapor releases. Tank waste mixing and tank waste conditions were considered in the DSA analysis. Tank waste mixing with other tank waste (i.e., reactions due to a transfer from one tank to another) do not 
result in a significant release as discussed in RPP-9689, Offsite Radiological Consequence Calculation for the Bounding Mixing of Incompatible Materials Accident. The organic waste remaining in the tank waste consists of either low volatility solvents or water soluble complexants which were shown to be compatible with tank wastes. Therefore, organic vapors would not be released in significant quantities due to the addition of sluicing liquid.

Ammonia releases were also considered in the DSA analysis. Process knowledge and past history of the various waste disturbing activities (e.g., waste transfers, remediation of DST 241-SY-101) has shown the potential to release dissolved ammonia. These releases, while shown to be a potential facility worker concern, result in low consequences to the onsite worker or offsite public even for waste released into the headspace of a ventilated tank. These situations are adequately and appropriately addressed by the industrial hygiene safety management program. The analysis also looked at the potential to generate additional ammonia due to the addition of caustic solutions (such as the sluicing liquid). It was found that the $\mathrm{pH}$ in the tank would have to be made extremely basic to reach the saturation point for ammonia release (equivalent to $4 \mathrm{M} / \mathrm{L}$ of sodium hydroxide in the waste). Using supernatant from DST 241-AN-106 as a sluicing liquid would not cause the tank waste to be sufficiently basic to result in a saturated solution. Even if these conditions are achieved, the release would be below the evaluation guidelines resulting in low consequences.

\section{E4.1.1.3 Conclusions}

The sluicing operations using DST 241-AN-106 supernatant in 241-C Tank Farms are bounded by the current hazard and accident analysis and no additional controls are required.

\section{E4.1.2 Waste Transfer Leaks}

\section{E4.1.2.1 DSA Representative Accidents}

The DSA representative accidents are the "fine spray into the air" scenario and the "large pipe break into a pit" scenario. The fine spray into the air scenario assumes that a small width crack (the optimal width for producing fine aerosol) has occurred in a waste transfer line, and that waste slurry is spraying into the air under maximum available pump pressure. The large pipe break into a pit scenario assumes that a large pipe break has occurred, and that waste is leaking into an open pit at the maximum flow rate of the transfer pump. DSA Section 3.3.2.4.13, "Waste Transfer Leak," addresses these hazardous conditions. The DSA section also addresses several other accident scenarios, but the fine spray into the air and the large pipe break into a pit scenario are the limiting scenarios. The DSA estimates the frequency of the fine spray into the air scenario to be "unlikely," and the large pipe break into a pit scenario to be "anticipated." The onsite radiological and toxicological guidelines are exceeded for the two representative accident scenarios, and safety SSCs and/or TSR controls are required. The offsite radiological and toxicological guidelines are not exceeded. 


\section{E4.1.2.2 Waste Retrieval System Operations Hazardous Conditions}

Based on the hazard identification and evaluation in Chapter 3.0, the potential waste transfer leak hazards for SST 241-C-103 sluicing operations are represented by existing hazardous conditions and bounded by existing waste transfer leak analysis. However, further evaluation of waste transfer leak TSR controls for three hazardous conditions was required. For additional details see RPP-13750, Waste Transfer Leaks Technical Basis Document.

The first hazardous condition is a pool leak as a result of a back siphon from DST 241-AN-106 to SST 241-C-103. The current DSA assumes a siphoning accident that overflows a waste tank is "beyond extremely unlikely" based on existing planned waste transfer configurations in the tank farms. The planned waste transfer between SST 241-C-103 and DST 241-AN-106 has the potential to siphon supernatant waste from DST 241-AN-106 back to SST 241-C-103, which is much lower in elevation. Therefore, the design of the DST supernatant pump and DST waste discharge drop leg incorporates siphon breaks to prevent this hazardous condition.

The second hazardous condition is the operation of the sump pump in case of a leak in the portable aboveground valve and instrument pit. When a leak is detected in the portable valve and instrument pit, the leak detector is considered inoperable and, therefore, the pump must be under administrative lock. Therefore, an exception from TSR LCO 3.1.1, "Transfer Leak Detection Systems," was identified for waste transfer-associated structures where the active waste transfer pump physically connected to the structure is a sump pump located in the structure. Performing a material balance for sump pump transfers of waste out of a waste transfer-associated structure are also not possible or practical. Therefore, the following two exceptions to AC 5.11.2.b.1 material balancing monitoring requirement were identified.

1. Transfers of waste present in a waste transfer-associated structure directly back to the underlying tank using a sump pump.

2. Transfer of $<1,000$ gal of waste out of a waste transfer-associated structure using a sump pump and connecting waste transfer system to a tank.

Note: For waste transfers of $>1,000$ gal using a waste transfer-associated structure sump pump where material balance monitoring is not possible or practical, radiation surveys of the waste transfer route and alternative methods for detecting misroutes are required (see Appendix D).

The third hazardous condition affects the operability of the electrical conductivity probes from hydraulic fluid leaks in the sluice and pump pits where the SST 241-C-103 sluice nozzles are located. For some types of electrical conductivity probes the presence of hydraulic fluid on the electrodes may interfere with the ability to detect a waste leak. However, the TraceTek electrical conductivity leak detection system planned for use in the SST 241-C-103 sluice pits has been tested and shown not to be affected by hydraulic fluid leaks using Mobile, Quaker Quintolubric 8-22-EHC, and Shell Tellus Plus 46 hydraulic fluid (RPP-19524). 


\section{RPP-17965 REV 5}

\section{E4.1.2.3 Conclusions}

An amendment for the DSA and TSRs has been developed to (1) add waste transfer system siphon breaks as a Design Feature, (2) exempt the operability of the leak detection in waste transfer-associated structures where the waste is being pumped out by sump pump, (3) provide limited exceptions to material balance monitoring requirements when using sump pumps to transfer waste from a waste transfer-associated structure, and (4) clarify that electrical conductivity probes may be used in waste transfer-associated structures.

\section{E5.0 CONTROLS}

Based on the hazard and accident analyses of SST modified sluicing in SST 241-C-103 using DST 241-AN-106 supernatant, no new accidents were identified, and the existing DSA analyses were found to be encompassing and bounding. The DSA controls (i.e., safety SSCs and TSRs) were also found to acceptably prevent or mitigate potential hazardous conditions and postulated accidents with the exception of the exception to TSR LCO 3.1.1, "Transfer Leak Detection Systems," and AC 5.11.2.b.1 material balance monitoring requirements (see Section D4.1.2) during sump pump operation, and the addition of the Design Feature of the waste transfer system siphon breaks.

\section{E6.0 REFERENCES}

HNF-SD-WM-TSR-006, Tank Farms Technical Safety Requirements, as amended, CH2M HILL Hanford Group, Inc., Richland, Washington.

RPP-5924, 2003, Radiological Source Terms for Tank Farms Safety Analysis, Rev. 4, CH2M HILL Hanford Group, Inc., Richland, Washington.

RPP-6213, 2005, Hanford Waste Tank Bump Accident and Consequence Analysis, Rev. 4, CH2M HILL Hanford Group, Inc., Richland, Washington.

RPP-8369, 2003, Chemical Source Terms for Tank Farms Safety Analyses, Rev. 2, CH2M HILL Hanford Group, Inc., Richland, Washington.

RPP-9689, 2003, Offsite Radiological Consequence Calculation for the Bounding Mixing of Incompatible Materials Accident, Rev. 3, CH2M HILL Hanford Group, Inc., Richland, Washington.

RPP-13033, Tank Farms Documented Safety Analysis, as amended, CH2M HILL Hanford Group, Inc., Richland, Washington.

RPP-13438, 2005, Technical Basis for the Tank Bump Accident and Associated Representative Hazardous Conditions, Rev. 2, CH2M HILL Hanford Group, Inc., Richland, Washington. 


\section{RPP-17965 REV 5}

RPP-13750, 2005, Waste Transfer Leaks Technical Basis Document, Rev. 11-A, CH2M HILL Hanford Group, Inc., Richland, Washington.

RPP-15188, 2005, Hazard Evaluation Database Report, Rev. 7-C, CH2M HILL Hanford Group, Inc., Richland, Washington.

RPP-19524, 2004, Hydraulic Fluid Compatibility with TraceTek Leak Detection System and Mini-Probe, Rev. 1, CH2M HILL Hanford Group, Inc., Richland, Washington.

RPP-19618, 2004, AN-106 Supernatant Pump Process Flow for C-103 Sluicing, Rev. 1, CH2M HILL Hanford Group, Inc., Richland, Washington.

RPP-19621, 2004, C-103 Slurry Pump Process Flow Calculation, Rev. 1, CH2M HILL Hanford Group, Inc., Richland, Washington.

RPP-21753, 2005, C-Farm 100 Series Tanks, Retrieval Process Flowsheet Description, Rev. 1, CH2M HILL Hanford Group, Inc., Richland, Washington. 
RPP-17965 REV 5

This page intentionally left blank. 
RPP-17965 REV 5

ATTACHMENT E1

HAZARD EVALUATION DATABASE TABLES

Attach E1-i 
RPP-17965 REV 5

This page intentionally left blank.

Attach E1-ii 

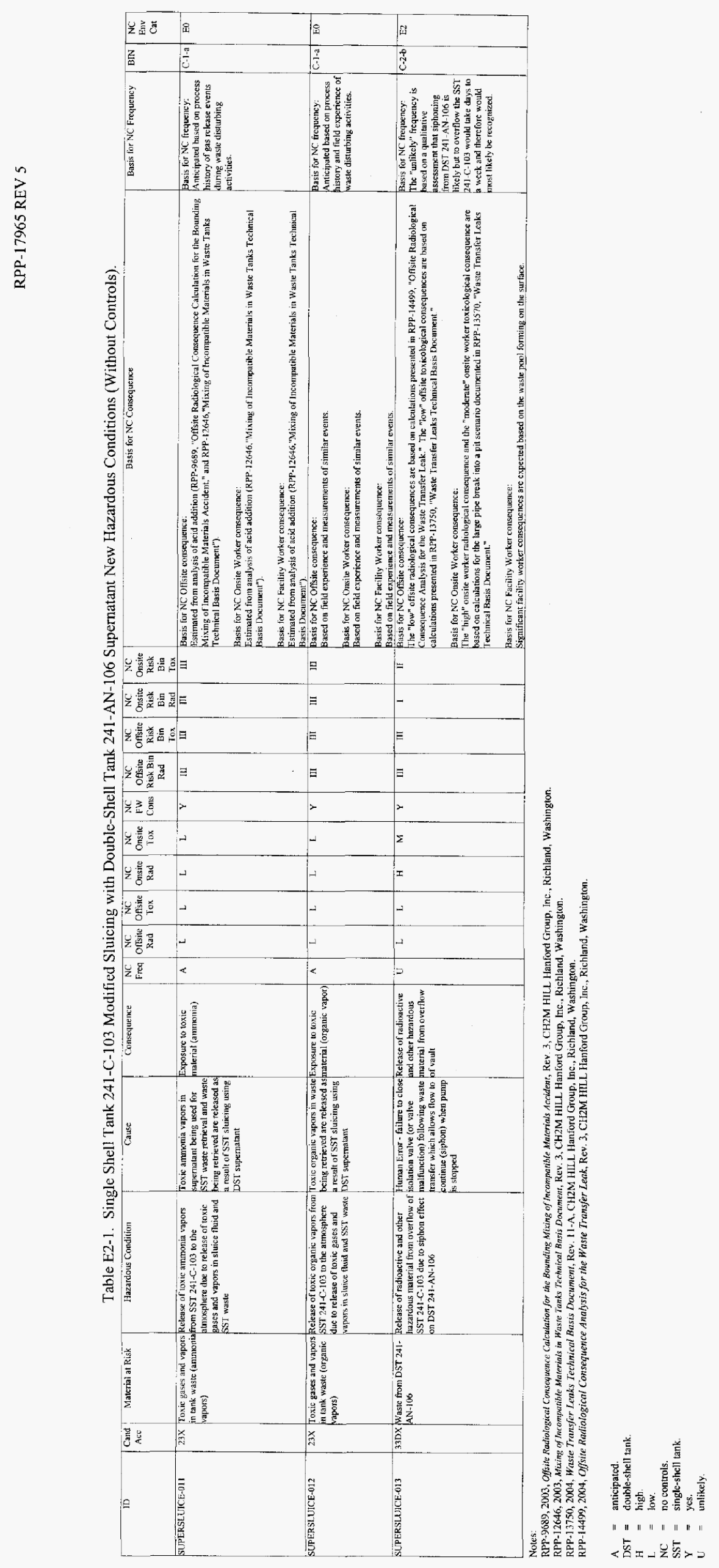

\section{立}




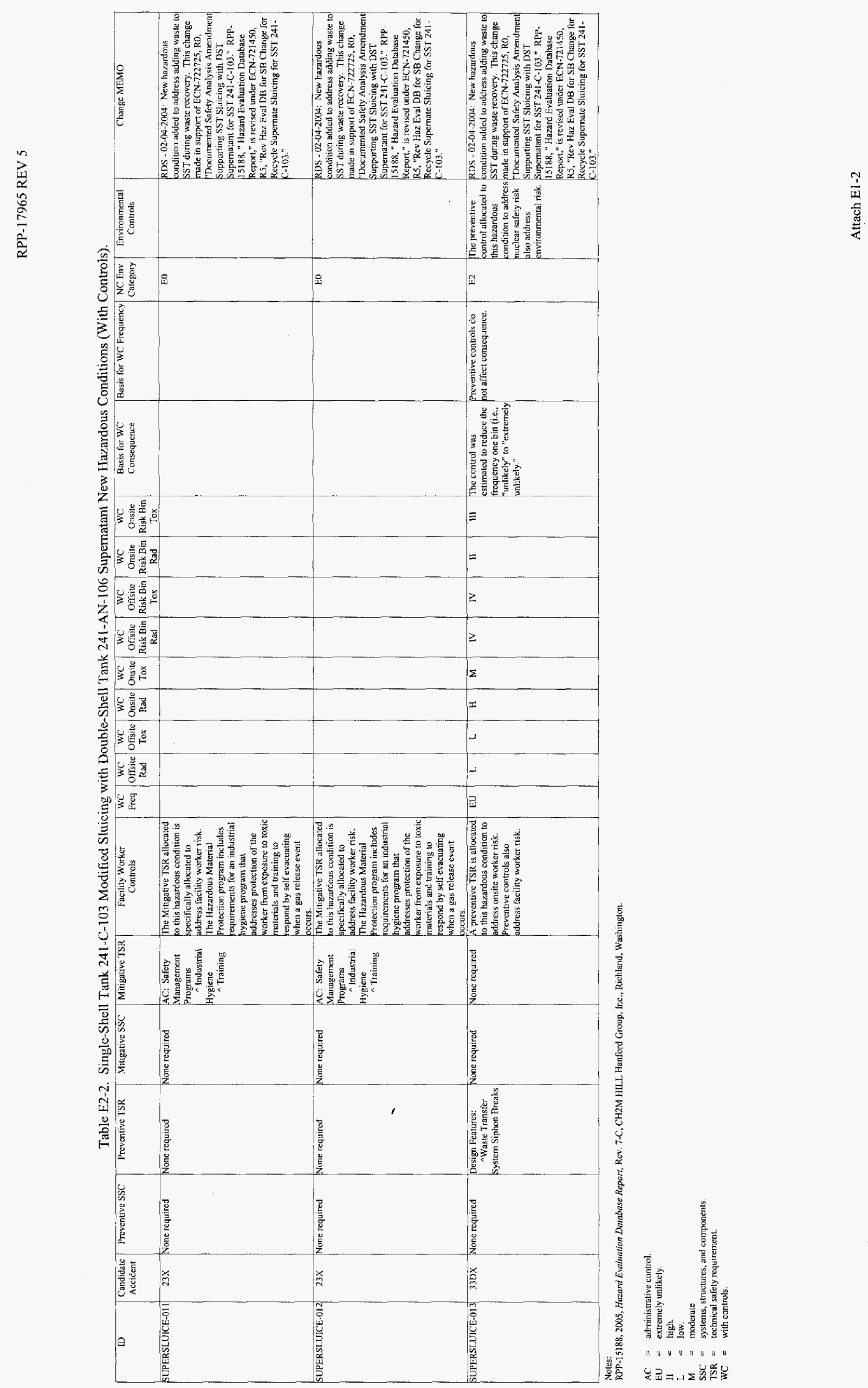

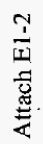

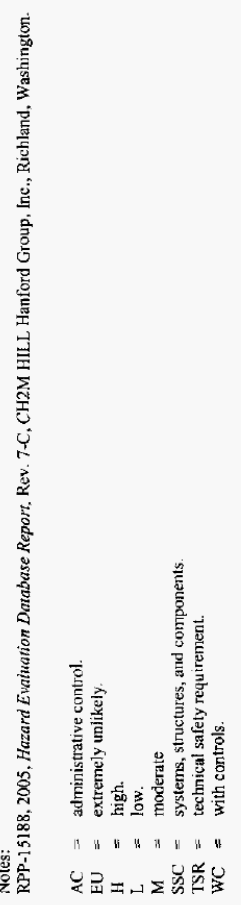

$n$
3
$\frac{1}{2}$
3
$\frac{2}{5}$
$\frac{1}{2}$
$\frac{1}{2}$ 
RPP-17965 REV 5

APPENDIX F

SAFETY EVALUATION FOR SODIUM HYDROXIDE ADDITION TO SINGLE-SHELL TANK 241-S-112 
Page 119 of 143 of DA02557226

RPP-17965 REV 5
Rage 119 of 143 of DA02557226

This page intentionally left blank.

F-ii

\title{
s \\ - ii
}

\author{
.
}

-




\section{RPP-17965 REV 5}

\section{CONTENTS}

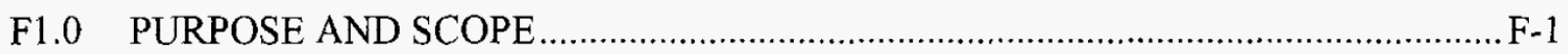

F2.0 DESCRIPTION OF THE SODIUM HYDROXIDE ADDITION TO SINGLE-

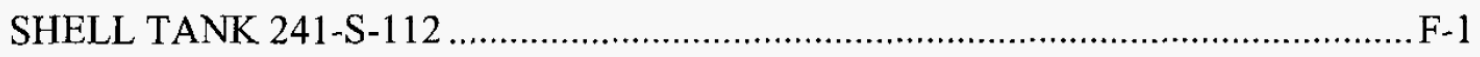

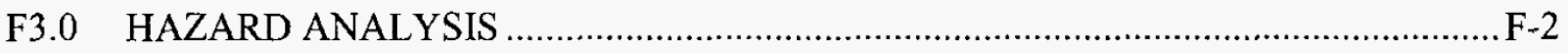

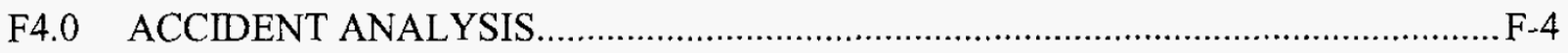

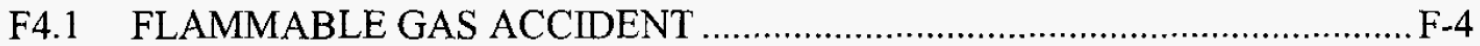

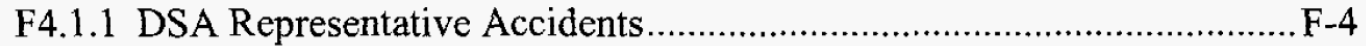

F4.1.2 Hazardous Conditions .................................................................... F-4

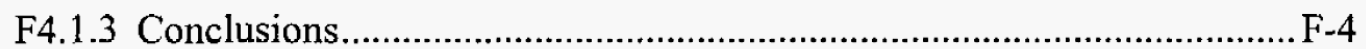

F4.2 MIXING OF INCOMPATIBLE MATERIALS .........................................F-5

F4.2.1 DSA Representative Accidents ......................................................F-5

F4.2.2 Hazardous Conditions .................................................................... F-5

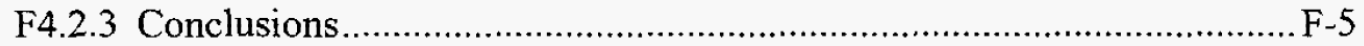

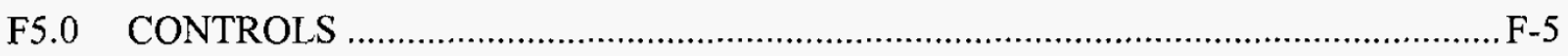

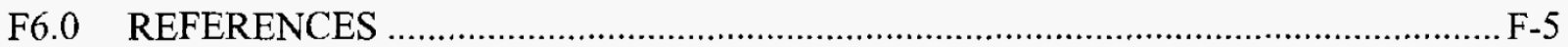




\section{RPP-17965 REV 5}

This page intentionally left blank.

F-iv 
RPP-17965 REV 5

\section{F1.0 PURPOSE AND SCOPE}

\section{F1.1 PURPOSE}

The purpose of this appendix is to determine if the potential risk associated with adding sodium hydroxide to sluice single-shell tanks (SST) to support waste retrieval is adequately addressed and bounded by the tank farms safety basis (RPP-13033, Tank Farms Documented Safety Analysis [DSA], and HNF-SD-WM-TSR-006, Tank Farms Technical Safety Requirements [TSR]) and to determine if additional controls may be required.

\section{F1.2 SCOPE}

The scope of this appendix is the process and design for the sodium hydroxide chemical addition to SST 241-S-112 in support of modified sluicing waste retrieval. Note that the general modified sluicing design has been previously evaluated in the main body of this document. This attachment focuses on the unique aspects of adding sodium hydroxide to SST 241-S-112. Although this safety evaluation is based on the specific process and design for adding sodium hydroxide to SST 241-S-112, this process and design could be used in future 100-series SST retrievals. When the system designs and processes for the retrieval of these subsequent SSTs are established, the analysis contained in this safety evaluation, including this appendix, will be reviewed via the unreviewed safety question process to determine whether this analysis satisfactorily bounds the retrievals from these tanks.

\section{F2.0 DESCRIPTION OF THE SODIUM HYDROXIDE ADDITION TO SINGLE-SHELL TANK 241-S-112}

Because most of the brine created during retrieval of saltcake from the SSTs is not within the corrosion specification for double-shell tanks (DST), caustic (NaOH) and/or sodium nitrite $\left(\mathrm{NaNO}_{2}\right)$ has to be added. In the past this has been added to the DST prior to receiving the SST waste. In order to make beneficial use of the volume associated with chemical additions to retrieve the solids from the SST, it is proposed to introduce the corrosion control chemical (sodium hydroxide) into the SST where it can transport insoluble solids as it is pumped to the receiving DST. Additionally, if the water insoluble solids in the SST are aluminum oxide compounds, the possibility exists that the solids can dissolve in a caustic solution.

The initial plan for SST 241-S-112 is to add four trucks (nominal 4,500 gal each) of $8 \underline{\mathrm{M}}$ ( $25 \mathrm{wt} \%$ ) sodium hydroxide. The 5,000 gal volume of waste currently in SST $241-\mathrm{S}-112$ is assumed to be $45 \mathrm{vol} \%$ solids and therefore $55 \mathrm{vol} \%$ water. The sodium hydroxide may soak in SST $241-S-112$ for up to a month and then be transferred to DST 241-SY-102 along with up to $100,000 \mathrm{gal}$ of sluice water. If the first sodium hydroxide soak is successful in dissolving aluminum, more trucks may be added. The remote water lance may be operated using water or the sluice nozzles using water or sodium hydroxide to stir the liquid pool and suspend the solids 


\section{RPP-17965 REV 5}

so the resulting slurry can be pumped to DST 241-SY-102. This soak with chemical application may be repeated multiple times until the sodium hydroxide is no longer effective in dissolving the aluminum.

The existing design, equipment, and process for adding bulk chemicals to DSTs are planned for the sodium hydroxide addition to SST 241-S-112. Sodium hydroxide is delivered in vendorowned tanker trucks and added directly to the SST. The sodium hydroxide is typically introduced into the SST using a pressurized tanker truck via the dilution leg on the transfer pump or into the supernatant recirculation pump. Sodium hydroxide may also be introduced via the sluice nozzles using the pressurized tanker truck in conjunction with a skid-mounted pump. The maximum addition rate of sodium hydroxide is $175 \mathrm{gal} / \mathrm{min}$. A flexible hose system delivers the sodium hydroxide to the SST using a flow metering device to measure the amount of chemical added to the SST. All equipment that may come in contact with the sodium hydroxide has been evaluated for compatibility.

\section{F3.0 HAZARD ANALYSIS}

Bulk chemical additions to SSTs are an activity that is not explicitly described in the DSA. However, bulk chemical additions to DSTs, double-contained receiver tanks (DCRT), and catch tanks are described in the DSA. Therefore, as a starting point, the hazardous conditions identified for bulk chemical additions to DSTs were reviewed to aid in the hazard evaluation. The hazard analyses included a multi-disciplinary team that systematically evaluated the addition of sodium hydroxide in SST 241-S-112 to identify any hazards that could have a potential adverse effect on people or the environment, and energy sources that are present which could potentially contribute to the release of material at risk. The attendance roster is included in Attachment F1 to document the presence of each team member.

Based on the hazard analyses, a "delta HAZOP" technique with elements of the "whatif/checklist" was selected to identify possible impacts on the DSA hazard and accident analyses. This technique uses the accidents analyzed in the DSA as "study nodes" and the system/process characteristics of the DSA analyses as "process parameters." The DSA representative and candidate accidents were used to assist in identifying unique conditions and formulating new, unique, hazardous conditions.

The application of the graded approach results in hazardous condition screening taking place in two phases. Only postulated hazards that meet at least one of the following criteria are captured for the second phase of screening.

- The activity related hazard is new or has significant differences from the DSA.

- The activity involves equipment and system configurations significantly different from those addressed in the DSA.

This significantly reduces resource expenditures on hazards/hazardous conditions already evaluated in the DSA. 
In the second phase of screening, these hazardous conditions are evaluated to determine if they potentially (1) are not represented by a DSA representative or candidate accident analysis, (2) are similar to but not bounded by a DSA representative or candidate accident analysis, or (3) are similar to and bounded by a DSA representative or candidate accident analysis but require new or modified controls. Hazardous conditions that meet one or more of these criteria undergo further detailed evaluation (e.g., hazard evaluation and accident analysis). Only those hazardous conditions that are found to meet the screening criteria after further evaluation are incorporated into the DSA hazard evaluation database (see Attachment F2).

DSA representative and candidate accidents are described in DSA Sections 3.3.2.3.1, 3.3.2.4.1 through 3.3.2.4.17, and 3.4.2.1 through 3.4.2.7. As a result of the hazard analysis, it was identified that the Flammable Gas (Sections 3.3.2.4.1 and 3.4.2.1) representative accident and Mixing of Incompatible Materials (Section 3.3.2.4.11 and 3.4.2.3) representative accident require further evaluation as described in Section 4.0. No candidate accidents required further evaluation.

Other DSA accidents that are not applicable, not impacted, or that remain bounding are those that:

- Do not occur within 100-series SSTs (i.e., occurs aboveground, in contaminated soil or plumes, or within DSTs only) and thus are not affected by the addition of sodium hydroxide to SSTs to support waste retrieval (Transportation Accidents [Section 3.3.2.3.1], Aboveground Tank Failure [Section 3.3.2.3.1], Large Fire Involving Aboveground Tank/Vessel [Section 3.3.2.3.1]), Evaporator Dump [Section 3.3.2.3.1], Steam Intrusion from Interfacing Systems [Section 3.3.2.3.1], and Unplanned Excavation/Drilling [Sections 3.3.2.4.15 and 3.4.2.5]).

- May occur in 100-series SSTs, but the accident topography, critical assumptions, and control strategies are not affected by the addition of sodium hydroxide to SSTs to support waste retrieval (Organic Solvent Fire [Section 3.3.2.3.1], Filtration Failures Leading to Unfiltered Releases [Section 3.3.2.3.1], Tank Failure Due to Excessive Loads [Sections 3.3.2.4.6 and 3.4.2.2]).

- May occur in 100-series SSTs, but the vacuum retrieval system is not being used with the addition of sodium hydroxide to support waste retrieval (Vacuum Exhaust Line Rupture [Section 3.3.2.4.3]).

- May occur in associated waste transfer systems and structures, but the accident topography, critical assumptions, and control strategies are not affected by the addition of sodium hydroxide to SSTs to support waste retrieval (Release from Contaminated Facility [Section 3.3.2.4.4] and Waste Transfer Leaks [Sections 3.3.2.4.13 and 3.4.2.4]).

- May occur when withdrawing equipment from SSTs, but the accident topography, critical assumptions, and control strategies are not affected by the addition of sodium hydroxide to SSTs to support waste retrieval (Aboveground Structure Failure [Section 3.3.2.4.10]). 


\section{RPP-17965 REV 5}

- May initiate previously postulated accidents (e.g., waste transfer leak accidents, tank failure due to excessive load accidents, flammable gas accidents) but are otherwise unaffected by the addition of sodium hydroxide to SSTs to support waste retrieval (External Events [Sections 3.3.2.4.16 and 3.4.2.6] and Natural Events [Sections 3.3.2.4.17 and 3.4.2.7]).

- Are not credible in SSTs and the addition of sodium hydroxide to SSTs to support waste retrieval does not create conditions that would make the accident credible (Tank Bump [Sections 3.3.2.3.1]).

- Remain bounded by the DSA description as analyzed by the nuclear criticality safety program (Nuclear Criticality [Section 3.3.2.4.2]).

A DSA accident analysis source term evaluation was also performed that concluded that the addition of sodium hydroxide to SSTs to support waste retrieval is bounded by existing source terms used in these accident analyses.

\section{F4.0 ACCIDENT ANALYSIS}

\section{F4.1 FLAMMABLE GAS ACCIDENT}

\section{F4.1.1 DSA Representative Accidents}

The related DSA representative accident is 01 (Candidate Accident 04/05), Flammable Gas Accidents. The technical basis for the flammable gas analysis is summarized in DSA Section 3.3.2.4.1, "Flammable Gas Accidents."

\section{F4.1.2 Hazardous Conditions}

The hazard analysis postulated that chemical additions to SSTs could affect the flammable gas accidents. Results of the evaluation show that the addition of sodium hydroxide to an SST has no affect on the frequency or consequences of the accidents nor does it have an affect on the TSR controls. However, the implementation of the TSR controls for AC 5.10, "Flammable Gas Controls," needs to be expanded to include chemical additions to SSTs (i.e., SST waste group evaluations to determine the applicability of spontaneous and induced gas release hazard controls; and SST time to LFL determinations). (Note: The control for waste gel prevention did not require revision to encompass chemical additions to SSTs.)

\section{F4.1.3 Conclusions}

The chemical additions of sodium hydroxide to 100-series SSTs to support waste retrieval are bounded by the current hazard and accident analyses and controls for flammable gas accidents. Implementation of the flammable gas controls, however, is required to be expanded to include chemical additions to SSTs. 


\section{F4.2 MIXING OF INCOMPATIBLE MATERIALS}

\section{F4.2.1 DSA Representative Accidents}

The related DSA representative accident is 11 (candidate accidents 03 and 23), Mixing of Incompatible Materials. The technical basis for the mixing of incompatible materials analysis is summarized in DSA Section 3.3.2.4.11, "Mixing of Incompatible Materials."

\section{F4.2.2 Hazardous Conditions}

The hazard analysis postulated that the mixing of incompatible material in a waste tank could result in a chemical reaction that produces aerosols and enough internal pressure to expel headspace gases, vapors, and aerosolized waste. Bulk chemical additions to DSTs are already analyzed in RPP-9689, Offsite Radiological Consequence Calculation for the Bounding Mixing of Incompatible Materials Accident, and RPP-12646, Mixing of Incompatible Materials in Waste Tanks Technical Basis Document. The frequency of this postulated accident remains "unlikely." However, it was identified that the source term for the consequence calculations needed to be evaluated to include SSTs. Results of this analysis as documented in RPP-12646 show that the onsite radiological and toxicological consequences remain "moderate" while the offsite toxicological consequences remain "low" for 100-series SSTs.

\section{F4.2.3 Conclusions}

The chemical additions of sodium hydroxide to 100-series SSTs to support waste retrieval are bounded by the current hazard and accident analyses. However, the TSR AC 5.13, "Bulk Chemical Controls," needs to be revised to include 100-series SSTs.

\section{F5.0 CONTROLS}

Based on the identification and evaluation of potential hazardous conditions for the addition of sodium hydroxide to SSTs to support waste retrieval, no new accidents were identified. However, the existing DSA hazard and accident analyses for the flammable gas and mixing of incompatible materials representative accidents were identified as needing to be revised. Revisions to these accidents require the implementation of TSR AC 5.10, "Flammable Gas Controls," and AC 5.13, "Bulk Chemical Controls," be expanded to include 100-series SSTs to allow the addition of sodium hydroxide to SSTs in support of waste retrieval.

\section{F6.0 REFERENCES}

HNF-SD-WM-TSR-006, Tank Farms Technical Safety Requirements, as amended, CH2M HILL Hanford Group, Inc., Richland, Washington.

RPP-9689, 2006, Offsite Radiological Consequence Calculation for the Bounding Mixing of Incompatible Materials Accident, Rev. 4, CH2M HILL Hanford Group, Inc., Richland, Washington. 


\section{RPP-17965 REV 5}

RPP-12646, 2006, Mixing of Incompatible Materials in Waste Tanks Technical Basis Document, Rev. 4, CH2M HILL Hanford Group, Inc., Richland, Washington.

RPP-13033, Tank Farms Documented Safety Analysis, as amended, CH2M HILL Hanford Group, Inc., Richland, Washington. 
RPP-17965 REV 5

ATTACHMENT F1

HAZARD EVALUATION ATTENDANCE ROSTER

Attach F1-i 
RPP-17965 REV 5

This page intentionally left blank.

Attach F1-ii 
S-112 Caustic Addition Date $4 / 28 / 06$ HazOp Attendance Sign In Sheet

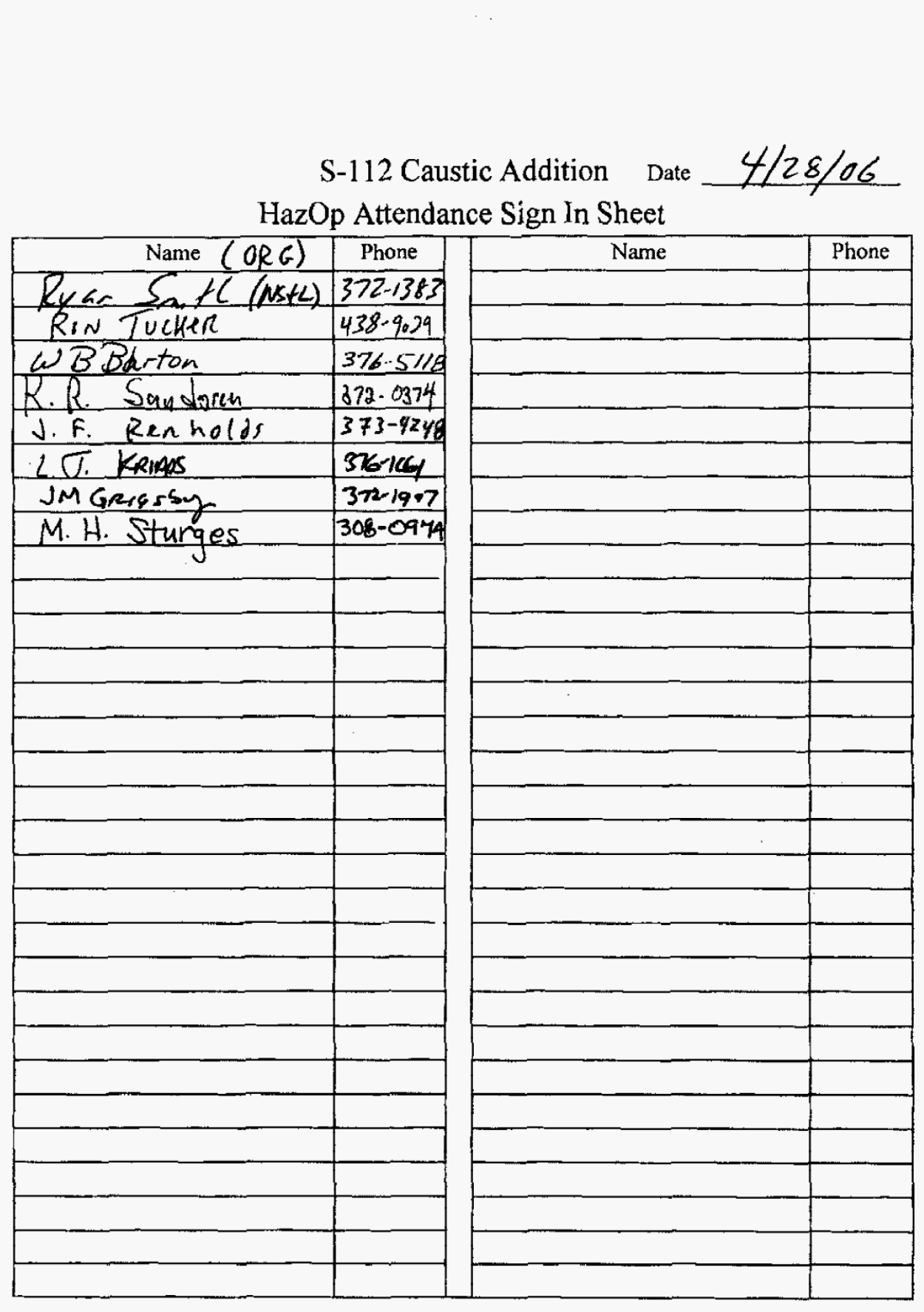

\section{Attach F1-1}

RPP-17965 REV 5

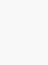

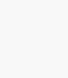

\section{.}


Page 131 of 143 of $\mathrm{DA} 02557226$

RPP-17965 REV 5

This page intentionally left blank.

Attach F1-2 
RPP-17965 REV 5

ATTACHMENT F2

HAZARD EVALUATION DATABASE TABLES

Attach F2-i 
RPP-17965 REV 5

This page intentionally left blank.

Attach F2-ii

5




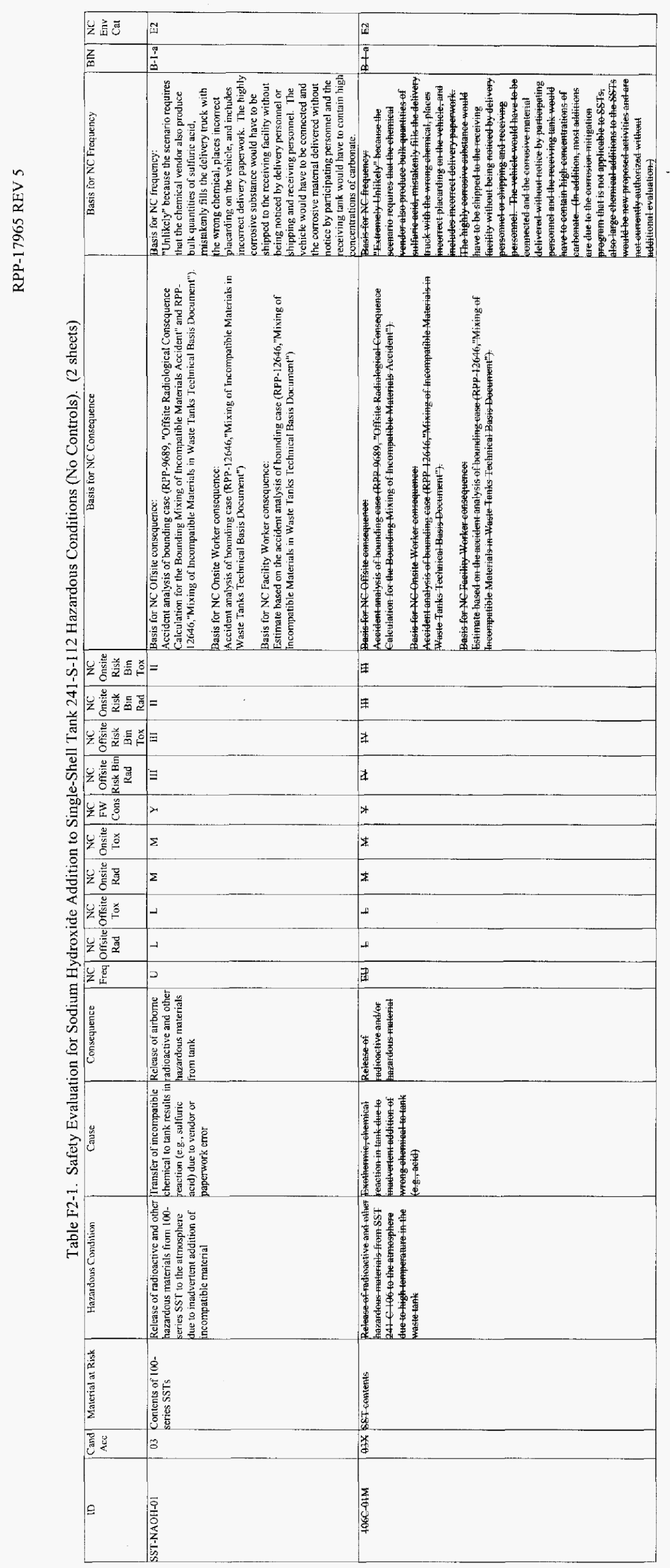

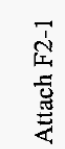




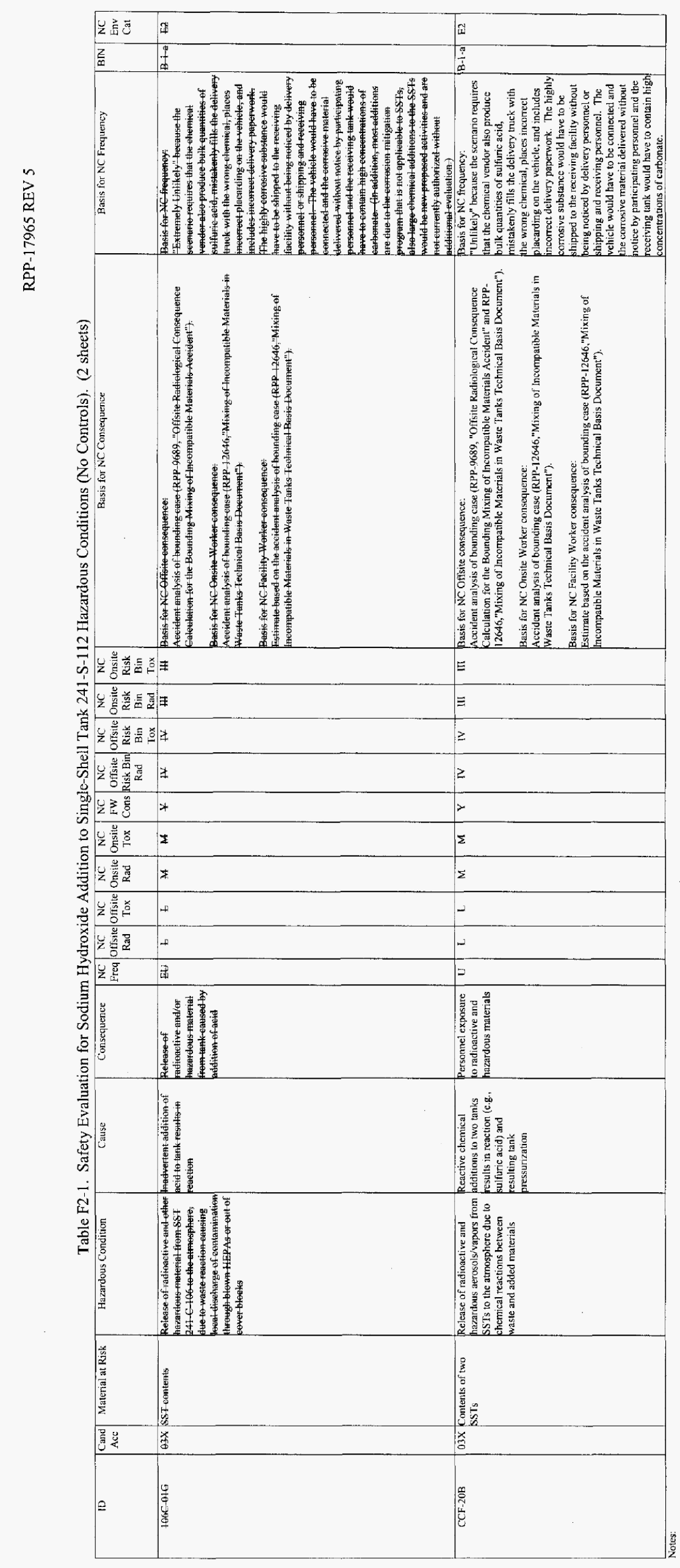

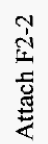


Page 136 of 143 of $\mathrm{DA} 02557226$

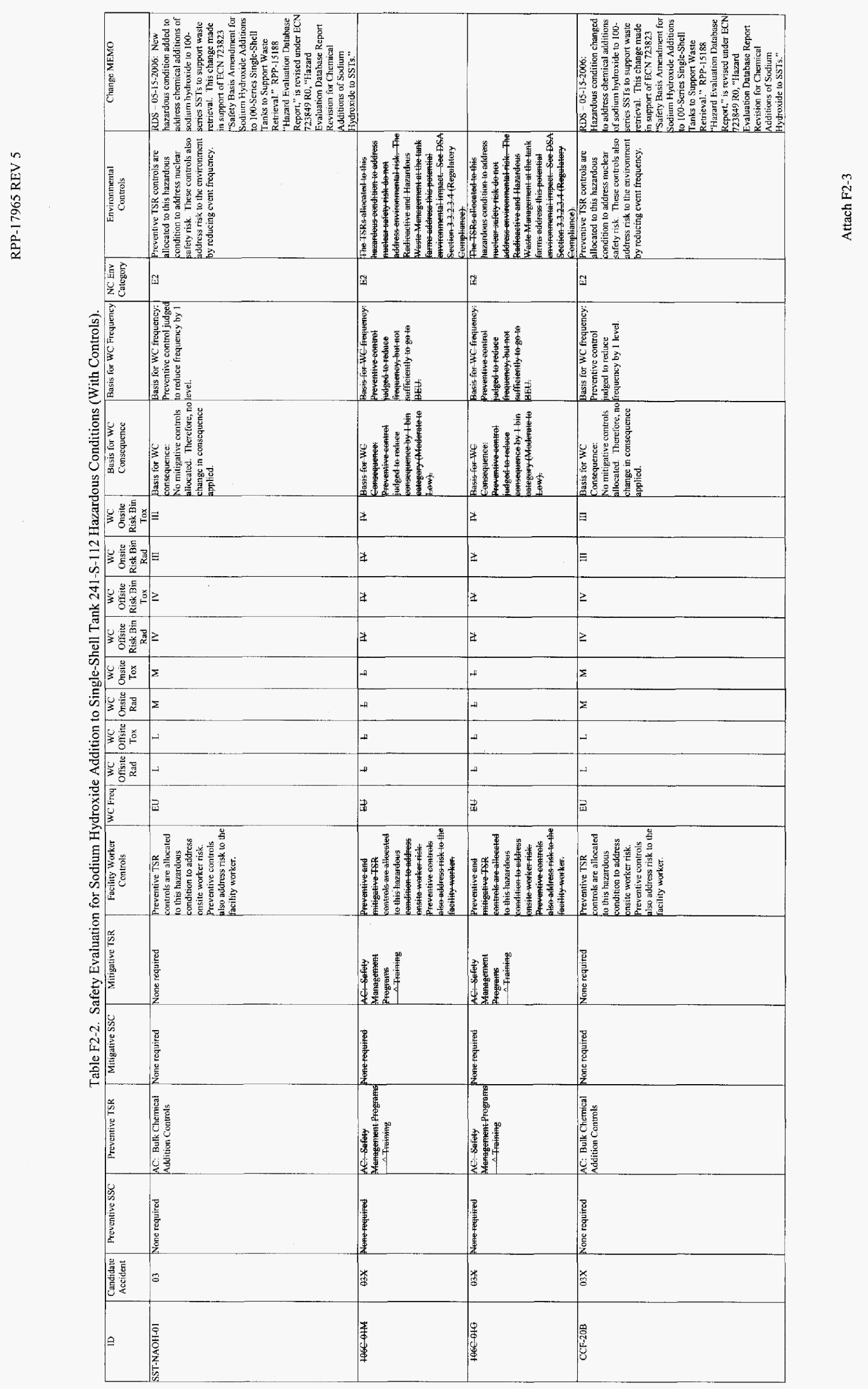

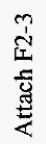

.

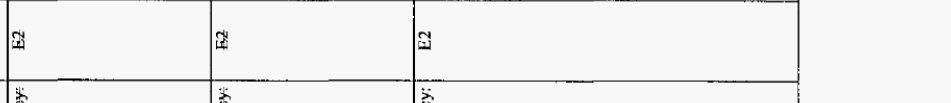


RPP-17965 REV 5

This page intentionally left blank.

Attach F2-4 
Page 138 of 143 of $\mathrm{DA} 02557226$

RPP-17965 REV 5

APPENDIX G

PEER REVIEW CHECKLISTS

G-i 
RPP-17965 REV 5

This page intentionally left blank.

G-ii 


\section{APPENDIX G}

\section{PEER REVIEW CHECKLISTS}

\section{CHECKLIST FOR TECHNICAL PEER REVIEW}

Document Reviewed: RPP-17965, Safety Evaluation of the Single-Shell Tanks Modified

Sluicing Waste Retrieval System, Rev. 5

Scope of Review (e.g., document section or portion of calculation): Revision 5.

Yes No NA*

[x] [] [] 1. Previous reviews are complete and cover the analysis, up to the scope of this review, with no gaps.

[x] [ ] [ ] 2. Problem is completely defined.

[x] [] [] 3. Accident scenarios are developed in a clear and logical manner.

[x] [] [ ] 4. Analytical and technical approaches and results are reasonable and appropriate. (ORP QAPP criterion 2.8)

[x] [ ] [ ] 5. Necessary assumptions are reasonable, explicitly stated, and supported. (ORP QAPP criterion 2.2)

[ ] [] [x] 6. Computer codes and data files are documented.

[] [] [x] 7. Data used in calculations are explicitly stated.

[] [ ] [x] 8. Bases for calculations, including assumptions and data, are consistent with the supported safety basis document (e.g., the Tank Farms Final Safety Analysis Report).

[x] [1] [] 9. Data were checked for consistency with original source information as applicable. (ORP QAPP criterion 2.9)

[x] [ ] [ ] 10. For both qualitative and quantitative data, uncertainties are recognized and discussed, as appropriate. (ORP QAPP criterion 2.17)

[ ] [] [x] 11. Mathematical derivations were checked including dimensional consistency of results. (ORP QAPP criterion 2.16)

[ ] [] [x] 12. Models are appropriate and were used within their established range of validity or adequate justification was provided for use outside their established range of validity.

[] [ ] [x] 13. Spreadsheet results and all hand calculations were verified.

[ ] [ ] [x] 14. Calculations are sufficiently detailed such that a technically qualified person can understand the analysis without requiring outside information. (ORP $Q A P P$ criterion 2.5)

[] [] [x] 15. Software input is correct and consistent with the document reviewed.

[] [] [x] 16. Software output is consistent with the input and with the results reported in the document reviewed.

[ ] [ ] [x] 17. Software verification and validation are addressed adequately. (ORP QAPP criterion 2.6)

[x] [ ] [ ] 18. Limits/criteria/guidelines applied to the analysis results are appropriate and referenced. Limits/criteria/guidelines were checked against references. (ORP QAPP criterion 2.9)

[x] [] [] 19. Safety margins are consistent with good engineering practices.

[x] [ ] [ ] 20. Conclusions are consistent with analytical results and applicable limits.

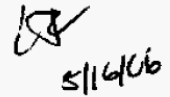




\section{RPP-17965 REV 5}

\section{CHECKLIST FOR TECHNICAL PEER REVIEW}

[x] [ ] [ ] 21. Results and conclusions address all points in the purpose. (ORP QAPP criterion 2.3)

[x] [ ] [] 22. All references cited in the text, figures, and tables are contained in the reference list.

[x] [ ] [ ] 23. Reference citations (e.g., title and number) are consistent between the text callout and the reference list.

[x] [ ] [ ] 24. Only released (i.e., not draft) references are cited. (ORP QAPP criterion 2.I)

[x] [] [] 25. Referenced documents are retrievable or otherwise available.

[x] [ ] [ ] 26. The most recent version of each reference is cited, as appropriate. (ORP QAPP criterion 2.1)

[x] [] [] 27. There are no duplicate citations in the reference list.

[x] [ ] [ ] 28. Referenced documents are spelled out (title and number) the first time they are cited.

[x] [ ] [ ] 29. All acronyms are spelled out the first time they are used.

[x] [] [] 30. The Table of Contents is correct.

[x] [] [] 31. All figure, table, and section callouts are correct.

[x] [ ] [] 32. Unit conversions are correct and consistent.

[x] [1] [] 33. The number of significant digits is appropriate and consistent.

[ ] [ ] [x] 34. Chemical reactions are correct and balanced.

[x] [ ] [ ] 35. All tables are formatted consistently and are free of blank cells.

[x] [] [ ] 36. The document is complete (pages, attachments, and appendices) and in the proper order.

[x] [ ] [ ] 37. The document is free of typographical errors.

[x] [] [] 38. The tables are internally consistent.

[x] [ ] [] 39. The document was prepared in accordance with HNF-2353, Section 4.3, Attachment B, "Calculation Note Format and Preparation Instructions".

[x] [ ] [ ] 40. Impacted documents are appropriately identified in Blocks 7 and 24 of the Engineering Change Notice (form A-6003-563.1).

[x] [] [] 41. If more than one Technical Peer Reviewer was designated for this document, an overall review of the entire document was performed after resolution of all Technical Peer Review comments and confirmed that the document is selfconsistent and complete.

\section{[x] [ [ [ [ []}

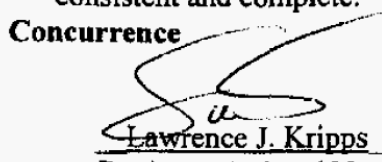

$$
\text { Reviewer (Printed Name and Signature) }
$$

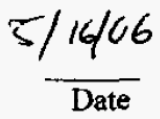

* If No or NA is chosen, provide an explanation on this form.

RPP-17965, Rev. 5, did not use any computer codes, data files, or spreadsheets; did not contain any calculations, mathematical derivations, or models; and did not state any chemical reactions. 
RPP-17965 REV 5

\section{CHECKLIST FOR TECHNICAL PEER REVIEW}

Document Reviewed: RPP-17965, Safety Evaluation of the Single-Shell Tanks Modified Sluicing Waste Retrieval System, Rev. 5

Scope of Review (e.g., document section or portion of calculation): Technical edit

Yes No NA*

[ ] [ ] [x] 1. Previous reviews are complete and cover the analysis, up to the scope of this review, with no gaps.

[ ] [ ] [x] 2. Problem is completely defined.

[] [ ] [x] 3. Accident scenarios are developed in a clear and logical manner.

[ ] [ ] [x] 4. Analytical and technical approaches and results are reasonable and appropriate. (ORP QAPP criterion 2.8)

[ ] [ ] [x] 5. Necessary assumptions are reasonable, explicitly stated, and supported. (ORP QAPP criterion 2.2)

[] [] [x] 6. Computer codes and data files are documented.

[] [] [x] 7. Data used in calculations are explicitly stated.

[] [ ] [x] 8. Bases for calculations, including assumptions and data, are consistent with the supported safety basis document (e.g., the Tank Farms Final Safety Analysis Report).

[ ] [ ] [x] 9. Data were checked for consistency with original source information as applicable. (ORP QAPP criterion 2.9)

[] [ ] [x] 10. For both qualitative and quantitative data, uncertainties are recognized and discussed, as appropriate. (ORP QAPP criterion 2.17)

[ ] [] [x] 11. Mathematical derivations were checked including dimensional consistency of results. (ORP $Q A P P$ criterion 2.16)

[ ] [ ] [x] 12. Models are appropriate and were used within their established range of validity or adequate justification was provided for use outside their established range of validity.

[ ] [ ] [ $\mathrm{x}$ ] 13. Spreadsheet results and all hand calculations were verified.

[] [ ] $[\mathrm{x}]$ 14. Calculations are sufficiently detailed such that a technically qualified person can understand the analysis without requiring outside information. (ORP $Q A P P$ criterion 2.5)

[ ] [ ] [x] 15. Software input is correct and consistent with the document reviewed.

[1] [] [ $\mathrm{x}$ ] 16. Software output is consistent with the input and with the results reported in the document reviewed.

[ ] [ ] [ $\mathrm{x}]$ 17. Software verification and validation are addressed adequately. (ORP QAPP criterion 2.6)

[] [ ] [x] 18. Limits/criteria/guidelines applied to the analysis results are appropriate and referenced. Limits/criteria/guidelines were checked against references. (ORP QAPP criterion 2.9)

[ ] [ ] [x] 19. Safety margins are consistent with good engineering practices.

[] [ ] [x] 20. Conclusions are consistent with analytical results and applicable limits

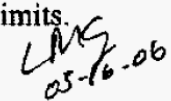




\section{CHECKLIST FOR TECHNICAL PEER REVIEW}

[ ] [] [x] 21. Results and conclusions address all points in the purpose. (ORP QAPP criterion 2.3)

[x] [ ] [ ] 22. All references cited in the text, figures, and tables are contained in the reference list.

[x] [ ] [ ] 23. Reference citations (e.g., title and number) are consistent between the text callout and the reference list.

[x] [ ] [ ] 24. Only released (i.e., not draft) references are cited. (ORP QAPP criterion 2.1)

[x] [] [] 25. Referenced documents are retrievable or otherwise available.

[x] [1] [ ] 26. The most recent version of each reference is cited, as appropriate. (ORP QAPP criterion 2.1)

[x] [ ] [ ] 27. There are no duplicate citations in the reference list.

[x] [ ] [ ] 28. Referenced documents are spelled out (title and number) the first time they are cited.

[x] [] [] 29. All acronyms are spelled out the first time they are used.

[x] [ ] [ ] 30. The Table of Contents is correct.

[x] [] [] 31. All figure, table, and section callouts are correct.

[x] [] [] 32. Unit conversions are correct and consistent.

[x] [] [ ] 33. The number of significant digits is appropriate and consistent.

[ ] [ ] [x] 34. Chemical reactions are correct and balanced.

[x] [ ] [ ] 35. All tables are formatted consistently and are free of blank cells.

[x] [] [ ] 36. The document is complete (pages, attachments, and appendices) and in the proper order.

[x] [ ] [] 37. The document is free of typographical errors.

[x] [ ] [ ] 38. The tables are internally consistent.

[x] [] [] 39. The document was prepared in accordance with HNF-2353, Section 4.3, Attachment B, "Calculation Note Format and Preparation Instructions".

[] [] [x] 40. Impacted documents are appropriately identified in Blocks 7 and 24 of the Engineering Change Notice (form A-6003-563.1).

[x] [ ] [] 41. If more than one Technical Peer Reviewer was designated for this document, an overall review of the entire document was performed after resolution of all Technical Peer Review comments and confirmed that the document is selfconsistent and complete.

[x] [I [] Concurrence

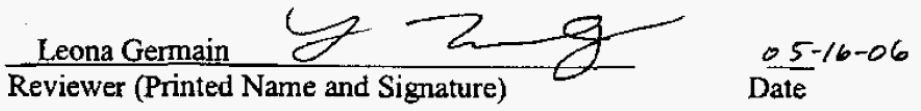

* If No or NA is chosen, provide an explanation on this form.

Technical Edit 